\title{
Avaliação da trilha da glenoide no ombro
}

\author{
Tese apresentada à Faculdade de \\ Medicina da Universidade de São Paulo \\ para obtenção do título de Doutor em \\ Ciências \\ Programa de Ortopedia e Traumatologia \\ Orientador: Dr. Arnaldo Amado Ferreira \\ Neto
}

(Versão Coriigida. Resolução CoPGr 6018, de 13 de outubro de 2011. A versão original está disponível na Biblioteca da FMUSP) 
Dados Internacionais de Catalogação na Publicação (CIP)

Preparada pela Biblioteca da

Faculdade de Medicina da Universidade de São Paulo

Creprodução autorizada pelo autor

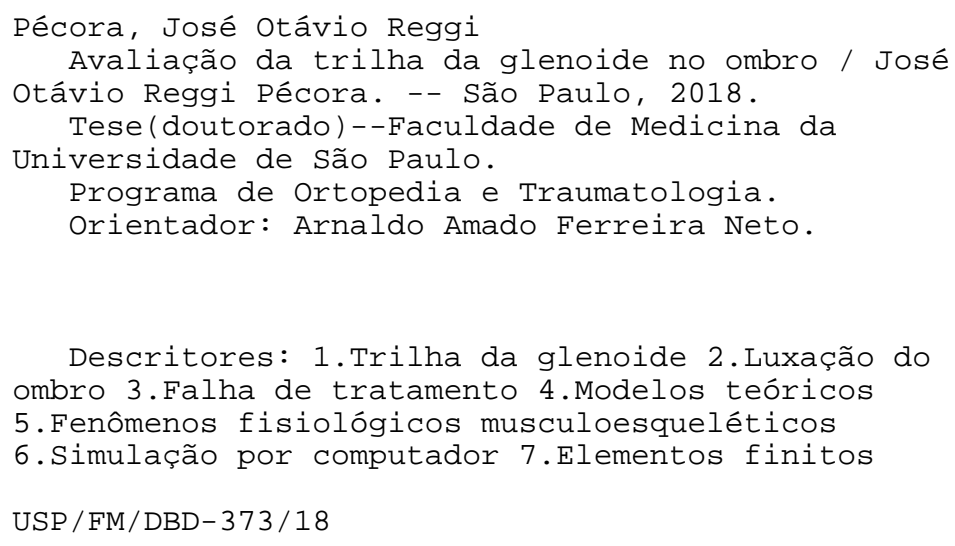


DEDICATÓRIA

Aos meus pais, José Ricardo e Virgínia, pela minha educação, formação pessoal e amor incondicional. Sendo exemplos eternos, esta tese é fruto direto de seus esforços e dedicação ao longo de minha vida.

À minha esposa Natasha, grande incentivadora e parceira, pelo apoio contínuo, compreensão, companheirismo, amizade e por todo o amor dedicado a mim e a nossa família. Sem ela, esta tese jamais teria sido possível.

Aos meus filhos, Daniel e Gustavo, os maiores tesouros de minha vida. 


\section{AGRADECIMENTOS}

Aos meus irmãos, Helena, Alexandre, Henrique e Lídia pelo incentivo, ajuda prestada, e por nossos laços invioláveis dos quais tenho grande orgulho.

Aos meus queridos avós, Aparecida e Moacyr (in memoriam), lone e José Flávio (in memoriam), pela formação de nossa família.

A toda família Reggi, Pecora, Damasio e Fairbanks pela amizade, incentivo e suporte.

Ao Professor Doutor Gilberto Luis Camanho, Titular do Departamento de Ortopedia e Traumatologia da Faculdade de Medicina do Hospital das Clínicas da Universidade de São Paulo, pelos conselhos e estímulo ao estudo do tema.

Ao Professor Doutor Olavo Pires de Camargo, Titular do Departamento de Ortopedia e Traumatologia da Faculdade de Medicina do Hospital das Clínicas da Universidade de São Paulo, pelo incentivo e confiança depositada no projeto de pesquisa.

Ao Professor Doutor Tarcísio E. P. Barros Filho, Titular do Departamento de Ortopedia e Traumatologia da Faculdade de Medicina da do Hospital das Clínicas da Universidade de São Paulo, pela promoção da ciência e oportunidade concedida. 
Ao Dr. Arnaldo Amado Ferreira Neto, pelo suporte, confiança no projeto e orientação na tese.

Aos Drs. Raul Bolliger Neto, Américo Zoppi Filho, Eduardo Angeli Malavolta, Mauro Emílio Conforto Gracitelli, Jorge Henrique Assunção, pela contribuição científica ao Grupo de Ombro e Cotovelo e pelos auxílios nas diversas etapas deste estudo.

Aos Profs. Ari Digiacomo O. C. Moré, Carlos Rodrigo Roesler e Eduardo Alberto Fancello, do Laboratório de Engenharia Biomecânica da Universidade Federal de Santa Catarina, pela preciosa parceria, incentivo e indispensável contribuição.

Ao Eng. Alexandre Neves Trichez Junior, pela imensurável contribuição em todas as fases do desenvolvimento do modelo numérico, pela cortês e paciente assessoria, e vital sinergia nesta empreitada.

Aos Drs. Marco Kawamura Demange e André Mathias Baptista, pela contribuição e confiança depositada no exame de qualificação.

Ao Dr. Marcelo Bordalo Rodrigues, pela ajuda na aquisição dos exames de imagem.

Ao Dr. Virgínio Rubin Netto, pela generosa contribuição na fase de segmentação dos exames de imagem. 
Ao Sr. Arthur Camanho e grupo ESI, pela contribuição para concepção deste projeto.

Às secretárias Rosana Moreno da Costa e Tânia Borges, pela zelosa assessoria durante toda a pós-graduação.

Às bibliotecárias Andressa da Costa Santos Souza e Camila Gomes da Rocha Agostini e à Sra. Cátia Rejane Alvares, pela solicitude nos diversos levantamentos bibliográficos e atenciosa assessoria.

À Sra. Tânia Fernanda C. da Silva, pelo auxílio nas etapas burocráticas do projeto.

À Sra. Maria Cristina Silva Emerick, pelo extenso e incessante empenho para a obtenção de aprovação do projeto junto à FAPESP.

À Sra. Leide de Souza Salomão, pela ajuda junto à comissão científica do IOTHC-FMUSP. 


\section{EPÍGRAFE}

"Pouco conhecimento faz com que as pessoas se sintam orgulhosas. Muito conhecimento, com que se sintam humildes". Leonardo da Vinci

"Se você quer ser bem sucedido, precisa ter dedicação total, buscar seu último limite e dar o melhor de si mesmo." Ayrton Senna da Silva 
"It deserves to be known how a shoulder which is subject to frequent dislocations should be treated. For many persons owing to this accident have been obligated to abandon gymnastic exercises, though otherwise well qualified for them; and from the same misfortune have become inept in warlike practices, and have thus perished. And this subject deserves to be noticed, because I have never known any physician [to] treat the case properly; some abandon the attempt altogether, and others hold opinions and practice the very reverse of what is proper". Hippocrates, 5th century BCE

"O tratamento de um ombro que está sujeito a frequentes deslocamentos merece ser conhecido. Pois devido a esse fenômeno, muitas pessoas foram obrigadas a abandonar os exercícios de ginástica, mesmo que bem qualificados para tanto; e, do mesmo infortúnio, tornaram-se ineptos em práticas bélicas, e assim pereceram. Essa patologia merece ser destacada, porque eu nunca conheci qualquer médico que tratasse o caso de forma adequada; alguns abandonam a tentativa completamente, e outros têm opiniões e práticas inversas do apropriado". Hippocrates - V A.C 


\section{NORMATIZAÇÃO ADOTADA}

Esta tese está de acordo com as seguintes normas em vigor no momento desta publicação:

Referências: adaptado de International Committee of Medical Journals Editors (Vancouver).

Universidade de São Paulo. Faculdade de Medicina. Divisão de Biblioteca e Documentação. Guia de apresentação de dissertações, teses e monografias. Elaborado por Anneliese Carneiro da Cunha, Maria Julia de A. L. Freddi, Maria Crestana, Marinalva de Souza Aragão, Suely Campos Cardoso, Valéria Vilhena. 3a ed. São Paulo: Divisão de Biblioteca e Documentação; 2011.

Abreviaturas dos títulos dos periódicos de acordo com List of Journals Indexed in Index Medicus. Sociedade Brasileira de Anatomia. São Paulo: Ed. Manole Ltda.; 2001.

Nomes das estruturas anatômicas baseados na Nomina Anatômica, $5^{\mathrm{a}}$ ed. Rio de janeiro, 1984.

Utilizaram-se a terminologia e as definições estatísticas conforme o Guia para expressão da incerteza de medição, Segunda Edição Brasileira do Guide to the Expression of Uncertainty in Measurement (BIPM, IEC, IFCC, ISSO, IUPAC, IUPAP, OIML, 1983). Edição Revisada (Agosto de 1998) - Rio de Janeiro: ABNT, INMETRO, SBM, 1998.

Vocabulário ortográfico da língua portuguesa, 5a edição, 2009, elaborado pela Academia Brasileira de Letras, em consonância com o Acordo Ortográfico da Língua Portuguesa, promulgado pelo decreto $n^{\circ} 6583 / 2008$. 
SUMÁRIO

2

OBJETIVO

7

3

REVISÃO DA LITERATURA

9

3.1 Falha da cirurgia de Bankart: estudo das lesões ósseas

9

3.2 Estudo do contato articular no ombro: evolução do conceito

da trilha da glenoide

3.2.1 Ciência básica

3.2.2 Estudos clínicos

3.2.3 Artigos de revisão

3.3 O uso do método de elementos finitos e sua aplicação na medicina e ortopedia

3.4 Modelos numéricos de ombro

3.4.1 Modelos numéricos do ombro: Avaliação genérica e reprodutibilidade de características biomecânicas

3.4.2 Modelos numéricos do ombro: utilização para questões específicas

4.1 Desenvolvimento do modelo numérico

4.1.1 Voluntário e exames de imagem 50

4.1.2 Segmentação dos dados dos exames de imagem 53

4.1.3 Construção do modelo tridimensional de elementos finitos 55

4.1.3.1 Definição do centro de rotação 56 
4.1.3.2 Definição do sistema de coordenadas

4.1.3.3 Refinamento geométrico dos modelos sólidos 58

$\begin{array}{lll}\text { 4.1.3.3.1 Reconstrução óssea } & 60\end{array}$

4.1.3.3.2 Morfologia da cartilagem da cabeça do úmero 61

4.1.3.3.3 Morfologia da cartilagem da cavidade glenoidal 64

4.1.3.3.4 Análise crítica dos resultados anatômicos 65

4.1.3.4 Determinação das propriedades dos materiais 66

4.1.3.5 Determinação das propriedades de contato 67

4.1.3.6 Determinação das condições de contorno 67

4.1.3.7 Determinação do carregamento das forças 68

$\begin{array}{lll}\text { 4.1.3.7.1 Direção das forças } & 70\end{array}$

$\begin{array}{lll}\text { 4.1.3.7.2 } & \text { Amplitude das forças } & 77\end{array}$

$\begin{array}{lll}\text { 4.1.3.7.3 Equilíbrio articular } & 79\end{array}$

4.1.3.7.4 Método de solução das equações de equilíbrio 81

4.1.4 Análise crítica dos resultados e validação do modelo 85

$\begin{array}{lll}4.2 & \text { Estudo da trilha da glenoide }\end{array}$

4.2.1 Comprimento anteroposterior da cavidade glenoidal 85

4.2.2 Comprimento da trilha da glenoide 87

$\begin{array}{lll}\text { 4.2.3 Limites da trilha da glenoide } & 88\end{array}$

$\begin{array}{lll}\text { 4.2.4 } & \text { Características avaliadas } & 89\end{array}$

$\begin{array}{lll}4.3 & \text { Análise de dados } & 90\end{array}$

\begin{tabular}{l|r}
5 & RESULTADOS
\end{tabular}

$\begin{array}{lll}5.1 & \text { Dados do voluntário }\end{array}$

$\begin{array}{lll}5.2 & \text { Ajuste geométrico } & 92\end{array}$ 
5.2.1 Sphere fitting, centro de rotação e raios articulares

5.2.2 Espessura da cartilagem

5.3 Características da reconstrução geométrica 95

$\begin{array}{lll}\text { 5.3.1 } & \text { Esfericidade das estruturas articulares }\end{array}$

5.3.2 Anatomia da extremidade proximal do úmero 96

$\begin{array}{lll}\text { 5.3.3 } & \text { Raios articulares da cabeça do úmero }\end{array}$

$\begin{array}{lll}\text { 5.3.4 Anatomia da cavidade glenoidal } & 99\end{array}$

$\begin{array}{lll}5.4 & \text { Rítmo escapuloumeral } & 100\end{array}$

5.5 Dados de força de reação articular e ativação muscular 100

5.6 Translação da cabeça do úmero 104

$\begin{array}{lll}5.7 & \text { Características do contato articular } & 104\end{array}$

$\begin{array}{lll}5.8 & \text { Trilha da glenoide } & 107\end{array}$

$\begin{array}{lll}6 & \text { DISCUSSÃO } & 111\end{array}$

$\begin{array}{llr}7 & \text { CONCLUSÕES } & 147\end{array}$

$8 \quad$ REFERENCIAS 149

$9 \quad$ ANEXOS

169 


\section{ABREVIATURAS, SÍMBOLOS E SIGLAS}

\begin{tabular}{|c|c|}
\hline 0 & graus \\
\hline$\%$ & porcentagem \\
\hline$=$ & igual \\
\hline$>$ & maior \\
\hline$\geq$ & maior ou igual \\
\hline (R) & marca registrada \\
\hline $3 \mathrm{D}$ & Tridimensional \\
\hline Artro-RM & Artrorressonância magnética \\
\hline Artro-TC & Artrotomografia computadorizada \\
\hline CAD & Computed assisted design \\
\hline $\mathrm{cm}$ & centímetros \\
\hline CR & Centro de rotação \\
\hline CTI & Centro de Tecnologia da Informação \\
\hline EMG & Eletroneuromiografia \\
\hline Eq. & Equação \\
\hline EUA & Estados Unidos da América \\
\hline $\mathrm{f}_{\mathrm{m}}$ & força dos segmentos musculares \\
\hline$f_{i}$ & força de coaptação muscular \\
\hline$r_{a}$ & força de reação articular \\
\hline g & grama \\
\hline GRANTE & Grupo de Análise e Projeto Mecânico \\
\hline hs & horas \\
\hline
\end{tabular}




\begin{tabular}{|c|c|}
\hline IMC & Índice de massa corpórea \\
\hline IOT-HC-FMUSP & $\begin{array}{l}\text { Instituto de Ortopedia e Traumatologia do Hospital das } \\
\text { Clínicas da Faculdade de Medicina da Universidade de São } \\
\text { Paulo }\end{array}$ \\
\hline INRAD-FMUSP & $\begin{array}{l}\text { Instituto de Radiologia da Faculdade de Medicina da } \\
\text { Universidade de São Paulo }\end{array}$ \\
\hline ISB & International Society of Biomechanics \\
\hline $\mathrm{Kg}$ & quilograma \\
\hline LCA & Ligamento cruzado anterior \\
\hline LCL & Ligamento colateral lateral \\
\hline LEBm - UFSC & $\begin{array}{l}\text { Laboratório de Engenharia Biomecânica da Universidade } \\
\text { Federal de Santa Catarina }\end{array}$ \\
\hline $\mathrm{m}$ & metros \\
\hline MEF & Método de elementos finitos \\
\hline $\mathrm{mm}$ & milímetros \\
\hline $\mathrm{mm}^{2}$ & milímetros quadrados \\
\hline Mpa & megapascal \\
\hline$P$ & força devido ao peso do braço \\
\hline $\mathrm{N}$ & Newtons \\
\hline r_m & Raio médio \\
\hline RM & Ressonância magnética \\
\hline SV & Segmento vertical \\
\hline SHS & Segmento horizontal superior \\
\hline SHM & Segmento horizontal médio \\
\hline $\mathrm{SHI}$ & Segmento horizontal inferior \\
\hline
\end{tabular}


SHla

TC

tol
Segmento horizontal inferior anterior

Tomografia computadorizada

Tolerância 


\section{LISTA DE TABELAS}

Tabela 1 Divisão dos grupos musculares em diferentes segmentos e a representação da proporção muscular de cada um

Tabela 2 Raio e número de pontos utilizados para o sphere fitting 92

Tabela 3 Características geométricas utilizadas como referência para a cartilagem da cavidade glenoidal

Tabela 4 Dados de espessura das cartilagens reconstruídas

Tabela 5 Características da morfologia advinda dos exames de imagem. Desvios padrão das estruturas utilizadas para o sphere fitting; e d/R: média das distâncias entre o centro da esfera e os pontos selecionados na superfície da estrutura (d) e o raio da esfera $R$

Tabela 6 Desvio padrão da superfície articular da cartilagem da cabeça do úmero reconstruída

Tabela $7 \quad$ Características geométricas da extremidade proximal do úmero deste modelo e do estudo de lannotti

Tabela 8 Resultado dos raios ósseos da extremidade proximal do úmero

Tabela 9 Resultado dos raios articulares e dados de espessura da cartilagem da cabeça do úmero

Tabela 10 Dimensões da cavidade glenoidal segundo parâmetros de lkemoto e sua comparação

Tabela 11 Dimensões da cavidade glenoidal segundo parâmetros 
de lannotti e sua comparação

Tabela 12 Ângulo glenoumeral e ângulo escapulotorácico encontrado nas diferentes posições de abdução

Tabela 13 Dados da força e momento do peso do braço para cada posição, e correspondente valores das forças de reação articular e musculares encontradas para a estabilização do modelo

Tabela 14 Translação do CR de acordo com a posição e o eixo. Eixo X: posterior (+) e anterior (-); eixo $\mathrm{Y}$ : superior (+) e inferior (-); eixo Z: medial (+) e lateral (-); e total (deslocamento 3D)

Tabela 15 Características do contato articular nas posições $60^{\circ}, 90^{\circ}$ e $120^{\circ}$

Tabela 16 Dados dos valores de referência para o cálculo da trilha da glenoide e valores da trilha da glenoide por posição

Tabela 17 Comparação dos valores de comprimento (em $\mathrm{mm}$ ) do ponto medial de contato até a inserção do manguito rotador e correspondente valor da trilha da glenoide (em \%) por posição articular, antes e depois do carregamento das forças

Tabela 18 Resultado do comprimento (em $\mathrm{mm}$ ) e da razão (em \%) da trilha da glenoide (ponto $M$ até a cartilagem ou inserção do manguito rotador) desse modelo, com e sem 
ativação das forças musculares, segundo os parâmetros de Yamamoto, e sua comparação

Tabela 19 Resultado do comprimento (em $\mathrm{mm}$ ) e da razão (em \%) da trilha da glenoide desse modelo, com e sem ativação das forças musculares, segundo os parâmetros de Omori, e sua comparação 


\section{LISTA DE FIGURAS}

Figura 1 Fases do desenvolvimento do modelo

Figura 2 A. Aplicação de contraste intra-articular com ajuda de radioscopia. B. Imagem da radioscopia que confirma a localização intra-articular do contraste

Figura 3 Realização de artro-RM no IOT-HC-FMUSP

Figura 4 Realização de artro-TC no INRAD-FMUSP em $90^{\circ}$ de rotação lateral. A. $0^{\circ}$ de abdução. B. $60^{\circ}$ de abdução. C. $90^{\circ}$ de abdução. D. $120^{\circ}$ de abdução

Figura 5 Modelo sólido. A. Posição $0^{\circ}$ de abdução. B. Posição $90^{\circ}$ abdução. C. Detalhe da sobreposição de imagens da extremidade proximal do úmero e superfície articular da cavidade glenoidal. D. Vista anterior, do modelo com detalhes de superfícies articulares e áreas de inserção do manguito rotador. E. Vista superior, do modelo com detalhe das áreas de inserção do manguito rotador

Figura 6 Variáveis da construção do modelo numérico de Elementos Finitos

Figura $7 \quad$ Sphere fitting: Centro da esfera que melhor se encaixa na superfície articular da cartilagem da cavidade glenoidal

Figura 8 Sistema de coordenadas articular: Origem (CR) e eixos X, Ye Z

Figura 9 Modelo sólido após reconstrução óssea da escápula, 
extremidade proximal do úmero e detalhe da extensão da diáfise

Figura 10 Modelo sólido reconstruído nas posições: A- $60^{\circ}$, B $-90^{\circ}$, C $-120^{\circ}$

Figura 11 Determinação do plano do colo anatômico do úmero. Em cinza, estão as curvas traçadas na superfície da cabeça do úmero e, em amarelo, suas curvaturas. $O$ ponto $A$ ilustra um dos pontos de inflexão utilizados para definir o plano do colo anatômico do úmero

Figura 12 Corte coincidente com o plano do colo anatômico do úmero. Ponto $U$ - centroide do plano do colo anatômico do úmero

Figura 13 Características geométricas da cartilagem da cabeça do úmero

Figura 14 Raios do elipsoide utilizados na reconstrução da cartilagem da cabeça do úmero

Figura 15 A- Imagem bruta do contorno da cartilagem da cavidade glenoidal, a partir de pontos da artro-RM. B- Contorno ósseo no plano normal da fossa glenoidal. CRefinamento final da morfologia da cartilagem da cavidade glenoidal, após ajuste à morfologia do plano normal

Figura 16 Raio médio e espessura inicial da cartilagem da cavidade glenoidal 
Figura 17 Ilustrações do trajeto muscular na posição $60^{\circ}$ de abdução e $90^{\circ}$ de rotação lateral: subescapular (rosa), deltoide (amarelo), infraespinal (vermelho), redondo menor (azul) e supraespinal (verde). A. Vista anterior. B. Vista lateral. C. Vista posterior. D. Vista superior

Figura 18 Visão posterior da escápula. Os trajetos musculares dos músculos infraespinal e redondo menor são representados pela linha preta, enquanto que as direções das forças exercidas por esses músculos são representadas pelas setas vermelhas e azuis, respectivamente

Figura 19 Peso do braço na posição de 0 graus

Figura 20 Ritmo escapuloumeral com o ombro na posição de $0^{\circ}$ de abdução (a) e na posição de $90^{\circ}$ de abdução (b). As linhas $\mathrm{H}$ (eixo da diáfise do úmero), G (coincidente com o plano da cavidade glenoidal) e T (plano sagital), formam os ângulos glenoumeral (G-H) e escapulotorácico (S-T) 72

Figura 21 Determinação da direção do peso do braço em uma posição $\mathrm{k}$ considerando que a escápula em ambas as posições são coincidentes

Figura 22 Forças atuantes em um sistema corda-polia sem atrito

Figura 23 Diagrama de corpo livre da corda (esquerda) e da polia (direita) 
Figura 24 Determinação do ponto $x \_r$ no modelo geométrico. As linhas em vermelho representam o trajeto muscular a partir dos pontos de inserção e são coincidentes com as direções de f_1 e f_2. Em preto o ponto de aplicação x_r e o vetor representando $f_{r}$

Figura 25 Fluxograma da metodologia utilizada para a determinação da amplitude das forças exercidas pelos músculos

Figura 26 Linhas de referência para medição do comprimento anteroposterior da cavidade glenoidal, a linha superior, "O”, corresponde ao método de Omori, e a linha inferior, "G", corresponde ao método de Griffith

Figura 27 Pontos de referência para localização da trilha da glenoide. A. Plano do colo anatômico. B. Ponto central U, no plano do colo anatômico. C. Ponto central articular C, localizado na superfície articular da cabeça do úmero, em linha perpendicular ao ponto $U$ e ao plano do colo anatômico

Figura 28 Medidas de referência da trilha da glenoide. A- Posição relativa da cavidade glenoidal em cada grau de abdução. B- Detalhe das posições relativas da cartilagem da cabeça do úmero (em verde), da cartilagem da cavidade glenoidal, e das inserções do manguito rotador. C- Corte da cartilagem da cabeça do úmero (em verde) no plano de referência UCM; distância do ponto $M$ até a inserção do manguito rotador corresponde à extensão da trilha da glenoide (arco em vermelho). G-Cartilagem da cavidade glenoidal; SE-subescapular; SS-supraespinal; IS- 
Figura 29 Distribuição de espessura da cartilagem da cabeça do úmero

Figura 30 Distribuição de espessura na cartilagem da cavidade glenoidal

Figura 31 Em vermelho, a circunferência traçada para representar o contorno na cabeça do úmero em um corte congruente ao plano do colo anatômico do úmero. Em azul, uma elipse com a mesma finalidade

Figura 32 A. Gráfico indicando valores de força de reação e força muscular por segmento muscular: B. Supraespinal, C. Subescapular; D. Infraespinal; E. Redondo menor; F. Deltoide; G. Deltoide anterior; H. Deltoide intermediário e; I. Deltoide posterior

Figura 33 Gráfico dos valores das forças musculares por posição articular

Figura 34 Gráfico indicando valores proporcionais de contribuição de força muscular dos segmentos musculares por posição. A. $60^{\circ}$; B; $90^{\circ}$; C. $120^{\circ}$

Figura 35 Distribuição de pressão na superfície articular da cavidade glenoidal e da região posterior da cabeça do úmero de acordo com grau de abdução. A, B- $60^{\circ}$; C, D- $90^{\circ}$; E, F$120^{\circ}$ 
Figura 36 llustrações do conceito de trilha da glenoide ${ }^{32}$. Contato que a cavidade glenoidal promove na superfície articular da cabeça do úmero a $90^{\circ}$ de rotação lateral e diferentes graus de abdução: A. $60^{\circ}$; B. $90^{\circ}$; C. $120^{\circ}$; D. Contorno da silhueta da cavidade glenoidal em relação ao úmero em cada posição articular; E. Trajeto do contato das 3 posições ilustrando topografia da trilha da glenoide

Figura 37 Índice de publicações internacionais baseadas em modelos numéricos de ombro por período

Figura 38 Modelo numérico da articulação glenoumeral com uso do MEF. A. Aspecto final do modelo a $0^{\circ}$ de abdução. B. Detalhes das malhas de elementos finitos das cartilagens articulares da cavidade glenoidal e da cabeça do úmero. C. Detalhes da área e pressão de contato promovida pela cavidade glenoidal na superfície articular da cabeça do úmero

Figura 39 Aspecto final da anatomia do modelo numérico em CAD após trabalho geométrico na posição de $0^{\circ}$ de abdução 


\section{RESUMO}

Pecora JOR. Avaliação da trilha da glenoide no ombro [tese]. São Paulo: Faculdade de Medicina, Universidade de São Paulo; 2018.

Introdução: A trilha da glenoide é determinada pelo contato que a cartilagem da cavidade glenoidal promove na superfície articular da cabeça do úmero em abdução e rotação lateral. É considerada importante parâmetro na tomada de decisão do tipo de tratamento cirúrgico da instabilidade glenoumeral anterior. Os limites da trilha da glenoide foram definidos por meio de estudos em cadáveres ou por exames de imagem, que não contemplam as forças articulares fisiológicas envolvidas no contato articular. Modelos numéricos de elementos finitos têm a capacidade de simular essas forças articulares e seus efeitos no contato entre as superfícies articulares. Objetivo: Avaliar a trilha da glenoide em modelo numérico de elementos finitos do ombro. Métodos: Será construído um modelo numérico de elementos finitos do ombro baseado em exames de imagem de um voluntário. O modelo contemplará o úmero, a escápula, suas respectivas cartilagens articulares e os músculos do manguito rotador e deltóide. O modelo será validado quanto a sua anatomia e fisiologia e terá liberdade de translação em três eixos. A trilha da glenoide será avaliada nas seguintes posições: $0^{\circ}, 60^{\circ}, 90^{\circ}$ e $120^{\circ}$ de abdução, todas a $90^{\circ}$ de rotação lateral. Para cada posição serão avaliadas as características de contato articular e medida a trilha da glenoide conforme referências da literatura. Resultados: $O$ valor da trilha da glenoide em $90^{\circ}$ de abdução, segundo parâmetros de Yamamoto, foi de $86 \%$ do comprimento máximo anteroposterior da cavidade glenoidal antes do carregamento das forças, e de $79 \%$ após. A trilha da glenoide em $60^{\circ}, 90^{\circ}$ e $120^{\circ}$ de abdução, segundo parâmetros de Omori, correspondeu respectivamente a $71 \%, 88 \%$ e $104 \%$ do comprimento anteroposterior de Omori antes do carregamento das forças, e, após, de $76 \%, 84 \%$ e $103 \%$. Conclusão: Foi construído um modelo numérico validado de elementos finitos do ombro adequado para estudo do contato articular. A análise do contato articular desse modelo ratifica o conceito da trilha da glenoide e contribui para sua evolução.

Descritores: trilha da glenoide; luxação do ombro; falha de tratamento; modelos teóricos; fenômenos fisiológicos musculoesqueléticos; simulação por computador; elementos finitos. 


\section{ABSTRACT}

Pecora JOR. Evaluation of the glenoid track in the shoulder [thesis]. São Paulo: "Faculdade de Medicina, Universidade de São Paulo"; 2018.

Introduction: The glenoid track is determined by the contact of the glenoid on the articular surface of the humeral head in abduction and external rotation. It is considered an important parameter in decision-making on the type of surgical treatment for anterior glenohumeral instability. The limits of the glenoid track were defined through cadaver studies, or by imaging exams, which do not take into account the physiological articular forces involved in the articular contact. Finite elements numerical models are able to simulate these articular forces and their effects on the contact between the articular surfaces. Objective: To evaluate the glenoid track in a finite elements numerical model of the shoulder. Methods: A finite elements numerical model of the shoulder will be made, based on imaging exams of a volunteer. The model will include the humerus, scapula, their respective articular cartilages, and the rotator cuff and deltoid muscles. The model will have its anatomy and physiology validated, and will have freedom of translation in three axes. The glenoid track will be evaluated in the following positions: $0^{\circ}, 60^{\circ}, 90^{\circ}$ and $120^{\circ}$ of abduction, all at $90^{\circ}$ external rotation. For each position, characteristics of articular contact will be evaluated, and the glenoid track measured according to the literature references. Results: The value of the glenoid track at $90^{\circ}$ abduction, according to the parameters of Yamamoto, was $86 \%$ maximum anteroposterior length of the glenoid before loading of forces, and $79 \%$ afterwards. The glenoid track at $60^{\circ}, 90^{\circ}$ and $120^{\circ}$ of abduction, according to Omori's parameters, corresponded, respectively, to $71 \%, 88 \%$ and $104 \%$ of Omori's anteroposterior length before loading of forces, and $76 \%, 84 \%$ and $103 \%$ afterwards. Conclusion: A validated finite elements numerical model of the shoulder suitable for the articular contact evaluation was made. The articular contact analysis ratifies the glenoid track concept and contributes to its evolution.

Descriptors: glenoid track; shoulder dislocation; treatment failure; models, theoretical; musculoskeletal physiological phenomena; computer simulation; finite elements. 
1. INTRODUÇÃO 


\section{INTRODUÇÃO}

Estima-se que $1.7 \%$ dos seres humanos apresentarão um episódio de luxação glenoumeral no curso de suas vidas ${ }^{1}$. Dentre as grandes articulações, o ombro apresenta as maiores taxas de luxação e pode corresponder a até metade dos casos em algumas populações ${ }^{2}$. Segundo Rockwood et al. ${ }^{3}$, as luxações do cíngulo escapular correspondem a $45 \%$ das luxações que acometem o corpo humano e, dentre estas, $84 \%$ envolvem a articulação do ombro $^{4-6}$

A luxação glenoumeral é evento comum nos atendimentos de pronto socorro. No período de 2002 a 2006, foi estimada a ocorrência anual de 69.486 casos de luxação de ombro nos EUA, o que corresponde a uma incidência de 23.9 casos por 100.000 pessoas/ano ${ }^{7}$. Cerca de $85 \%$ dos casos de luxações do ombro são na direção anterior ${ }^{8}$, das quais $60 \%$ tornam-se recorrentes, o que leva a limitações no desempenho de atividades laborais e esportivas ${ }^{9,10}$. Essa incidência promove um significativo impacto econômico gerado pelo número de trabalhadores afastados de suas atividades habituais ${ }^{11}$. Quanto mais jovem o paciente, maior será o impacto econômico e existirão potenciais sequelas geradas pela luxação ${ }^{11,12}$. Além disso, a recorrência leva a maior taxa de lesões associadas e índices de complicações.

A fim de identificar os fatores de risco para recorrência da luxação anterior do ombro, faz-se necessário aprofundar o conhecimento da fisiopatologia da instabilidade glenoumeral anterior. Existem muitos fatores preditivos de recorrência de luxação glenoumeral anterior, destacando-se a idade do 
primeiro episódio, o grau de atividade e a presença de lesões ósseas ${ }^{5,13-15}$. Devido a maior incidência de recidivas, existe um consenso que nestes pacientes é indicado o tratamento cirúrgico ${ }^{6,11,16-18}$. O tratamento cirúrgico visa reestabelecer as importantes relações anatômicas que estabilizam a articulação, o que pode ser feito por meio de diversas técnicas ${ }^{19-24}$.

No início do século XX, a avulsão capsulolabral anterior, chamada de "lesão de Bankart"21, era considerada a lesão anatômica primordial da instabilidade glenoumeral anterior, e sua reinserção na cavidade glenoidal, conhecida como "cirurgia de Bankart", seria fundamental para evitar novos episódios $^{25}$. Porém, evidenciou-se que outras lesões anatômicas também deveriam ser consideradas, como a fratura da borda anterior da cavidade glenoidal, chamada de "Bankart Ósseo", e a fratura de impacção da cabeça do úmero, conhecida como "Lesão de Hill-Sachs" ${ }^{26}$. No decorrer do século, maior atenção foi dada ao estudo e tratamento dessas lesões ósseas, já que sua presença aumenta o risco de falha da cirurgia de Bankart assim como a complexidade do tratamento ${ }^{13,27-30}$.

Inicialmente essas lesões eram avaliadas individualmente mas, durante o século XXI, essa visão mudou e começou-se a entender essas lesões como bipolares e integradas ${ }^{31-39}$. Observou-se que o mau resultado cirúrgico do reparo capsulolabral ocorre principalmente nos casos em que, em algum momento do arco de movimento do ombro, a lesão de Hill-Sachs ultrapassa o limite anterior de contato articular e entra em contato com a borda anterior da cavidade glenoidal, íntegra ou com o Bankart ósseo, o que geraria um mecanismo de fulcro, que leva a uma nova luxação, e à falha do reparo. A esse 
fenômeno foi dado o nome de engaging Hill-Sachs ${ }^{31}$, ou encaixe ósseo ${ }^{*}$ Sua ocorrência depende da localização do defeito de Hill-Sachs e do seu contato com os limites da cavidade glenoidal, mais especificamente com sua borda anterior. A superfície articular da cavidade glenoidal, íntegra ou não, é que determina os limites da área de contato articular na cabeça do úmero ${ }^{32}$.

Para entender melhor qual o parâmetro de contato delimitado pela cavidade glenoidal, estudos desenvolveram o conceito chamado glenoid track $^{* *}$, ou trilha da glenoide ${ }^{32-34,40,41}$. Essa trilha está localizada na superfície articular da cebeça do úmero, e sua localização é definida pelo contato proporcionado pela cartilagem da cavidade glenoidal durante $\mathrm{o}$ arco de movimento em $90^{\circ}$ de rotação lateral do úmero. A aferição dos limites da trilha da glenoide foi realizada por meio de estudos em cadáveres ou por sobreposição de relevos obtidos de estudos de imagem, que não contemplaram as forças fisiológicas presentes na articulação glenoumeral ${ }^{32,41}$. Negligenciar esse fator pode subestimar a ocorrência do encaixe ósseo, ao alterar a posição da cavidade glenoidal e, portanto, a área de contato entre as superfícies articulares.

Os modelos numéricos de articulações são ferramentas matemáticas que possibilitam simular forças articulares em diversos graus e direções, além de prever seus desdobramentos. Têm a vantagem de não serem invasivos e propiciarem algumas respostas de forma mais efetiva do que análises em

\footnotetext{
* O termo Engagind Hill Sachs, utilizado na literatura estrangeira para designar a ocorrência de contato entre as lesões de Hill-Sachs e Bankart, foi traduzido por nós pelo termo encaixe ósseo, por entendermos que simboliza, da melhor maneira, a ocorrência da conexão das lesões e do mecanismo de fulcro que decorre do mesmo.

${ }^{* *}$ O termo Glenoid track, utilizado na literatura estrangeira para designar o trajeto do contato articular que a cartilagem da glenoide proporciona na cabeça do úmero, foi traduzido por nós pelo termo trilha da glenoide, por entendermos que representa da melhor maneira o percurso do contato articular proporcionado pela glenoide.
} 
peças de cadáver ou estudos clínicos ${ }^{42}$, porém, para que os resultados sejam válidos, faz-se importante simular de forma adequada a fisiologia articular, além de direcionar a construção do modelo para a melhor análise do questionamento científico em foco ${ }^{43,44}$. A associação do método de elementos finitos (MEF) agrega à análise numérica a capacidade de prever respostas mais assertivas sobre a pressão e área de contato, fato importante no estudo do contato $\operatorname{articular}^{45,46}$.

Nossa proposta é desenvolver um modelo numérico tridimensional (3D) para a articulação glenoumeral provido da tecnologia de elementos finitos visando verificar as características da trilha da glenoide. Ao desenvolver um modelo que contemple as principais características biomecânicas que atuam na articulação glenoumeral, e realizar análise por meio da tecnologia de elementos finitos, pretende-se observar as características do contato articular durante o arco de movimento e, assim, inferir áreas de vulnerabilidade para ocorrência do encaixe da lesão de Hill-Sachs. Com esse conhecimento, esperamos aprimorar o conceito da trilha da glenoide e esclarecer parâmetros que ajudem no tratamento das lesões ósseas. Até o momento, nenhum estudo em modelo numérico caracterizou a trilha da glenoide com o uso da técnica de elementos finitos. 
2. OBJETIVO 
2 OBJETIVO

Avaliar a trilha da glenoide por meio de modelo numérico de elementos finitos do ombro. Para isso deverão ser cumpridas as seguintes metas:

I. Construção e validação de modelo numérico de elementos finitos do ombro adequado para a análise do contato articular.

II. Avaliar a trilha da glenoide do ombro por meio da análise do contato articular desse modelo numérico. 
3. REVISÃO DA
LITERATURA 
3.1 Falha da cirurgia de Bankart: estudo das lesões ósseas

3.2 Estudo do contato articular no ombro: evolução do conceito da trilha da glenoide

3.3 O uso do método de elementos finitos e sua aplicação na medicina e ortopedia

$3.4 \quad$ Modelos numéricos de ombro

\subsection{Falha da cirurgia de Bankart: estudo das lesões ósseas}

Em 1978, Rowe et al. ${ }^{47}$, avaliam 162 ombros de 161 pacientes submetidos ao reparo capsulolabral da lesão de Bankart. Referem recidiva da instabilidade em cinco pacientes $(3,5 \%)$ e tendo um destes apresentado comprometimento ósseo de $25 \%$ da cavidade glenoidal. Identificam a avulsão da cápsula anterior da borda da cavidade glenoidal em $85 \%$ dos casos; a lesão de Hill-Sacks em 77\%; e as lesões na borda anterior da cavidade glenoidal em $73 \%$. São os primeiros a quantificar o tamanho das falhas ósseas da borda anterior da cavidade glenoidal: $35 \%$ apresentaram falha de cerca de $15 \%$ da cavidade; $51 \%$ tinham falha de $25 \%$; e $14 \%$ perda de $33.3 \%$ da cavidade.

Hawkins e Hawkins ${ }^{27}$ avaliam, em 1985, 46 pacientes com falhas no tratamento cirúrgico da instabilidade glenoumeral anterior, seja recidiva da luxação, dor pós-operatória ou perda da amplitude articular. Dos 31 casos de recidiva da luxação do ombro, 11 apresentam correção inadequada das lesões 
anatômicas como a avulsão capsulolabral, a frouxidão da cápsula articular anterior ou um defeito ósseo da borda anterior da cavidade glenoidal.

Em 1997, Doneux et al. ${ }^{48}$ publicam resultados cirúrgicos de 13 pacientes com lesões ósseas da borda anterior da cavidade glenoidal. Três casos foram tratados com enxerto tricortical do ilíaco e o restante com transferência do processo coracoide. Após seguimento médio de 22,6 meses, apesar da média de limitação de rotação lateral de $15^{\circ}$, todos evoluem com resultado satisfatório. Os autores inferem que a indicação para a utilização do enxerto deveria ser baseada na experiência do cirurgião, pois não existia à época tal padronização na literatura.

Bigliani et al. ${ }^{28}$, em 1998, estudam retrospectivamente 25 ombros de pacientes com instabilidade glenoumeral anterior associada às lesões da borda anterior da cavidade glenoidal. Analisam exames de imagem e classificam as lesões tipo I como pequenas avulsões com cápsula inserida, tipo II como fragmentos consolidados medialmente e tipo III como erosões da borda anterior de até $25 \%$ (IIIA), ou acima de $25 \%$ (IIIB). Observam que $88 \%$ dos casos apresentam resultados satisfatórios e sem recidiva de luxação após 30 meses de seguimento. Concluem que as lesões ósseas da cavidade glenoidal podem ser tratadas com a sutura do lábio glenoidal na borda da cavidade glenoidal em lesões menores que $25 \%$ da superfície articular, e com a reconstrução óssea por enxertia do processo coracoide em lesões maiores que $25 \%$.

Em 2000, Checchia et al. ${ }^{49}$ publicam uma análise de tratamento cirúrgico de instabilidade glenoumeral anterior em 19 pacientes convulsivos. Encontram em $21 \%$ dos casos erosão da borda anterior da cavidade glenoidal. A técnica cirúrgica empregada dependeu dos achados intraoperatórios, como em casos 
de grande destruição articular. Os autores descrevem um índice de recidiva de $42 \%$, mas apontam bons resultados pela escala de UCLA em $79 \%$ dos pacientes. Citam que não há uma padronização na literatura quanto ao tamanho da lesão óssea a partir da qual o uso do enxerto ósseo estaria indicado e concluem que a inserção rotineira de enxerto ósseo nos pacientes convulsivos com instabilidade glenoumeral anterior gera resultados pouco previsíveis. Destacam, por fim, a importância da reconstrução anatômica da articulação e o controle clínico da doença no controle das recidivas.

Itoi et al. ${ }^{29}$ publicam em 2000 um estudo realizado em 10 peças de cadáveres em que reproduzem diversos graus de lesão óssea da cavidade glenoidal. Constatam que a presença de lesões ósseas na borda anteroinferior da cavidade glenoidal iguais ou superiores a $21 \%$ de sua extensão podem causar instabilidade e limitação de movimento após a cirurgia de Bankart. Por fim, sugerem que na presença dessas lesões, sejam feitas cirurgias que reestabeleçam o arco ósseo da cavidade glenoidal cavidade glenoidal em vez da cirurgia de Bankart.

Burkhart e De Beer $^{31}$ publicam em 2002 um artigo correlacionando as lesões ósseas às falhas da cirurgia de Bankart ao analisar 194 reparos artroscópicos de Bankart. Dos 21 casos de recidiva, 14 apresentam lesões ósseas significativas. Os autores denominam as lesões ósseas significativas da cavidade glenoidal como pera invertida, e as lesões significativas de Hill-Sachs como engaging Hill-Sachs, que correspondem às lesões que alcançam a borda da cavidade glenoidal durante a rotação lateral quando ocorre o encaixe. Por fim, sugerem que na presença dessas lesões não seja realizado o reparo artroscópico de Bankart. 
Em 2002, Greis et al. $^{\mathbf{5 0}}$, realizam testes biomecânicos em oito peças anatômicas de ombros com cavidade glenoidal e lábio glenoidal íntegros, cavidade glenoidal sem o lábio glenoidal, e lesões ósseas de $10 \%, 20 \%$ e $30 \%$ do diâmetro do quadrante anteroinferior da cavidade glenoidal. As áreas de contato e as pressões proporcionadas pela cabeça do úmero são avaliadas com o sensor tátil e flexível Tekscan. Os autores observam que a área de contato diminui e a pressão de contato aumenta com a progressão do tamanho da lesão, e são mais significativos a partir de $20 \%$ de perda óssea. A pressão de contato aumenta principalmente no quadrante anteroinferior. Os autores concluem que quanto maior a lesão óssea da cavidade glenoidal maior será a pressão em sua região anteroinferior.

Em 2004, Tauber et al. ${ }^{51}$ buscam fatores preditivos de falha da cirurgia artroscópica de Bankart ao avaliar 41 sujeitos com recidiva da luxação. Encontram, nas cirurgias de revisão, defeitos ósseos na borda anterior da cavidade glenoidal em 56\%; cápsula redundante em $22 \%$ e lesão lateral na cápsula em $5 \%$ dos casos. Realizam reconstruções com enxerto ósseo do ilíaco nos casos em que havia defeito ósseo, e observam, em todos os casos, a estabilização do ombro. Concluem que a não reconstrução da falha óssea é um fator importante para a recidiva da instabilidade pós-cirúrgica do ombro.

Em 2006, Boileau et al. ${ }^{52}$ estudam 92 pacientes submetidos à reparação artroscópica da lesão de Bankart. Observam recidiva da instabilidade glenoumeral anterior em 15,3\% pacientes, em média, após 17,6 meses. Uma análise multivariada indica que a recidiva está relacionada principalmente com a presença da erosão da borda anterior da cavidade glenoidal, definida como perda de $25 \%$ da superfície articular, e com a frouxidão capsular inferior. A 
associação dos fatores leva a um índice de recidiva de $75 \%$, com significância estatística. Os autores concluem que pacientes com a presença de lesões ósseas ou frouxidão ligamentar apresentam risco de recidiva após o reparo de Bankart.

Balg e Boileau ${ }^{18}$, em 2007, realizam um estudo prospectivo de 131 pacientes submetidos ao reparo artroscópico de Bankart. Após seguimento médio de 31 meses encontram $14,5 \%$ de recidiva. Identificam os seguintes fatores de risco: idade abaixo dos 20 anos no momento da cirurgia; prática de esportes de contato ou que envolvam elevação da mão acima da cabeça; frouxidão ligamentar do ombro; e presença de lesão de Hill-Sachs em radiografia anteroposterior em rotação lateral ou perda do contorno esclerótico anterior da cavidade glenoidal na radiografia. Esses parâmetros são integrados no escore instability severity index score (ISIS), que pontua até 10 o risco de recidiva pós cirurgia de Bankart. Os autores avaliam retrospectivamente o índice na mesma população e observam que pacientes com pontuação maior do que 6 apresentam $70 \%$ de probabilidade de recidiva, o que contraindica o reparo artroscópico. Nesses casos, os autores sugerem a cirurgia de Latarjet.

Pagnani $^{53}$, em 2008, avalia 112 pacientes tratados com reparo capsular, com seguimento mínimo de dois anos. Realiza, previamente ao procedimento cirúrgico aberto, uma avaliação artroscópica para investigar a presença de lesões ósseas da cavidade glenoidal e da cabeça do úmero. Encontra lesões da borda anterior da cavidade glenoidal em $14 \%$, sendo que em $4 \%$ dos casos o defeito é maior que $20 \%$ do comprimento anteroposterior da cavidade glenoidal. O maior defeito não ultrapassa 30\%. A série não apresenta recidiva, e a única complicação é a limitação da rotação lateral, em média $7^{\circ}$ nos 
pacientes com lesão da cavidade glenoidal e $12^{\circ}$ nos casos de lesão maior que 20\%. Em contraste com o preconizado na literatura, o autor conclui que a capsuloplastia aberta é uma boa opção e que o uso de enxertos ósseos nesses casos não é obrigatório.

Yamamoto et al. $^{54}$, em 2009, publicam um estudo sobre as lesões ósseas da borda da cavidade glenoidal em cadáveres. Realizam osteotomias na borda anterior da cavidade glenoidal paralelas ao eixo vertical, de diversos graus, e estudam o efeito na estabilidade do ombro. Concluem que a lesão da borda anterior tem comportamento similar às lesões anteroinferiores e que lesões, a partir de $20 \%$ do comprimento anteroposterior da cavidade glenoidal, comprometem substancialmente a estabilidade anterior do ombro e devem ser reconstruídas.

Hovelius et al. ${ }^{\mathbf{5}}$, em 2011, comparam as técnicas de Bankart com a de Bristow/Latarjet por meio de um estudo retrospectivo de 185 casos com seguimento médio de 17 anos. No grupo de Bristow/Latarjet, ocorre recidiva em 13 dos 97 casos, sendo necessário uma cirurgia de revisão. Já no grupo da cirurgia de Bankart, ocorre recidiva em 25 dos 87 casos e cinco cirurgias de revisão. Embora os índices clínicos e de satisfação dos pacientes sejam semelhantes entre as duas técnicas, a técnica de Bristow/Latarjet apresenta melhores resultados. Os autores também concluem que os resultados da cirurgia de Bankart clássica são melhores do que a técnica de fixação com âncoras.

Cho et al. ${ }^{56}$, em 2011, avaliam tomografias (TC) em estudo com o objetivo de entender quais características das lesões de Hill-Sachs promovem o encaixe ósseo e a falha da cirurgia de Bankart. Mensuram a extensão, 
profundidade, angulação e localização em relação à goteira do bíceps e ao eixo vertical. Verificam que as lesões que apresentam encaixe ósseo são mais largas e com angulação mais horizontal.

Em 2011, Ferreira Neto et al. ${ }^{57}$ avaliam retrospectivamente 159 casos de instabilidade glenoumeral anterior tratados com a cirurgia artroscópica, de 2001 a 2005. Avaliam 108 casos que apresentam lesão de Bankart e 62 pacientes com SLAP. Observam a recidiva da luxação em 16 casos: 8 dos 35 pacientes com lesões ósseas da borda anterior da cavidade glenoidal, e 8 dos 124 casos sem fraturas. Concluem que houve maior índice de recidiva na presença da lesão óssea da borda anterior da cavidade glenoidal.

Em 2011, Gracitelli et al. ${ }^{58}$, avaliam retrospectivamente 10 ombros com instabilidade glenoumeral anterior associada à lesão de Hill-Sachs tratados com a cirurgia de remplissage, que consiste em preencher o defeito de HillSachs com a tenodese do infraespinal. O defeito do Hill-Sachs, classificado como "engaging Hill-Sachs", apresenta tamanho médio de 17,3\% em relação ao diâmetro da cabeça. Após seguimento médio de 13,7 meses, os autores observam melhora do escore de Rowe e UCLA, com significância estatística, mas dois casos apresentam retorno da instabilidade. Concluem que a técnica apresenta bons resultados em curto prazo para o tratamento da instabilidade glenoumeral anterior com lesão "engaging Hill Sachs".

Por meio de revisão sistemática feita em 2012, Randelli et al. ${ }^{13}$ identificam fatores de risco para a falha da cirurgia de Bankart realizada com âncoras. Os fatores relacionados à alta taxa de falha são: pacientes jovens, sexo masculino, prática de atividades esportivas em nível competitivo, falha para identificar uma frouxidão capsular e presença de grandes defeitos ósseos. 
Em revisão de literatura de 2017, Yates et al. ${ }^{35}$ descrevem a evolução da identificação e da fisiopatologia das lesões ósseas e de seu tratamento. Relatam que existe um grande número de opções cirúrgicas que tem bons resultados, mas a comparação entre as técnicas é limitada pela diversidade de tipos de lesões e técnicas. Após avaliação dos conceitos atuais de tratamento e técnicas disponíveis, concluem que existe maior entendimento da interação entre as lesões bipolares e que isso seria importante de ser levado em consideração para a escolha terapêutica.

Em 2018, Lädermann et al. $^{59}$ descrevem os conceitos atuais do tratamento da instabilidade glenoumeral anterior com lesão óssea anteroinferior da cavidade glenoidal. Relatam que o tratamento dessa entidade necessita de reconstrução óssea, ou seja, uso da técnica de Latarjet ou de enxerto estruturado. A cirurgia de Latarjet possibilita uma estabilidade mecânica superior pelo efeito mola imediato, mas é uma cirurgia que modifica a anatomia do ombro e com índices consideráveis de complicações. A cirurgia de enxerto livre estruturado possibilita uma reconstrução mais anatômica da concavidade da cavidade glenoidal, sem limite de tamanho de enxerto e com complicações de abordagem mais simples. Nenhuma técnica mostrou-se superior a outra. A escolha entre essas técnicas depende do tipo das dimensões do defeito, do conceito de trilha da glenoide e das características individuais do paciente. Ambas as técnicas são descritas de forma artroscópica ou aberta e apresentam resultados satisfatórios, o que permite a escolha de acordo com habilidades individuais e nível de experiência do cirurgião.

Em 2018, Nakagawa et al. ${ }^{39}$ propõem um novo índice para avaliar o prognóstico de recidiva da cirurgia de Bankart e o comparam ao conceito da 
trilha da glenoide. Realizam análise retrospectiva de TC de 85 ombros de 80 atletas do sexo masculino para quantificar as lesões ósseas com relação ao comprimento, largura e profundidade, pontuando-se de 0 - sem lesão, a 4 maior lesão para cada critério. As pontuações do úmero e da cavidade glenoidal são somadas e são definidas 5 classes: classe 1, 0-1 ponto, classe 2 ,

2 pontos, classe 3,3 pontos, classe 4,4 pontos e classe $5, \geq 5$ pontos. A taxa de prevalência de lesões ósseas bipolares e a recidiva pós-operatória após 2 anos é comparada entre as classes, com o nível de intensidade da atividade esportiva desempenhada pelo atleta, e com o conceito da trilha da glenoide. A taxa de recidiva apresenta um comportamento semelhante entre as classes: $0 \%$ para a classe $1,8 \%$ a $16 \%$ para a classe 2 e $26 \%$ a $35 \%$ a partir da classe 3. A recorrência pós-operatória é prevista de forma independente com relação à lesão estar dentro ou fora da trilha, e ocorre em menores classes quanto maior o nível da intensidade do esporte realizado. Os autores concluem que a classificação é útil em prever a taxa de recorrência da cirurgia de Bankart em atletas, e que a mesma é influenciada pelas dimensões dos defeitos ósseos e pelo nível de atividade esportiva, independentemente de a lesão estar dentro ou fora da trilha da glenoide.

3.2 Estudo do contato articular no ombro: evolução do conceito da trilha da glenoide

\subsubsection{Ciência básica}


Em 1992, Soslowsky et al. ${ }^{60}$ analisam ombros normais de cadáveres, por meio de técnica estereofotográfica e, sem comprometer a cápsula e ligamentos, descrevem áreas de contato entre a cavidade glenoidal e a cabeça do úmero durante um arco de movimento que simula a ação dos músculos do manguito rotador e do deltoide. Concluem que o contato feito na cabeça do úmero migra consideravelmente da posição inferior para posição superoposterior à medida que o ombro realiza elevação em rotação lateral, enquanto a área de contato na cavidade glenoidal migra para posterior durante o mesmo movimento.

Em 1998, Warner et al. ${ }^{61}$ estudam o padrão de contato articular do ombro normal em 10 peças de cadáveres. As peças de cadáver têm as partes moles retiradas, exceto pela cápsula e tendões do manguito rotador, e são posicionadas em aparelho que permite posicionamento adequado dos ossos e translação em três planos. Os autores analisam o contato articular em abdução de $0^{\circ}, 45^{\circ}$ e $90^{\circ}$, todos em rotação neutra. A impressão do contato é feita em filmes Fujiß pré-dimensionados, que são sensíveis às variações de pressão, e demostram o padrão de forças de contato articular de $222 \mathrm{~N}$ e $444 \mathrm{~N}$. Após essa aferição, os autores colocam Liquidpaper® nas áreas sem contato articular a fim de confirmar a área de contato presente nos filmes. Observam que a área de maior pressão de contato na cavidade glenoidal corresponde à região chamada de "bare area", que corresponde à área de menor espessura de cartilagem e maior densidade de osso subcondral. Identificam que existe uma não conformidade articular em adução, e que quanto maior o grau de abdução, maior a congruência articular, maior a área de contato e menor a pressão de contato. 
Em 2007, Yamamoto et al. ${ }^{32}$ introduzem um novo conceito para a área de contato articular entre a cavidade glenoidal e a cabeça do úmero: Glenoid Track, ou trilha da glenoide. O contato articular de nove ombros de cadáveres é estudado nas posições de máxima rotação lateral, em $0^{\circ} 30^{\circ}$ e $60^{\circ}$ de abdução. Observa-se a migração de inferomedial para superolateral do contato que a cavidade glenoidal promove na cabeça do úmero, o que delimita a zona de contato chamada de trilha da glenoide. Quando o ombro está em rotação lateral máxima, na posição de $60^{\circ}$ de abdução entre o úmero e a cavidade glenoidal, ou seja, $90^{\circ}$ de abdução do úmero em relação ao tronco, a distância da borda medial da trilha da glenoide até a inserção do manguito rotador corresponde a $84 \%$ da largura da cavidade glenoidal.

Em 2013, Kurokawa et al. ${ }^{\mathbf{4 0}}$ estudam as características das lesões ósseas em TC de 100 pacientes com instabilidade glenoumeral anterior. Definem como out-track (fora da trilha da glenoide) as lesões causadoras do encaixe ósseo, que são lesões de Hill-Sachs localizadas medialmente ao limite da trilha da glenoide. Estas seriam correspondentes ao "engaging Hill-Sachs" descrito por Burkhart e De Beer ${ }^{31}$ e foram encontradas em 7\% dos casos. Classificam as lesões de Hill-Sachs fora da trilha em dois tipos: uma larga com área maior, e outra mais estreita com menor área.

Em publicação de 2014 , Omori et al. ${ }^{41}$ avaliam a trilha da glenoide por meio de ressonância magnética $(\mathrm{RM})$ realizada em posição supina em 30 voluntários, nas posições de $60^{\circ}, 90^{\circ}, 120^{\circ}$ e $150^{\circ}$ graus de abdução e máxima rotação lateral e extensão. Realizam avaliação do posicionamento relativo das imagens tridimensionais da cabeça do úmero e escápula. A cartilagem articular e o lábio glenoidal não são levados em consideração. Após análise estatística 
verificam que o contato articular da cavidade glenoidal na cabeça do úmero migra de inferomedial para superolateral. As dimensões da trilha da glenoide a $60^{\circ}, 90^{\circ}, 120^{\circ}$ e $150^{\circ}$ graus de abdução são respectivamente $20.7 \pm 4.5 \mathrm{~mm}$, $19.4+3.9 \mathrm{~mm}, 18.9 \pm 2.7 \mathrm{~mm}$ e $18.7 \pm 2.5 \mathrm{~mm}$, o que corresponde respectivamente a $89 \%, 83 \%, 82 \%$, e $81 \%$ do comprimento anteroposterior em ponto médio da cavidade glenoidal.

Giacomo et al. ${ }^{33}$, em 2014, propõem um fluxograma de tratamento da instabilidade glenoumeral anterior em que consideram, além das lesões ósseas da cavidade glenoidal e da cabeça do úmero, o conceito da trilha da glenoide. Concluem que nos casos em que a lesão de Hill-Sachs ultrapasse a margem da trilha da glenoide (borda anterior da cavidade glenoidal), denominados como Hill-Sachs fora da trilha da glenoide, os possíveis tratamentos são a cirurgia de remplissage ou de Latarjet. A escolha de um desses métodos dependerá do tamanho da lesão óssea da cavidade glenoidal. Nos casos de lesão acima de $25 \%$, os autores aconselham a realizar a reconstrução óssea.

Em 2014, Giacomo et al. $^{34}$, em estudo multicêntrico que utiliza os conceitos do contato articular e das lesões ósseas de Hill-Sachs e da cavidade glenoidal (lesões bipolares), propõem um novo paradigma para o tratamento da instabilidade glenoumeral anterior. Ao unir os conceitos da trilha da glenoide com o do encaixe ósseo da lesão de Hill-Sachs na borda da cavidade glenoidal, definem que o novo paradigma é sempre converter uma lesão de Hill-Sachs que esteja fora da trilha da glenoide em uma lesão que esteja contida na trilha

Trivedi et al. $^{62}$ publicam em 2014 uma revisão sistemática sobre o tratamento da instabilidade glenoumeral anterior e seus princípios terapêuticos. 
Vinte e quatro estudos são incluídos: quatro anatômicos, quatro de métodos quantitativos da lesão, nove estudos biomecânicos sobre encaixe ósseo, seis que analisam os tratamentos atuais e um estudo clínico. Os autores destacam que defeitos ósseos da borda anterior da cavidade glenoidal diminuem a dimensão da trilha da glenoide, o que facilita o encaixe da lesão de Hill-Sachs. Verificam que o princípio do tratamento consiste, geralmente, em aumentar a dimensão da trilha da glenoide antes de abordar diretamente a lesão de HillSachs. Concluem que o conceito da trilha da glenoide consegue prever o encaixe ósseo ao considerar ambas as lesões essenciais de forma integrada, e que o encaixe patológico da lesão de Hill-Sachs depende se a borda medial da lesão se encontra fora da trilha da glenoide. Por fim, sugerem que restaurar a trilha da glenoide às suas dimensões naturais deve ser uma das prioridades do cirurgião.

Hartzler et al. ${ }^{63}$ publicam em 2016 um ensaio biomecânico realizado em oito peças de cadáveres para validar o conceito de trilha da glenoide. Realizam lesões ósseas de $15 \%$ do comprimento anteroposterior na cavidade glenoidal, e de $15 \%$ (dentro da trilha da glenoide) e $30 \%$ (fora da trilha da glenoide) da circunferência da cabeça do úmero. Os testes são feitos por meio de força translacional anterior progressiva e posicionamento em $60^{\circ}$ e $90^{\circ}$ de abdução. A ocorrência de encaixe ósseo é analisada antes e após reparo de Bankart e, em caso de ocorrência de encaixe, após a associação de cirurgia de remplissage. Apenas uma (12,5\%) das peças que tinha lesão de Hill-Sachs dentro da trilha apresenta encaixe, que é resolvido após o reparo de Bankart. Todas as peças com lesão fora da trilha apresentam encaixe em $90^{\circ}$ de abdução, e $75 \%$ delas apresentam encaixe em $60^{\circ}$ de abdução. A cirurgia de 
Bankart não diminui o encaixe em $90^{\circ}$ de abdução mas o previne em $67 \%$ das peças em $60^{\circ}$ de abdução. A associação do remplissage previne o encaixe em todas as peças. Os autores concluem que esses achados reforçam o conceito da trilha da glenoide e que a cirurgia de Bankart associada ao remplissage é necessária para prevenir o encaixe em pacientes que apresentam lesões ósseas de $15 \%$ da cavidade glenoidal e lesão de Hill Sachs fora da trilha.

Em 2017, Schneider et al. $^{64}$ avaliam a variabilidade intra e interobservadores sobre as medições da trilha da glenoide em TC. Quatro observadores realizam análise de TC de 71 pacientes com instabilidade glenoumeral anterior, e dois deles a repetem após 1 mês. A medição do comprimento anteroposterior da cavidade glenoidal demonstra boa relação inter $(90.1 \%)$ e intraobservadores (94\% e 96\%) ; a classificação da lesão de Hill-Sachs como dentro ou fora da trilha teve relação interobservador de $72 \%$, mas intraobservador de $90 \%$ e $80 \%$; o coeficiente de variabilidade da medição do tamanho da lesão de Hill-Sachs é de $19,2 \%$. Os autores concluem que a medição do tamanho da lesão de Hill-Sachs tem alta taxa de variabilidade interobservador.

Yamamoto et al. ${ }^{65}$, em 2017, publicam um estudo em que descrevem alteração do comprimento da trilha da glenoide de acordo com a amplitude de movimento em 10 peças cadavéricas. Realizam medições do contato da borda anterior da cavidade glenoidal por meio de fio de Kirshner a $60^{\circ}$ de abdução, com variações de $0^{\circ}$ à amplitude máxima de flexão-extensão horizontal e de rotação medial e lateral. A distância de cada ponto à inserção do manguito rotador é medida, considerando o comprimento da trilha da glenoide. Os autores verificam que a trilha da glenoide diminui com a extensão horizontal e 
rotação lateral progressivas e aumenta com maiores graus de flexão horizontal e rotação medial. O grau de flexoextensão horizontal apresenta maior influência na dimensão da trilha do que a rotação lateral e medial. Os autores concluem que o ângulo de extensão horizontal é uma importante variável a ser considerada ao aplicar-se o conceito da trilha da glenoide na prática clínica.

Em 2018, Ho et al. ${ }^{66}$ avaliam a acurácia e confiabilidade dos métodos de medição do tamanho da lesão de Hill-Sachs, tendo em vista o conceito da trilha da glenoide, e referem que até o momento não existe método aceito universalmente. Seis avaliadores realizam medições em tomografias de modelos de úmeros feitos de poliuretano previamente preparados com lesões ósseas de dimensões devidamente documentadas. São medidas as discrepâncias entre os valores reais e as medidas dos seguintes parâmetros: comprimento, largura, e distância da borda medial da lesão de Hill-Sachs ao manguito em TC 3D, e profundidade em TC 2D. Também são calculados o coeficiente de correlação inter e intraobservadores para cada parâmetro. Os coeficientes intra e interobservadores demonstram uma forte concordância mas a taxa de erro da medição de largura e profundidade é levemente subestimada na tomografia. Os autores concluem que as medições tomográficas das dimensões das lesões de Hill-Sachs são efetivas e reprodutíveis.

Yang et al. ${ }^{67}$, em 2018, sugerem um novo parâmetro para avaliar o conceito da trilha da glenoide, a razão $H / G$. Esse valor corresponde à divisão do intervalo do Hill-Sachs, que é a distância entre o ponto mais medial da lesão óssea até a inserção do manguito medida em corte axial de exame de imagem, pelo valor de $83 \%$ do comprimento máximo anteroposterior da cavidade glenoidal, esteja integra ou não. Para isto realizam análise retrospectiva de 160 
pacientes submetidos a cirurgia de Bankart de 2005 a 2013, com 72 meses de seguimento médio. Avaliam a sensibilidade, especificidade e curva ROC que esse índice apresenta em prever a recidiva da cirurgia. O resultado da curva ROC indica que a razão $H / G$ de 0,7 apresenta 0,74 de sensibilidade e 0,71 de especificidade. A análise de regressão logística univariada demonstra, com significância estatística, que uma razão $H / G \geq 0,7$ é um importante fator preditivo do risco de recidiva da cirurgia de Bankart. Os autores confirmam a correlação entre falha da cirurgia de Bankart e lesão fora da trilha da glenoide ao encontrar recorrência da em $8,8 \%$ dos pacientes com lesão dentro da trilha e em $69,2 \%$ com lesão fora da trilha. Concluem que a razão H/G é um parâmetro confiável para predizer a recorrência de instabilidade após o reparo de Bankart, e que novas estratégias cirúrgicas devem ser pensadas para índices $H / G \geq 0,7$.

\subsubsection{Estudos clínicos}

Em 2013, Metzger et al. ${ }^{68}$ realizam estudo de coorte retrospectivo para avaliar a aplicabilidade clínica do conceito da trilha da glenoide para definir se uma lesão de Hill-Sachs irá gerar o encaixe ósseo. São avaliadas RM de 140 pacientes e é observado se existe uma lesão de Hill-Sachs que ultrapasse o limite de segurança estabelecido pela trilha da glenoide. Esses dados são comparados aos achados de encaixe ósseo reportados durante artroscopias de ombro ou exames clínicos sob anestesia geral. São encontradas evidências clínicas de encaixe ósseo em $84,5 \%$ dos casos classificados pela ressonância 
magnética como em risco de encaixe ósseo, e em 12,4\% dos casos classificados como sem risco. Os autores concluem que o encaixe ósseo pode ser previsto pelo conceito da trilha da glenoide em exames de RM.

Em 2016, Locher et al. ${ }^{37}$ analisam retrospectivamente 254 pacientes submetidos ao reparo de Bankart artroscópico entre 2006 e 2013. São analisados 100 pacientes e são avaliadas a presença de lesão de Hill-Sachs em exames pré-operatórios de TC e RM, falhas dessa cirurgia, e a necessidade de cirurgia de revisão. Dos 88 pacientes que apresentam lesão de Hill-Sachs dentro da trilha, $6 \%$ são submetidos à cirurgia de revisão, enquanto são revisados $33 \%$ dos pacientes com lesão de Hill-Sachs fora da trilha. O odds ratio é de 8.3, com significância estatística. Os autores concluem que uma lesão de Hill-Sachs que esteja fora da trilha da glenoide é um importante fator de risco para recorrência de instabilidade glenoumeral anterior e necessidade de cirurgia de revisão após reparo capsulolabral artroscópico quando comparado a uma lesão dentro da trilha.

Em 2016, Shaha et al. ${ }^{69}$ realizam estudo de coorte retrospectivo de 57 ombros submetidos à cirurgia de Bankart, e avaliam a capacidade que a aplicação do conceito de trilha da glenoide tem em prever a estabilidade pósoperatória quando comparada com a quantificação isolada de perda óssea. Imagens de RM pré-operatória são usadas para determinar a perda óssea da cavidade glenoidal, o tamanho e localização da lesão de Hill-Sachs, e classificar se a lesão está dentro ou fora da trilha. O valor preditivo positivo para lesão fora da trilha é de $75 \%$, enquanto que para lesão óssea de cavidade glenoidal maior que $20 \%$ é de $44 \%$. Os autores concluem que, para prever 
recidivas da cirurgia de Bankart, a aplicação do conceito de trilha da glenoide é superior ao parâmetro de perda óssea.

Em série prospectiva de casos publicada em 2018 , Plath et al. ${ }^{70}$ seguem 36 pacientes operados pela cirurgia de Latarjet, entre março de 2013 e maio de 2014, com o objetivo de verificar se lesões fora da trilha da glenoide são efetivamente transformadas em lesões dentro da trilha. Avaliam a trilha da glenoide, a área de contato do enxerto de coracoide e o comprimento anteroposterior da cavidade glenoidal por meio de TC seriadas pré-operatórias, com 6 semanas, 6 meses e 1 ano de pós-operatório. Evidenciam que as lesões de Hill-Sachs se mantêm dentro da trilha em todas as TC pós-operatórias. Durante o seguimento, o enxerto do coracoide é reabsorvido progressivamente e, com isso, o diâmetro efetivo da cavidade glenoidal também diminuiu. Porém, todos os casos mantêm um diâmetro maior do que o de uma cavidade glenoidal íntegra quando comparado com o pré-operatório: $84,6 \%$ no período pré-operatório; 122,8\% com 6 semanas; 120,5\% com 6 meses; e 113,9\% com 1 ano. Os autores concluem que a cirurgia de Latarjet promove tratamento efetivo para as lesões de Hill-Sachs fora da trilha da glenoide.

\subsubsection{Artigos de revisão}

Em 2015, Yamamoto et al. $^{71}$ publicam artigo de revisão sobre o tratamento cirúrgico da instabilidade glenoumeral anterior. Sugerem levar em consideração para a escolha do tratamento o tamanho da perda óssea da 
cavidade glenoidal e se a lesão de Hill-Sachs está dentro ou fora da trilha. Afirmam que lesões de Hill-Sachs dentro da trilha e com lesão de cavidade glenoidal menor que $25 \%$ podem ser tratadas com reparo de Bankart isolado. Já as lesões de Hill-Sachs fora da trilha da glenoide e com lesão de cavidade glenoidal menor que $25 \%$ devem ser tratadas com cirurgia de Latarjet ou de remplissage. Por fim, lesões que tenham perda óssea de mais de $25 \%$ necessitam obrigatoriamente de enxerto ósseo, e se após esse procedimento a lesão de Hill-Sachs persistir fora da trilha, um tratamento subsequente ainda será necessário.

Itoi $^{38}$ publica em 2017 um artigo de revisão sobre a instabilidade glenoumeral anterior. Infere que o complexo capsulolabral seria o principal estabilizador nas maiores amplitudes de movimento, e a pressão negativa da intracapsular associada ao efeito compressivo da concavidade entre os ossos são os principais estabilizadores nas menores amplitudes. Classifica os defeitos ósseos em dois tipos: erosão e fratura. Refere que 4 em cada 5 casos de instabilidade apresentam lesões ósseas bipolares. Descreve que o contato que a cavidade glenoidal promove na cabeça do úmero desloca-se ao longo da margem posterior durante diversos graus de abdução com rotação lateral máxima e extensão máxima e que essa área de contato corresponde à trilha da glenoide. Por fim, relata que estudos de validação clínica da aplicação do conceito de trilha da glenoide no tratamento das lesões ósseas indicam que a cirurgia de Latarjet ou remplissage são necessárias para lesões de Hill-Sachs que estejam fora da trilha da glenoide.

Em 2017, Momaya et al. ${ }^{36}$ publicam uma revisão em que avaliam a recente evolução do tratamento cirúrgico da instabilidade glenoumeral anterior 
em vista do novo conceito da trilha da glenoide. Destacam que estudos em cadáver validaram o conceito, e um recente estudo clínico evidenciou uma taxa muito maior de falha após o reparo artroscópico de Bankart em lesões fora da trilha da glenoide. Concluem que o tratamento das lesões ósseas da cavidade glenoidal e da cabeça do úmero não estão mais sendo abordadas como entidades separadas e que a presença de lesão de Hill-Sachs fora da trilha da glenoide mostra-se um importante parâmetro na escolha da técnica cirúrgica ao requerer mais do que o reparo capsulolabral. A escolha de tratamento para este esse tipo de lesão é associar cirurgias de remplissage ou cirurgias de enxerto ósseo.

\subsection{O uso do método de elementos finitos e sua aplicação na medicina e ortopedia}

Turner et al. ${ }^{45}$, em 1956, introduzem o MEF como solução para análise de propriedades mecânicas de estruturas complexas em estudo publicado no jornal de ciências aeronáuticas. Descrevem o conceito da discretização, que é a divisão de estruturas complexas, ou sistema contínuo, que não apresentam solução matemática exata, em um número finito de elementos. Esses elementos possuem geometria e propriedades mecânicas conhecidas, e apresentam áreas de ligação, chamadas de nós. Ao saber do comportamento mecânico nas áreas de ligação, ou nós, o comportamento da estrutura como um todo pode ser previsto. Como exemplo, utilizam o método para calcular, com ajuda computacional, o comportamento de superfícies como treliça 
simples, placa plana e viga de caixa. O método prova ter boa correlação com a realidade e ser útil para resolver equações relacionadas à engenharia civil, aeronáutica e biomecânica.

Em 1967, Zienkiewicz ${ }^{72}$ estabelece as bases matemáticas do MEF ao publicar o livro intitulado: O método de elementos finitos e a mecânica estrutural e contínua. Ao longo do livro são descritos conceitos importantes para a aplicabilidade do MEF, a se destacar: criação de sistemas discretos padrão e sua integração; abordagem de problemas de elasticidade, estresse e cisalhamento; generalização do conceito, minimizações das estruturas, e uso de equações diferenciais parciais de acordo com as características específicas do modelo nodal da estrutura em questão. O objetivo é encontrar um sistema algébrico que apresente uma solução determinada para o problema.

Brekelmans et al. ${ }^{46}$ publicam, em 1972, o primeiro estudo com uso do MEF para a análise biomecânica dos ossos. Avaliam respostas a diversas situações de cargas em um modelo bidimensional de elementos finitos do fêmur. A análise de distribuição de cargas no fêmur demonstra que a geometria e distribuição de cargas complexas não são obstáculos para a análise matemática por esse método. Os autores consideram o método uma nova ferramenta para analisar o comportamento mecânico do tecido ósseo. Concluem que o MEF apresenta vantagem com relação às técnicas experimentais ou às técnicas matemáticas clássicas na análise da resposta do osso às diversas combinações de forças.

De acordo com artigo de revisão de Huiskes e Chao $^{73}$, em 1983, o uso do MEF já é considerado um método estabelecido na pesquisa de ciências básicas e apresenta resultados fidedignos apesar do reconhecimento de suas 
limitações. Seu uso é feito principalmente para três finalidades: estudar comportamento de artroplastias, aprimorar conhecimento biomecânico das estruturas musculoesqueléticas, e investigar processos adaptativos dos tecidos ao longo do tempo. O principal desafio consiste na aplicação de características biológicas dentro do ambiente biomecânico.

Huiskes $^{74}$, em 1993, avalia as causas da falta de avanço da longevidade das novas artroplastias totais de quadril quando comparadas ao implante de Charnley. Organiza todas as possíveis causas de falha em um protocolo de avaliação e observa que a avaliação é feita de forma isolada ou restrita a uma área, sem estudar repercussões biomecânicas mais amplas na articulação, ou em diferentes cenários. Como solução, destaca o MEF e sua utilização em análises biomecânicas que possibilitam avaliação sistemática mais eficaz do implante, além da possibilidade de uma avaliação pré-clínica do implante em ambiente virtual. Sugere também que a aprovação de licença de comercialização seja feita somente após comprovados bons resultados préclínicos.

Prendergast $^{75}$, em uma revisão feita em 1997, destaca o crescente uso da técnica na ortopedia e a potencial abertura de um novo campo de pesquisa após a incorporação de estudos de imagem para o seu processo criativo. A associação de modelos de elementos finitos aos procedimentos informáticos interativos poderia criar simulações de processos biológicos de adaptação, o que permitiria aos cientistas observar e testar algoritmos de crescimento de tecidos, processo degenerativo ou de adaptação biomecânica.

Em 2006, Fernandez e Pandy ${ }^{76}$ descrevem as técnicas de construção de modelos indivíduo-específicos por meio de ressonâncias magnéticas, 
radiografias biplanares e eletroneuromiografia (EMG) e explicam como as informações de forças musculoesqueléticas derivadas desses métodos podem ser usadas para elaborar modelos numéricos de elementos finitos e calcular a distribuição de pressão de contato articular.

Saha et al. ${ }^{77}$, em 2009, descrevem a aplicabilidade do MEF nos estudos dos implantes ortopédicos, principalmente no impacto articular, fadiga e desgaste de materiais, e no remodelamento ósseo. Relatam o grande avanço que o método proporcionou não só na evolução dos materiais de implante como também na compreensão do funcionamento de sistemas articulares complexos do corpo humano.

Em 2010, Veeger ${ }^{78}$ reforça a importância do MEF para o estudo de forças infringidas a estruturas musculoesqueléticas e o seu comportamento adaptativo observado nos modelos numéricos. Aponta também a dificuldade de validação das forças articulares e musculares desses modelos. Tal limitação poderia ser solucionada com o recente desenvolvimento de endopróteses instrumentadas. O autor conclui que modelos musculoesqueléticos encontrarão seu caminho na educação e na tomada de decisão clínica, e prevê que modelos indivíduoespecíficos terão maior importância para tomada de decisões individualizadas.

Em 2012, Herrera et al. ${ }^{44}$ enumeram os recentes usos do MEF, como em confecção de órteses, na previsão de fraturas por osteoporose, no estudo de artroplastias de quadril e no desenvolvimento de modelo virtual de uma coluna. Destacam que o principal desafio dos modelos numéricos de elementos finitos é alcançar uma reprodução acurada da anatomia e fazer uma correlação fidedigna das relações entre as diferentes estruturas do corpo. Para uma criteriosa reprodução anatômica, estão sendo desenvolvidas técnicas mistas de 
aquisição de imagens por meio de leitores a laser associados a imagens de tomografias ou ressonâncias.

Taylor e Prendergast ${ }^{79}$ publicam em 2015 um artigo que resume quatro décadas de estudos sobre os implantes ortopédicos por meio do MEF. Destacam o artigo de Huiskes ${ }^{74}$ que propiciou que modelos protéticos de mau desempenho não fossem comercializados. Reconhecem que o conhecimento sobre adaptação óssea promoveu grandes avanços no tamanho e sofisticação dos implantes, informações sobre danos teciduais acumulativos e desgaste dos materiais. Porém, fazem uma análise crítica sobre o uso do MEF destacando limitações de reprodução de ambiente biomecânico fidedigno, da correspondência entre adaptação tecidual temporal virtual e real, de desenho inapropriado do experimento e de ajustes métricos inadequados. Destacam que a construção de modelos indivíduo-específicos apresentam avanços e podem minimizar problemas decorrentes de variabilidade anatômica ou das diferentes técnicas de construção. Inferem que o MEF vem sendo subutilizado pois sua grande vantagem é a possibilidade de avaliar o comportamento dos materiais e tecidos sob múltiplas situações, enquanto que a maior parte dos estudos se assemelha a ensaios in vitro, que estudam somente um segmento do corpo sob condições restritas.

Em 2016, Hinckel et al. ${ }^{80}$ avaliam os efeitos do estresse em varo do joelho nas tensões dos ligamentos cruzado anterior e ligamento colateral lateral. Utilizam o MEF em modelo virtual de membro inferior para avaliar nove situações: combinações de $0^{\circ}, 30^{\circ}$ e $60^{\circ}$ de flexão de joelho com $0^{\circ}, 5^{\circ}$ e $10^{\circ}$ de estresse em varo. Evidenciam que, em $0^{\circ}$ e $30^{\circ}$ de flexão, níveis de estresse em varo de até $10^{\circ}$ promovem aumento de tensões no ligamento cruzado 
anterior (LCA), enquanto que o ligamento colateral lateral (LCL) tem aumento de tensão em todos os graus de flexão. Destacam que nessas posições o estresse do LCA concentra-se na banda posterolateral. Concluem que pequenos graus de estresse em varo de joelho promovidos por instabilidade lateral do joelho afetam negativamente o LCA e o LCL, e que nessas condições a cirurgia de reconstrução do LCA deva ser associada a osteotomias valgizantes corretivas ou reconstruções ligamentares laterais.

\subsection{Modelos numéricos de ombro}

\subsubsection{Modelos numéricos do ombro: Avaliação genérica e reprodutibilidade de características biomecânicas}

Em 1987, Engin e Peindl ${ }^{81,82}$ publicam os primeiros estudos sobre a eficiência dos modelos numéricos em prever respostas biomecânicas condizentes com a fisiologia humana. Avaliam que a criação de um ambiente biomecânico que reproduza a realidade de forma satisfatória é o principal desafio e, dentre todas as articulações, a do ombro seria a mais difícil de ser reproduzida. Descrevem, em duas partes, os resultados da técnica de digitalização sônica feita em três voluntários com a finalidade de aferir a cinemática escapuloumeral 3D e as propriedades de resistência passiva das estruturas do ombro.

Van der Helm ${ }^{83}$, em 1994, com auxílio da técnica de elementos finitos, desenvolve o modelo numérico conhecido como Delf Shoulder and Elbow 
Model (DSEM) que simula a complexa cinemática do ombro. Cada estrutura de morfologia relevante é representada por um elemento apropriado, seja por elementos de superfície de contato articular ou por elementos curvilíneos, que representam os músculos que contornam as estruturas ósseas. O modelo compreende 4 ossos, 3 articulações, 20 músculos e os planos de movimento escapulotorácico. O centro de rotação $(\mathrm{CR})$ da cabeça do úmero é considerado fixo, coincidindo com o centro geométrico, e o equilíbrio de forças considera a posição do braço e as forças externas atuantes na extremidade proximal do úmero. O equilíbrio interno é calculado a partir de informações qualitativas de estudos de EMG e pela distribuição de força nos grupamentos musculares para se chegar ao equilíbrio. Apesar da dificuldade para a validação dos resultados quantitativos, o autor conclui que o modelo reproduz de forma satisfatória as estruturas do ombro e sua biomecânica.

Van der Helm e Veeger ${ }^{84}$, em 1996, publicam uma análise de modelo numérico de ombro a fim de avaliar forças articulares e ativação muscular durante o deslocamento em cadeira de rodas de forma quasiestática. O modelo utiliza a técnica de dinâmica inversa ao basear-se na posição 3D dos ossos em cada posição, adquirida por técnica de palpação. Para cada posição estática, a medição dos valores de EMG de 10 músculos é aferida de acordo com as forças no aro da cadeira de rodas. Quatro voluntários são estudados ao executar cinco posições de apoio na cadeira, com cinco magnitudes de força diferentes. O cálculo dos momentos de força muscular, por meio da técnica de dinâmica inversa, baseia-se no algoritmo do modelo de Van der Helm (83). Há boa correlação entre os resultados e os dados de EMG, e observa-se que uma grande parte do esforço muscular nessa atividade é gasto para a estabilização 
articular. Os autores concluem que o modelo pode ser útil para determinar a contribuição muscular e cargas mecânicas em atividades específicas.

Em 1995, Högfors et al. ${ }^{85}$ publicam resultados de um modelo numérico, conhecido como Swedish Model, com a finalidade de calcular forças atuantes no ombro em posições estáticas, consideradas de baixa a moderada intensidade. As forças externas correspondem a estimativas de peso e centro de massa dos segmentos do membro superior de acordo com a posição. Equações de equilíbrio de força para o ombro e cotovelo, considerando clavícula, escápula, úmero e ossos do antebraço, distribuem as forças entre as estruturas estabilizadoras do membro superior. O modelo consegue prever forças musculares e ligamentares de 46 estruturas do ombro, bem como forças articulares glenoumerais, acromioclaviculares e esternoclaviculares. O centro de rotação é considerado o centro geométrico da cabeça do úmero e a solução para o sistema indeterminado de forças é dada pela somatória do quadrado do estresse muscular. Após análise dos resultados, os autores concluem terem desenvolvido um modelo numérico estável e capaz de prever forças musculares e articulares presentes nas atividades laborais do cotidiano.

Garner e Pandy $^{86}$, em 2001, descrevem resultados de um modelo baseado no projeto denominado Visible Human Male. A estrutura 3D dos ossos e músculos foi retirada de TC. O modelo contemplou 42 feixes musculares, clavícula, escápula, úmero, rádio, ulna, ossos do carpo e da mão e as correspondentes articulações. As linhas de ação e trajetos musculares são baseados na técnica denominada obstacle-setting (que consiste em ajustar o trajeto muscular para tangenciar estruturas que estão no percurso da linha de ação), e são comparados com resultados de estudos anatômicos da literatura. 
Torques isocinéticos máximos, obtidos por estudos in vivo, são utilizados como referência para estimar o efeito de cada grupo muscular atuante no modelo. Os autores concluem que desenvolveram um modelo reprodutível e que contempla as principais forças atuantes no membro superior.

Holzbaur et al. ${ }^{87}$, em 2005, publicam um modelo numérico com finalidade de simular cirurgias e avaliar o controle neuromuscular do ombro. O modelo, conhecido como "modelo de Stanford", tem 15 graus de liberdade de movimento e representa 50 músculos, o ombro, cotovelo, antebraço, punho, primeiro e segundo raio da mão. A cinemática de cada articulação e o parâmetro de força foram baseados na literatura. O modelo prevê o braço de alavanca, a força muscular e o momento e força de reação articular de uma forma dinâmica, dependendo da posição articular de cada segmento. Os resultados apresentam boa correlação com estudos experimentais.

Charlton e Johnson ${ }^{88}$, em 2006, avaliam forças de contato glenoumeral de 10 atividades cotidianas para validar seu modelo numérico. O modelo, conhecido como "modelo de Newcastle" ou UK National Model, é desenvolvido a partir de dados provenientes de bancos de dados de peças cadavéricas. As atividades cotidianas variam desde movimentos simples como alcançar a nuca, até pequenos esforços como levantar um bloco acima da cabeça. Verifica-se que atividades que cursam com maiores amplitudes de movimento ou cargas externas apresentam maior força de contato. O modelo apresenta forças de contato articular que variam de $23 \%$, como colocar a mão no pescoço contralateral, a $75 \%$ do peso corporal, como manter um bloco na altura dos ombros, e uma capacidade de discriminar magnitude de forças de $8 \%$ do peso corporal com um intervalo de confiança de 95\%. A comparação dos resultados 
de forças articulares nas diversas posições com dados de estudos que avaliam atividades similares de forma confiável valida o estudo. Os autores referem ter construído um modelo validado para estudo de forças articulares e pressão de contato.

Em 2007, Dickerson et al. ${ }^{89}$ desenvolvem modelo numérico de ombro a fim de prever tensões musculares em determinadas atividades laborais e sugerir ajustes ergométricos. O modelo, conhecido como modelo de Waterloo, tem como características considerar a cinemática escapular, boa representatividade antropométrica, anatomia realística, estabilidade articular empírica definida por otimização matemática, contemplação de forças de coaptação muscular (wrapping) e integração com softwares de análise ergométrica digital. Seus resultados demonstram capacidade de calcular a distribuição das forças musculares e articulares de acordo com a ergometria laboral de forma dinâmica e confiável. Os autores concluem que o modelo será muito útil para identificar fatores de risco para lesões de esforço repetitivo e sugerir possíveis ajustes ergométricos.

Em 2012, Favre et al. ${ }^{90}$ publicam um modelo validado que contempla forças musculares e articulares sem restrição a movimentos translacionais nos três eixos. O modelo baseia-se em estudos prévios para definição dinâmica do trajeto de 27 grupamentos musculares, algoritmo iterativo para previsão de forças em qualquer posição articular e liberação gradual da liberdade de movimentos translacionais nos três eixos. No fim do processo, a estabilidade é alcançada somente pela atividade muscular. Os dados de momento muscular, ativação muscular, translação da cabeça do úmero, forças de contato articular e razão de estabilidade são semelhantes aos dados de estudos in vivo na 
literatura. Os autores concluem ser o primeiro modelo validado de ombro que contempla liberdade de movimento translacional nos três eixos e é capaz de prever influência de forças musculares e articulares de forma dinâmica e efetiva em qualquer posição.

Prinold et al. ${ }^{91}$, em 2013, publicam revisão sobre os modelos numéricos genéricos de ombro em que resumem os pontos fundamentais da modelagem do ombro, fazem uma análise crítica da utilidade clínica dos principais modelos da literatura e propõem linhas de pesquisas futuras. Consideram que modelos completos seriam aqueles que representam todas as articulações influenciadas por músculos biarticulares, estes seriam: Delf Shoulder and Elbow, UK National Shoulder, Garner e Pandy, Sweedish Shoulder e o modelo de Waterloo. Os autores discutem os principais pontos técnicos de desenvolvimento dos modelos, suas escolhas, vantagens e desvantagens. Relatam que existe pouca transparência sobre os dados técnicos do desenvolvimento dos modelos, o que dificulta comparações. Concluem que a validação correta seria o principal passo para a aplicabilidade clínica do modelo e que técnicas futuras que calculem forças em voluntários vivos, como implantes introduzidos por artroscopia, podem ser o próximo passo para o avanço desses modelos.

Chadwick et al. ${ }^{92}$, em 2014 , descrevem a performance e comportamento biomecânico de um modelo numérico dinâmico de ombro, braço e cotovelo capaz de interações em tempo real. O modelo contempla o tórax, clavícula, escápula, úmero, ulna, rádio e mão e tem 11 planos de movimento articular. 0 modelo, construído a partir de banco de dados anatômicos, tem os dados de momento de força e braço de alavanca de 138 segmentos musculares inseridos por softwares, o equilíbrio de força e estabilidade são atingidos por 
cálculos de dinâmica inversa. Os autores observam que o modelo apresenta valores de torque isocinético máximo semelhante aos da literatura e que isso possibilita ao modelo simular forças atuantes no membro superior de um humano. Concluem que o método tem boa reprodutibilidade e prevê resultados de simulações específicas e dinâmicas de forma mais rápida e com baixo custo operacional.

\subsubsection{Modelos numéricos do ombro: utilização para questões específicas}

Em 1992, Friedman et al. ${ }^{93}$ desenvolvem um modelo de elementos finitos bidimensional da cavidade glenoidal para avaliar a distribuição de estresse de diferentes formatos de componentes protéticos para a cavidade glenoidal sob determinadas condições de carga. São estudados os formatos de quilha, cunha e haste escalonada, com diversas combinações de interface protéticas e de tipos de materiais. Consideram como achados importantes: caso não exista camada de tecido de partes moles interposta, o implante totalmente de polietileno tem distribuição de estresse mais fisiológica para cargas não axiais; o formato de implante em cunha e escalonado mostra uma distribuição de cargas mais natural do que o de quilha; a orientação dos parafusos não é parâmetro significativo.

Lacroix et al. ${ }^{94}$, em 2000, constroem um modelo 3D a partir de TC, com a finalidade de comparar a distribuição de estresse na camada de cimento entre o componente glenoidal em forma de quilha com o de formato de pegs, tanto 
em pacientes com ossos normais quanto em pacientes com artrite reumatoide. A avaliação é feita em $90^{\circ}$ de abdução e considera as forças musculares de acordo com os dados do estudo de 1994 de Van der Helm ${ }^{61}$. Os autores encontram probabilidade de $95 \%$ ou mais de preservação do cimento em $94 \%$ dos implantes tipo peg e em $68 \%$ dos tipos quilha em pacientes normais, e de $86 \%$ dos tipos peg e $99 \%$ dos tipos quilha em pacientes reumatoides. Concluem que o sistema em peg é melhor para ossos normais e o sistema em quilha é superior para pacientes com artrite reumatoide.

Em 2002, Buchler et al. ${ }^{95}$ constroem modelo numérico de elementos finitos para avaliar a influência da morfologia da cabeça do úmero na distribuição de estresse na cavidade glenoidal. O modelo, que se baseia em informações de TC, apresenta o úmero, a escápula e os músculos do manguito rotador somente com ação passiva. Os movimentos de elevação e abdução não são permitidos, e rotação medial e lateral são obtidas por deslocamento ativo do músculo de acordo com a posição de interesse. O osso segue uma lei constitutiva não homogênea e a cartilagem e os músculos seguem uma lei hiperelástica não linear, somente a translação axial é permitida. Na rotação lateral, o modelo demonstra subluxação posterior do úmero no ombro com osteoartrite, o que não ocorre no ombro normal. Isso aumenta as tensões na região posterior da cavidade glenoidal em ombros com osteoartrite, enquanto ombros normais têm distribuição de tensão mais homogêneas. Os autores concluem que as alterações clássicas da osteoartrite do ombro podem ser causadas por conta da mudança da geometria da cabeça do úmero e não somente por alterações de tensões de partes moles. 
Sibella et al. ${ }^{96}$, em 2002, desenvolvem modelo biomecânico a fim de avaliar o movimento dos membros superiores durante a marcha. Identificam sete segmentos corporais por meio de marcadores retrorreflexivos em pontos de referência. Para cada segmento, considerado um corpo rígido, é atribuído um sistema de coordenadas, ângulos articulares e centro de rotação. A validação é feita por meio de aplicação da mesma técnica em modelo mecânico com dois segmentos rígidos articulados com um grau de liberdade. Os autores referem que o procedimento de cálculo apresentou alta confiabilidade e reprodutibilidade e pode ser utilizado para o estudo da marcha.

Em 2005, Yeh et al. ${ }^{97}$ constroem modelo numérico de elementos finitos a fim de estudar a distribuição de estresse no lábio glenoidal superior de atletas arremessadores. O modelo do lábio glenoidal é desenvolvido com detalhes da inserção anterior, central e média do tendão da cabeça longa do bíceps braquial. Quatro posições são estudadas: pitching, início da armação, final da armação, aceleração e desaceleração. Os autores encontram maior estresse em todas as áreas de inserção do tendão do bíceps na fase de desaceleração. Tanto a variação anatômica da inserção do bíceps quanto a fase de movimento influenciam na distribuição de estresse no lábio glenoidal superior. Os autores concluem que a fase de desaceleração pode ser o momento em que ocorre a lesão por avulsão do lábio glenoidal superior.

Debski et al. ${ }^{98}$, em 2005, constroem modelo numérico de elementos finitos para predizer as forças na banda anteroinferior do ligamento glenoumeral inferior durante um exame físico simulado. $O$ modelo foi construído a partir de informações de cinemática escapular de uma RM dinâmica. Os dados de morfologia capsular foram obtidos por TC e as 
características biomecânicas tiradas de dados da literatura. A posição de interesse do braço é de abdução de $60^{\circ}$ entre úmero e escápula, $0^{\circ}$ de rotação e $0^{\circ}$ de flexoextensão; nessa posição, uma força de translação anterior é aplicada externamente por um examinador. No pico da translação o modelo aponta 4.3Mpa de pressão na inserção umeral do ligamento, e 6.4Mpa na inserção escapular. Os autores concluem que o modelo reproduz de forma aceitável as tensões capsulares e que no futuro análises experimentais individuo-específicas dos distúrbios capsulares poderão ser feitas para melhor entendimento e diagnóstico da instabilidade glenoumeral anterior.

Terrier et al. ${ }^{99}$, em 2006, publicam resultados de estudo sobre a influência da congruência dos componentes de uma artroplastia total de ombro na cavidade glenoidal. O modelo de elementos finitos contempla um ombro com prótese total, úmero, escápula e musculatura do manguito rotador. Os autores comparam resultados de diversos graus de congruência ( 0 a $15 \mathrm{~mm}$ de diferença radial) em duas posições preconizadas pelo fabricante: $0^{\circ}$ e $15^{\circ}$ de retroversão do componente glenoidal. Após movimentos rotacionais, calcularam-se a pressão de contato, estresse no cimento, forças de cisalhamento e micromovimentos entre a interface osso-cimento. Os autores observam que, com $0^{\circ}$ de retroversão, a congruência tem pouca influência, enquanto que com $15^{\circ}$ de retroversão, uma diferença a partir de $10 \mathrm{~mm}$ de raio gera aumento de pelo menos $200 \%$ dessas forças, o que indica maior probabilidade de falhas.

Adams et al. ${ }^{100}$, em 2007, publicam resultados de um modelo numérico de elementos finitos com a finalidade de avaliar mudanças morfológicas e biomecânicas nos tendões do manguito rotador após lesões. A geometria do 
modelo baseia-se em banco de dados e a cinemática seguiu um modelo experimental, que desloca o úmero de $45^{\circ}$ de rotação lateral a $45^{\circ}$ de rotação medial enquanto gera cargas constantes. Os autores observam que os braços de alavanca dos tendões diminuem quando os tendões são seccionados, o que pode explicar a perda de força encontrada em alguns pacientes. Concluem que o modelo servirá de boa plataforma para futuros estudos sobre mecanismos de perda de força e momento muscular na lesão do manguito rotador.

Terrier et al. ${ }^{101}$, em 2007, desenvolvem modelo numérico a fim de estudar as consequências biomecânicas da lesão do tendão supraespinal. O modelo, construído a partir de uma peça de cadáver sem lesão, contempla a escápula, o úmero e os músculos deltoide e do manguito rotador. A estabilidade do modelo é obtida por algoritmo de equilíbrio de forças musculares validado por um modelo algébrico e por comparação de momentos musculares com a literatura. Não há restrição cinemática ao mecanismo bolasoquete, o que possibilitou análises da translação do úmero, porém, a única variável de movimento é a abdução, e as forças são contempladas somente em duas dimensões. Compara-se o modelo com e sem ação do supraespinal, o modelo sem a ação do supraespinal apresenta translação superior do úmero 1,6 vezes maior, contato articular mais excêntrico, força de contato articular $6 \%$ maior e aumento de forças musculares de $30 \%$. Os autores concluem que a deficiência do supraespinal leva à maior migração superior da cabeça do úmero, contato articular excêntrico na cavidade glenoidal e maior resultante de forças articular e muscular, o que pode limitar a mobilidade e levar a lesões degenerativas. 
Gatti et al. ${ }^{102}$ constroem, em 2010, um modelo numérico de elementos finitos com a finalidade de estudar o estresse que ocorre no lábio glenoidal superior durante movimentos translacionais do úmero. As informações da geometria do modelo são retiradas de TC de ombro direito de cadáver de um homem de 84 anos e contempla o lábio glenoidal, o osso da fossa glenoidal e as cartilagens da cavidade glenoidal e da cabeça do úmero. Os resultados da simulação de translação superior da cabeça do úmero de 1,2 e $3 \mathrm{~mm}$ são comparados com um ensaio biomecânico na mesma peça de cadáver e obtêm boa correlação, sempre dentro de um desvio padrão. O modelo demonstra tensão máxima de $7.9 \%, 10.1 \%$ e $11.9 \%$ no lábio glenoidal superior respectivamente a 1, 2 e $3 \mathrm{~mm}$ de translação superior da cabeça do úmero. Os autores concluem que a boa correlação dos resultados do ensaio biomecânico com os do modelo numérico, o capacitam para o entendimento da patomecânica do lábio glenoidal superior.

Em 2010, Moore et al. ${ }^{103}$ constroem dois modelos numéricos indivíduoespecíficos para avaliar o comportamento do estresse capsular quando avaliado como um tecido contínuo ou somente pela sua região anteroinferior. O modelo usa referências de um cadáver posicionado a $60^{\circ}$ de abdução, $52^{\circ}$ de rotação lateral e com força de 52N aplicada em direção anterior. Determinase as propriedades mecânicas das estruturas do modelo de acordo com as características encontradas no cadáver após avaliação da deformação tecidual. A comparação dos resultados médios de estresse previstos pelo modelo de cápsula contínua mostrou boa correlação com o ensaio biomecânico, com diferença menor que $5 \%$, já o modelo com somente a banda anteroinferior demonstra um erro médio de $20 \%$. Os autores defendem que essa diferença 
pode ser atribuída à negligência das interações existentes entre a banda anteroinferior e os demais segmentos capsulares. Concluem que a cápsula articular não deve ser avaliada como diversas bandas independentes, mas como um tecido fibroso contínuo.

Em 2011, Drury et al. ${ }^{104}$ constroem dois modelos de elementos finitos indivíduo-específicos a fim de avaliar a distribuição de estresse máximo na cápsula anteroinferior e sugerir uma posição mais adequada para avaliação do exame físico da instabilidade glenoumeral anterior causada por insuficiência da cápsula anteroinferior. $O$ modelo é avaliado a $60^{\circ}$ de abdução e $10^{\circ}, 20^{\circ}, 30^{\circ} \mathrm{e}$ $40^{\circ}$ de rotação lateral, com uma carga em direção anterior de $25 \mathrm{~N}$. Os autores encontram que a tensão capsular na inserção da cavidade glenoidal é significativamente maior do que no restante da cápsula nas posições de $20^{\circ}$ a $40^{\circ}$ de rotação lateral. Concluem serem estas as melhores posições para a avaliação da insuficiência da cápsula anteroinferior.

Inoue et al. ${ }^{105}$, em 2013, estudam a distribuição de estresse mecânico no tendão supraespinal por meio de elementos finitos em um modelo numérico de ombro. O modelo contempla os pontos de inserção do manguito rotador e deltoide médio, e a análise é feita a $0^{\circ}, 45^{\circ}$ e $90^{\circ}$ de abdução em rotação neutra. A validação das forças no tendão é feita ao comparar os resultados com ensaio em cadáver e modelos de elementos finitos de duas dimensões. A localização do principal pico de estresse no tendão supraespinal está a $1 \mathrm{~cm}$ da inserção, e aumenta na região articular e anterior durante a abdução. Os autores concluem que esses achados podem explicar a maior frequência de lesões nessa região e a patomecânica das lesões parciais ou delaminadas. 
Em 2015, Walia et al. ${ }^{106}$ desenvolvem um modelo numérico de ombro com MEF para estudar a influência de lesões ósseas combinadas na estabilidade do ombro. O modelo representa, de forma quasiestática, duas posições de abdução: $30^{\circ}$ e $60^{\circ}$, e posições rotacionais variando de $40^{\circ}$ de rotação medial a $60^{\circ}$ de rotação lateral. A geometria óssea e a espessura da cartilagem são baseadas em estudos antropométricos da literatura e o ritmo escapular segue proporção de 3:2. São criados defeitos anteriores na cavidade glenoidal de $12,5 \%, 25 \%, 37,5 \%$ e $50 \%$ do comprimento anteroposterior; e na cabeça do úmero de $6 \%, 19 \%, 31 \%$ e $44 \%$ do seu diâmetro. A avaliação da estabilidade ocorre após o contato articular com força arbitrária de compressão medial de $50 \mathrm{~N}$, para simular tensão das partes moles, e ao liberar movimentos translacionais. O modelo prevê um aumento de sua instabilidade de forma proporcional ao aumento das lesões ósseas, tanto da cabeça do úmero quanto da cavidade glenoidal. Os autores concluem que a dimensão do defeito da cavidade glenoidal determina o índice basal de estabilidade, e que o defeito da cabeça do úmero é a variável que reduz o índice de estabilidade durante rotação lateral do braço.

Em 2017, Zheng et al. ${ }^{107}$ publicam artigo de revisão sobre os modelos numéricos do ombro que utilizam método de elementos finitos. Dividem os estudos em áreas de interesse: instabilidade glenoumeral anterior, lesão do manguito rotador, lesão do complexo capsulolabral e artroplastias de ombro. Realizam análise crítica sobre a técnica, principais achados, limitações e aplicabilidade clínica dos estudos. Relatam que os principais desafios são: adequada representação indivíduo-específico da anatomia e biomecânica de tecidos; definição de condições de contorno e cinemática individualizada; 
complexidade da representação e interação de todas as estruturas do ombro de forma 3D; e validação por meio de resultados de experimentos in vivo. Concluem que modelos com essas características aumentariam o entendimento biomecânico das patologias do ombro, o que levaria à evolução de técnicas diagnósticas, do tratamento clínico, de técnicas cirúrgicas e de implantes. 
4. MÉTODOS 


\section{MÉTODOS}

\subsection{Desenvolvimento do modelo numérico}

Como ponto de partida, foi necessário a construção de um modelo numérico de elementos finitos do ombro com a finalidade de estudar o contato articular nas posições propostas. O desenvolvimento do modelo seguiu quatro fases (Figura 1):

- Obtenção de informações anatômicas por meio de exames de imagem;

- Representação em modelos sólidos;

- Construção do modelo numérico: definição das características biomecânicas e malha de elementos finitos;

- Validação do modelo.
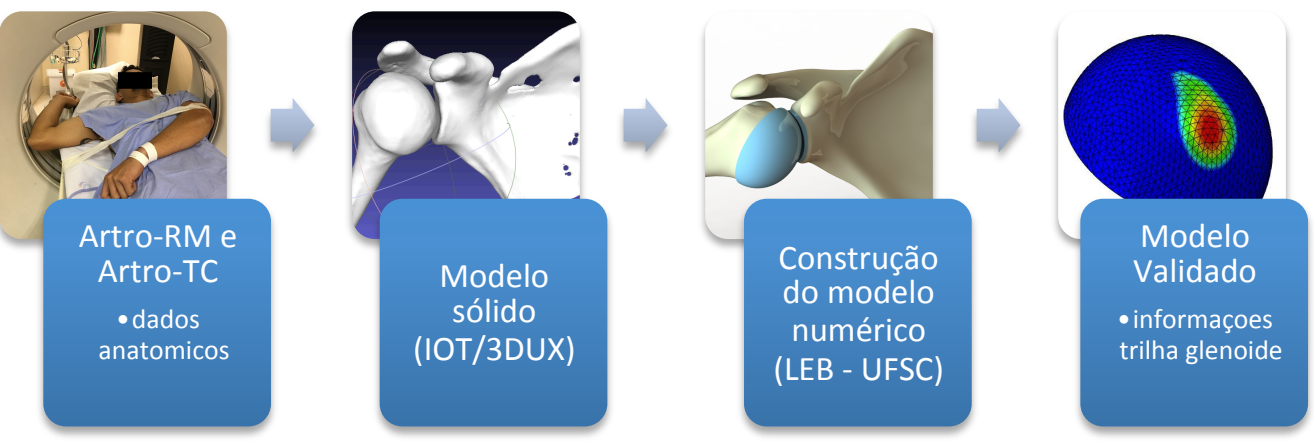

Figura 1 - Fases do desenvolvimento do modelo 


\subsubsection{Voluntário e exames de imagem}

O substrato anatômico do modelo foi obtido por meio de exames de imagem de um voluntário. A escolha do voluntário foi dada pelas seguintes características: ombro direito, sexo masculino, idade entre 25 e 30 anos, altura entre $1,70 \mathrm{~m}$ e $1,76 \mathrm{~m}$ e peso entre $70,0 \mathrm{~kg}$ e $75,0 \mathrm{~kg}$. Esses parâmetros foram baseados na idade com maior prevalência de instabilidade glenoumeral anterior $^{7,57}$ e nos dados antropométricos correspondentes, de acordo com o Instituto Brasileiro de Geografia e Estatística ${ }^{108}$. Histórico pessoal de lesão no ombro direito e histórico pessoal ou familiar de alergia a contraste foram fatores de exclusão do voluntário.

Foi selecionado um voluntário do ambulatório de ortopedia do Instituto de Ortopedia e Traumatologia do Hospital das Clínicas da Faculdade de Medicina da Universidade de São Paulo (IOT-HC-FMUSP). Foi entregue o termo de consentimento livre e esclarecido, exposto no anexo $C$ desta tese. $O$ paciente foi submetido a exames de artrorressonância magnética (artro-RM) e artrotomografia computadorizada (artro-TC). Antes dos exames, aplicou-se na articulação glenoumeral uma injeção intra-articular de solução contendo meio de contraste paramagnético de gadolínio, diluído em soro fisiológico e meio de contraste iodado, com o objetivo de distender a cápsula articular e facilitar a visualização e individualização dos limites das estruturas intra-articulares (Figura 2). O exame de artro-TC foi realizado imediatamente após o de artroRM, para que não houvesse necessidade de se repetir a injeção de contraste intra-articular. 
O exame de artro-RM disponibilizou as informações referentes ao arcabouço ósseo e tecidos de partes moles. Foi utilizado o aparelho GE Healthcare USA Discovery MR750, com 3 Tesla, com largura do gantry (túnel) de $60 \mathrm{~cm}$. As sequências volumétricas seguiram cortes finos (3D), com espessura inferior a 1,0 mm, ponderadas em T1 e em T2. As imagens foram adquiridas com 0 paciente em posição supina, ombro rodado a $90^{\circ}$ lateralmente e braço aduzido junto ao corpo (Figura 3).

O exame de artro-TC disponibilizou informações sobre a posição relativa entre os ossos para cada posição estudada, essas informações foram utilizadas como pontos de referência para a representação das diversas posições articulares do modelo. Será utilizado o aparelho Philips Healthcare ICT com 64 canais e largura do gantry de $97 \mathrm{~cm}$, e realizado protocolo volumétrico (3D) com cortes finos e espessura inferior a 1,0 $\mathrm{mm}$. As imagens foram adquiridas com o paciente deitado em posição supina, com flexão de cotovelo de $90^{\circ}$, ombro em rotação lateral de $90^{\circ}$ e nas seguintes posições de abdução do ombro: $0^{\circ}, 30^{\circ}, 60^{\circ}, 90^{\circ}, 120^{\circ}, 150^{\circ}$ e abdução máxima (Figura 4). As posições foram confirmadas por meio de um goniômetro. 
Métodos

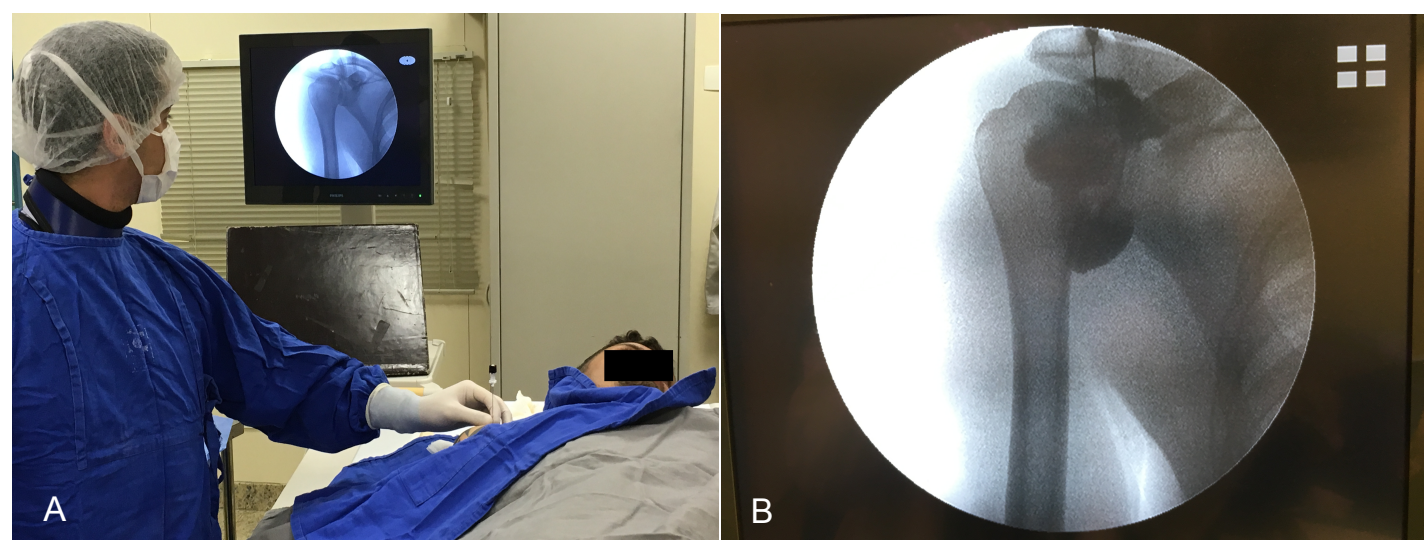

Figura 2 - A. Aplicação de contraste intra-articular com ajuda de radioscopia. B. Imagem da radioscopia que confirma a localização intra-articular do contraste

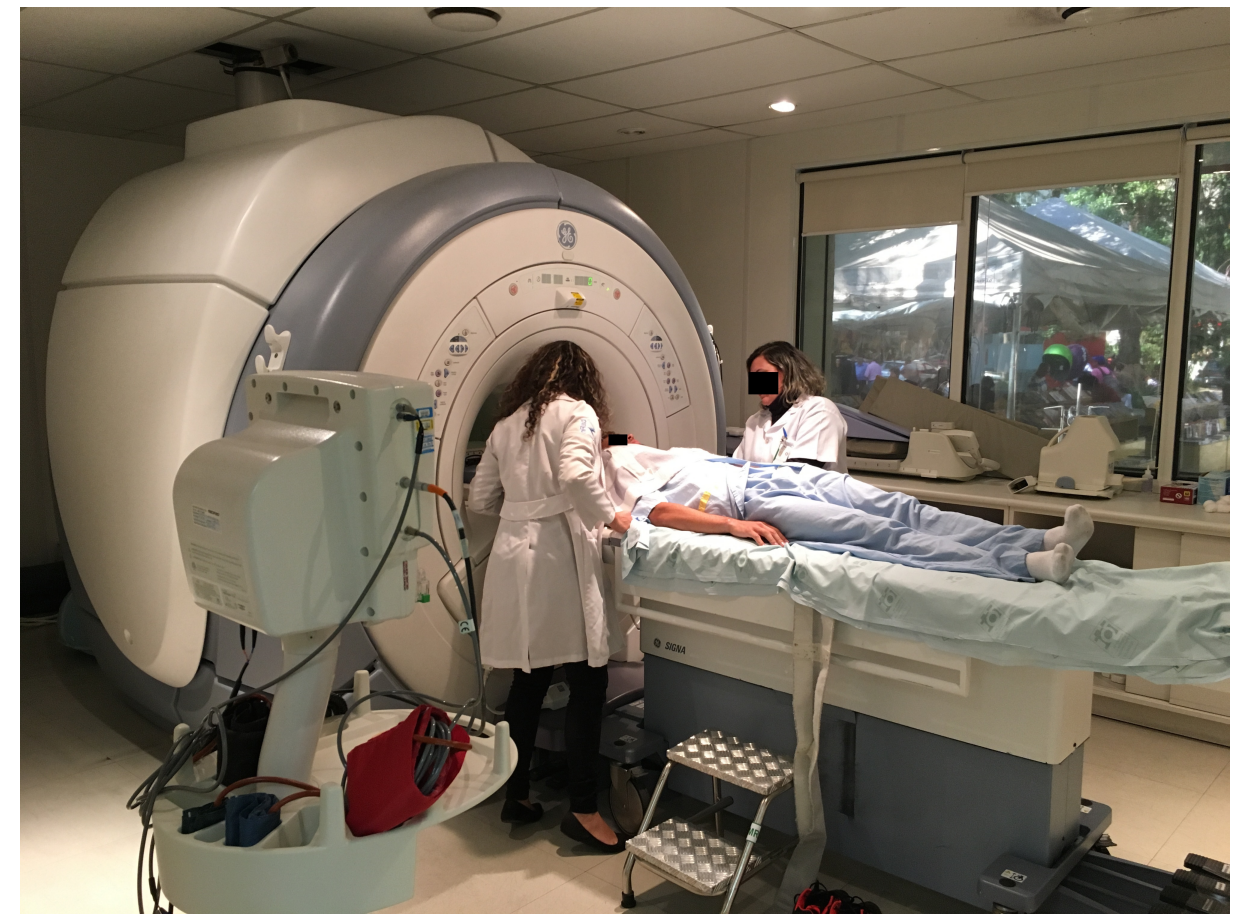

Figura 3 - Realização de artro-RM no IOT-HC-FMUSP 

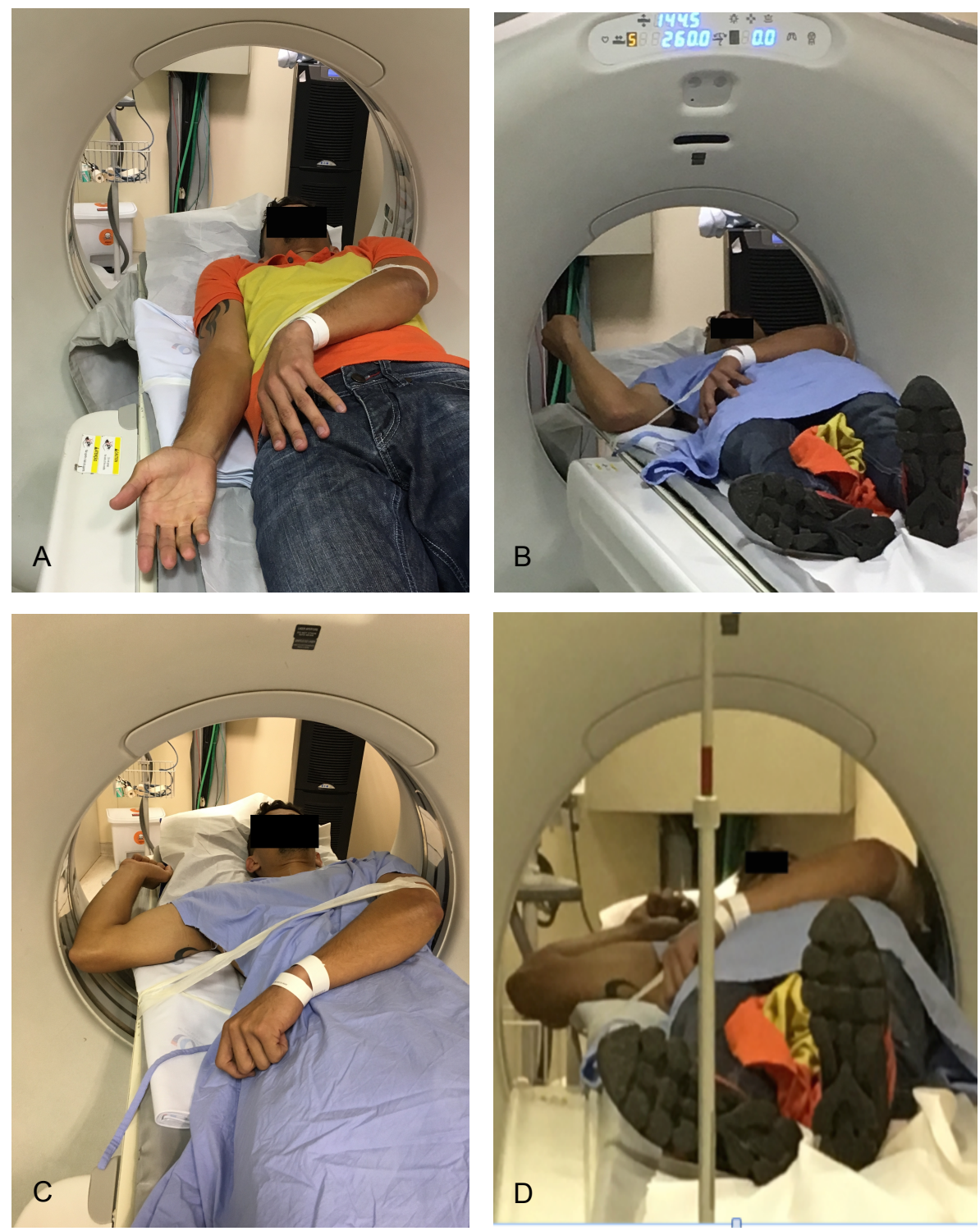

Figura 4 - Realização de artro-TC no INRAD-FMUSP em $90^{\circ}$ de rotação lateral. A. $0^{\circ}$ de abdução. B. $60^{\circ}$ de abdução. C. $90^{\circ}$ de abdução. D. $120^{\circ}$ de abdução

\subsubsection{Segmentação dos dados dos exames de imagem}

Esta etapa foi realizada pela empresa 3DUX Medical Solutions (Brasil).

Os dados obtidos pelos exames de imagem foram processados em uma nuvem de pontos para sua posterior utilização na construção dos modelos sólidos 
(Figura 5). A segmentação das estruturas anatômicas de interesse será realizada pelo software Invesalius 3.0 (CTI Renato Archer) e as modelagens em computed assisted design (CAD) pelo software Rhino 5 (Rhinoceros, Robert McNeel \& Associates).

As seguintes informações foram processadas:

- $\quad$ Ossos: Úmero, escápula;

- $\quad$ Cartilagem: Superfície articular da cabeça do úmero e da cavidade glenoidal;

- $\quad$ Área de inserção do manguito rotador na extremidade proximal do úmero (footprints): supraespinal, infraespinal, subescapular e redondo menor;

- Posição relativa entre o úmero e a escápula nas posições de interesse.

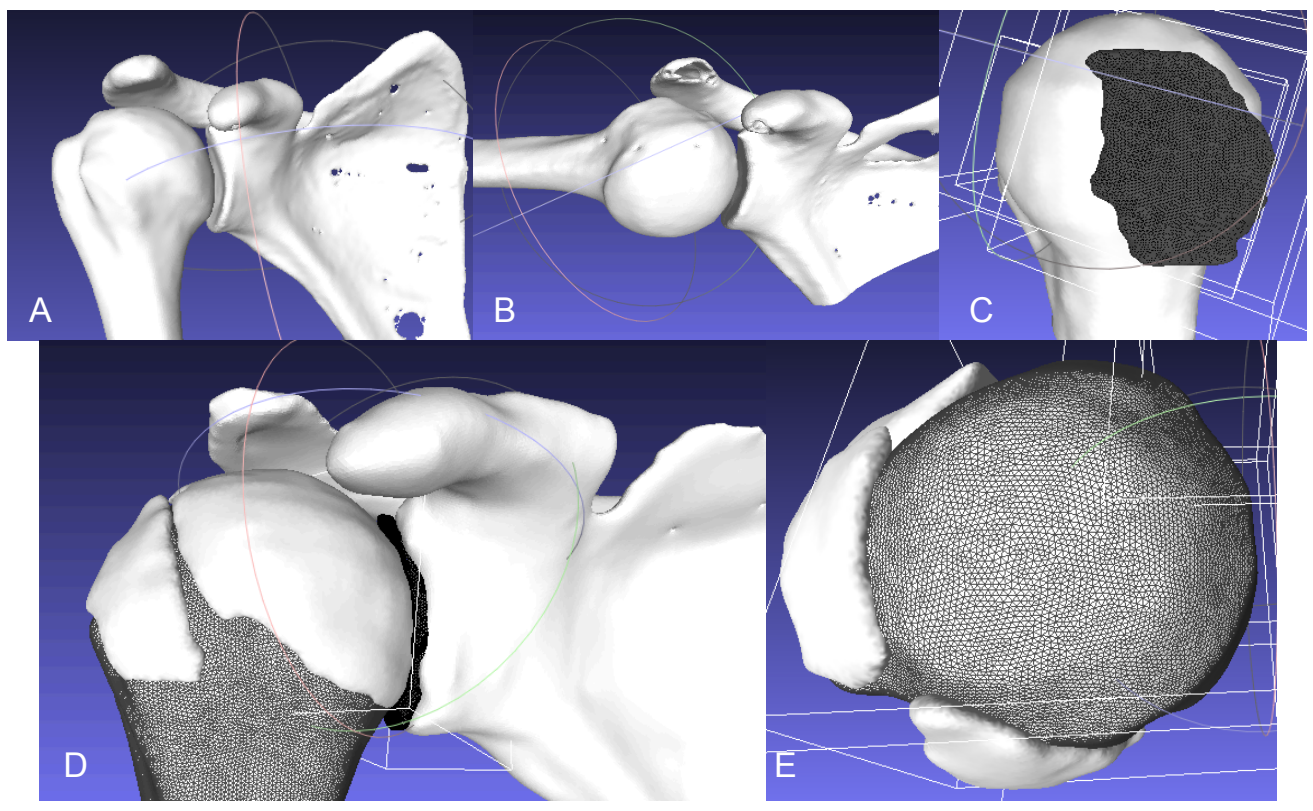


Figura 5 - Modelo sólido. A. Posição $0^{\circ}$ de abdução. B. Posição $90^{\circ}$ abdução. C. Detalhe da sobreposição de imagens da extremidade proximal do úmero e superfície articular da cavidade glenoidal. D. Vista anterior, do modelo com detalhes de superfícies articulares e áreas de inserção do manguito rotador. E. Vista superior, do modelo com detalhe das áreas de inserção do manguito rotador

\subsubsection{Construção do modelo tridimensional de elementos finitos}

Para viabilizar a execução do modelo numérico do ombro foi estabelecido um projeto de cooperação com a Universidade Federal de Santa Catarina (Laboratório de Engenharia Biomecânica - LEBm e Grupo de Análise e Projeto Mecânico - GRANTE). Esta parceria envolveu a elaboração de uma dissertação de mestrado em forma concomitante à presente tese, abordando especificamente os aspectos técnicos do modelo numérico (Desenvolvimento e Implementação Numérica de um Modelo da Articulação do Ombro Humano Alexandre Trichez - Programa de Pós Graduação em Engenharia Mecânica Universidade Federal de Santa Catarina).

O estudo das características de força e contato articular nas diversas posições articulares seguiu uma série de análises quasiestáticas. O modelo, representado em uma determinada posição, tem o contato e as forças articulares analisadas, depois muda-se a posição e repete-se a análise. Os dados do contato articular nos exames de artro-TC foram utilizados como referência para a definição das posições das análises. As posições reproduzidas foram as de $0^{\circ}, 60^{\circ}, 90^{\circ}$ e $120^{\circ}$.

A construção do modelo seguiu os seguintes passos (Figura 6):

- Definição do centro de rotação;

- Definição de sistema de coordenadas; 
- $\quad$ Refinamento geométrico dos modelos sólidos;

- Determinação das propriedades dos materiais;

- $\quad$ Determinação das propriedades de contato;

- $\quad$ Determinação das condições de contorno;

- $\quad$ Determinação dos carregamentos de forças.

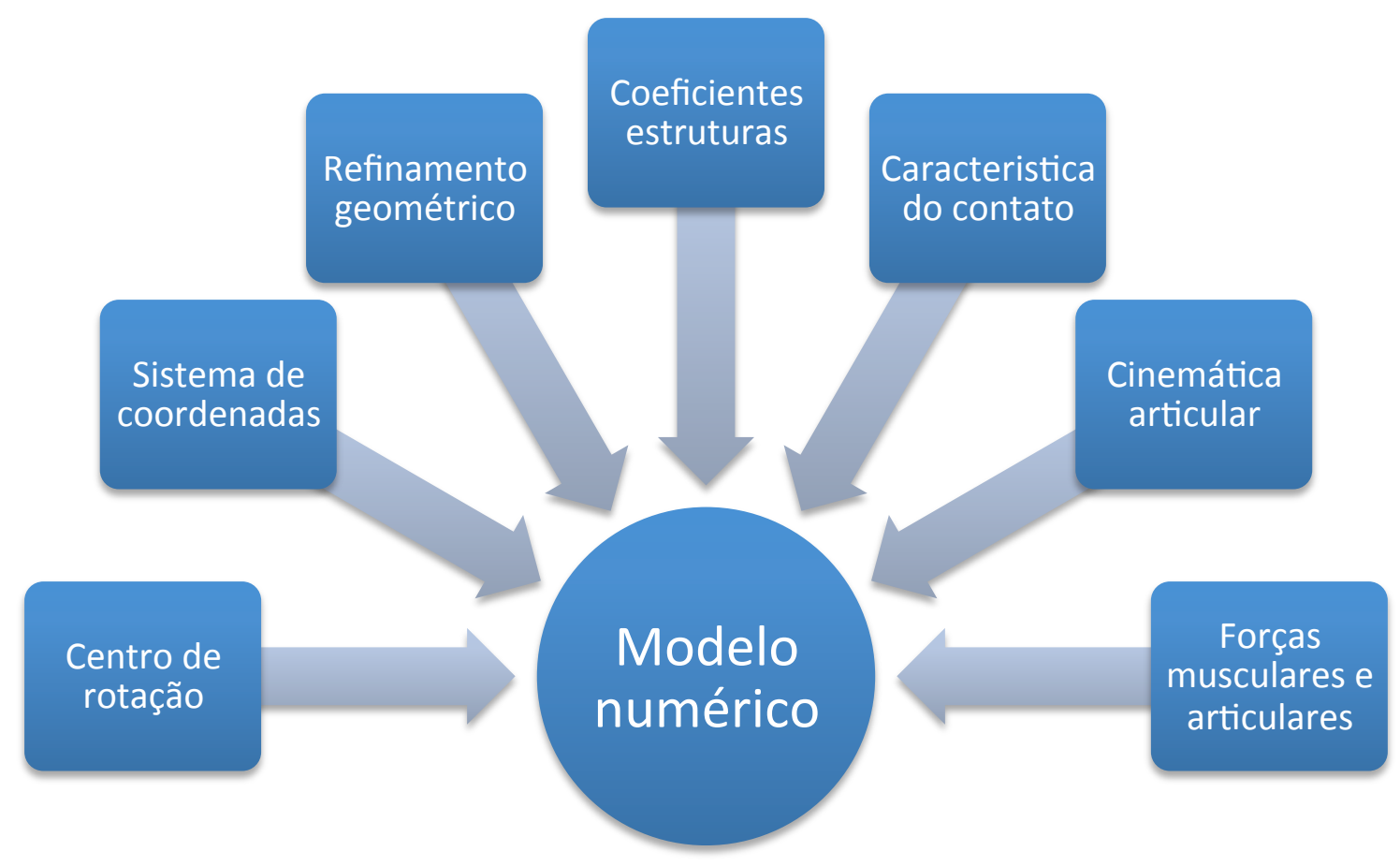

Figura 6 - Variáveis da construção do modelo numérico de Elementos Finitos

\subsubsection{Definição do centro de rotação}

A identificação do centro de rotação do úmero foi feita pelo método sphere fitting ${ }^{109,110}$. De acordo com o método, o centro de rotação corresponde 
ao centro de uma esfera de diâmetro igual ao da superfície articular da cartilagem da cabeça do úmero posicionada com o melhor encaixe na superfície articular da cavidade glenoidal (que não é concêntrica com a superfície articular da cartilagem da cavidade glenoidal) (Figura 7). Para determinar este ponto central, foram escolhidos pontos, de forma manual e aleatória, na superfície articular da cavidade glenoidal. O cálculo foi realizado por meio do software SolidWorks. Além de sua importância como referência para a ação das forças articulares, o centro de rotação também foi utilizado neste trabalho como o centro de referência do sistema de coordenadas, e como guia para a reconstrução geométrica das cartilagens articulares.

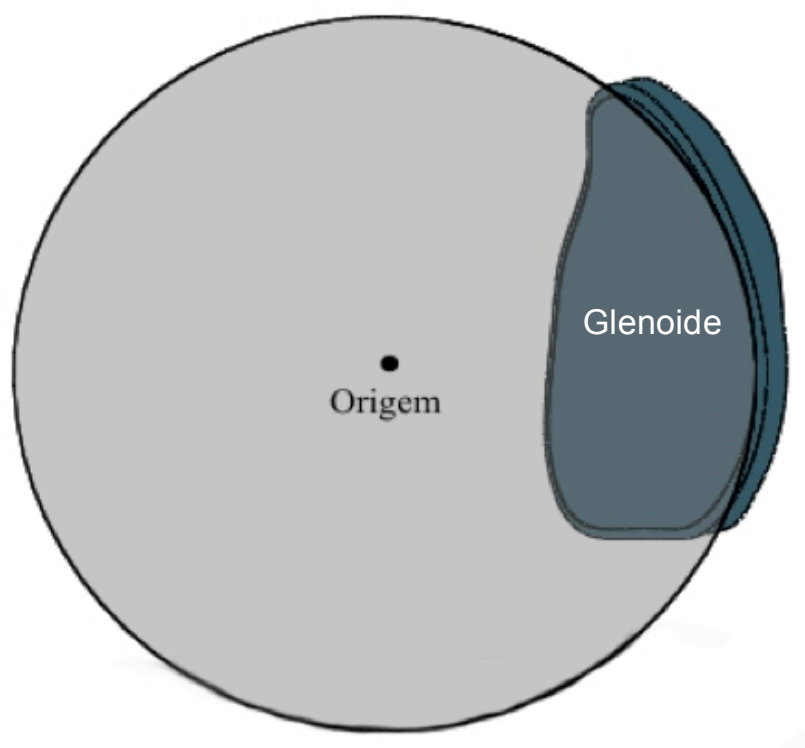

Figura 7 - Sphere fitting: Centro da esfera que melhor se encaixa na superfície articular da cartilagem da cavidade glenoidal

\subsubsection{Definição do sistema de coordenadas}


Um sistema local de coordenadas da região tribológica (par articular) foi criado para interligar os pontos do modelo em ambiente 3D. O centro desse sistema de coordenadas é coincidente com o centro de rotação articular definido na posição de $0^{\circ}$ de abdução. Este ponto é fixo e não se altera com as subsequentes mudanças de posicionamento e translação articular. A direção do eixo Z é normal, ou seja, perpendicular ao ponto central da superfície articular da cartilagem da cavidade glenoidal, no sentido lateral-medial; o eixo Y é definido arbitrariamente na direção inferior-superior; e o eixo $X$ definido normal ao plano YZ, na direção anterior-posterior (Figura 8).

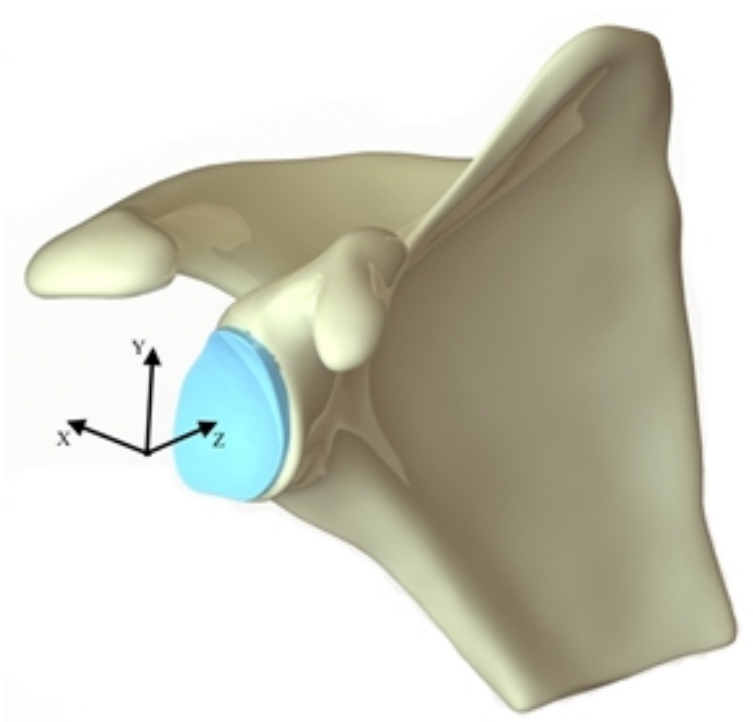

Figura 8 - Sistema de coordenadas articular: Origem (CR) e eixos X, Y e Z

\subsubsection{Refinamento geométrico dos modelos sólidos}


As informações dos exames de imagem foram transformadas em arquivos tridimensionais no formato ".stl” que são, basicamente, uma nuvem de pontos conectados para formar uma estrutura 3D. Essas estruturas não podem ser utilizadas para análise, pois não são estruturas sólidas. Primeiramente, foi necessário transformar essas estruturas em sólidos. Para tal finalidade, foi utilizado o software comercial de elementos finitos Abaqus.

A extremidade proximal do úmero e a escápula foram transformados em sólidos a partir de dados da artro-TC, enquanto suas respectivas cartilagens foram reconstruídas a partir de informações obtidas dos arquivos .stl da artroRM. Por tratar-se de exames de imagem diferentes, as coordenadas das estruturas cartilaginosas e a das estruturas ósseas não são as mesmas. Para que todas as estruturas possam ser representadas a partir de um mesmo sistema de coordenadas, assume-se que o centro da esfera relativa à cabeça do úmero é o mesmo da esfera relativa à face óssea da cartilagem da cabeça do úmero. Ou seja, a face óssea da cartilagem da cabeça do úmero é congruente à superfície óssea da cabeça do úmero.

As geometrias reconstruídas a partir desses dados foram analisadas pela a técnica do sphere fitting ${ }^{110}$, que consiste em determinar o raio e o centro da esfera que melhor se encaixa em uma determinada superfície a partir de pontos selecionados na superfície de interesse. Essa técnica foi utilizada para determinar a esfericidade, ou seja, o quanto a superfície em questão assemelha-se a uma superfície esférica, das seguintes estruturas: cabeça do úmero, fossa glenoidal, e superfícies ósseas e articulares das cartilagens ${ }^{111}$.

Para isso utilizou-se o critério de Meskers et al. ${ }^{110}$, que sugere uma quantidade mínima de 40 pontos para cada superfície. Os pontos foram 
selecionados de forma manual no software SolidWorks, tentando manter uma distância equidistante entre eles. A quantidade de pontos escolhida é a função, principalmente, do tamanho da superfície. A média dos raios dos pontos escolhidos definiu o raio da respectiva estrutura.

\subsection{Reconstrução óssea}

As estruturas ósseas da extremidade proximal do úmero e da escápula foram recriadas com o uso de um software CAD a partir dos dados obtidos na posição de 0 graus de abdução da artro-TC. Como não houve aquisição da estrutura completa do úmero, foi necessário reconstruir uma extensão de sua diáfise como um cilindro, para facilitar a posterior aplicação dos carregamentos presentes nessa estrutura, principalmente com relação à inserção do músculo deltoide (Figura 9). 


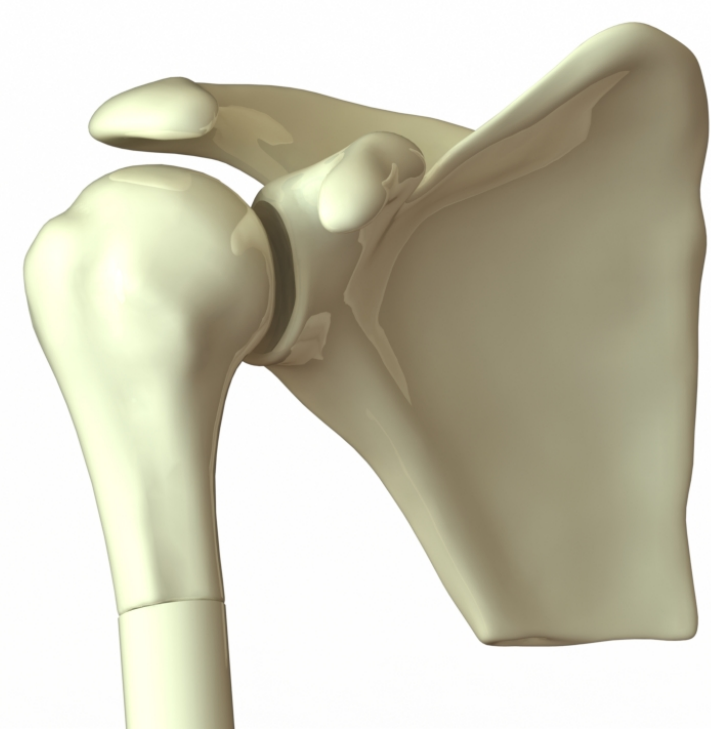

Figura 9 - Modelo sólido após reconstrução óssea da escápula, extremidade proximal do úmero e detalhe da extensão da diáfise

A partir das estruturas recriadas na posição de 0 graus de abdução, as outras posições articulares foram reconstruídas por meio do posicionamento dessas estruturas nas imagens obtidas pela artro-TC (Figura 10).

A

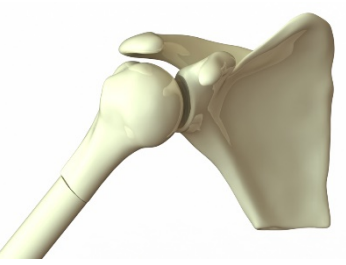

B

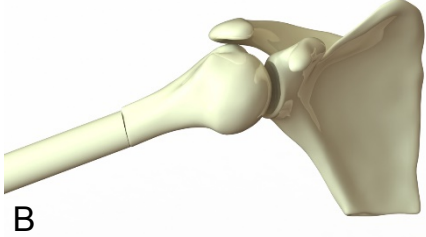

C

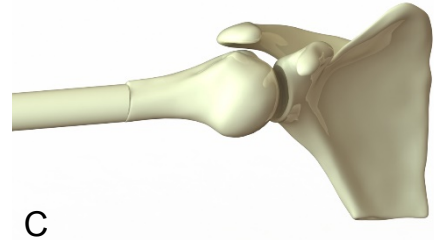

Figura 10 - Modelo sólido reconstruído nas posições: A- 60, B - $90^{\circ}$, C -120

\subsection{Morfologia da cartilagem da cabeça do úmero}


Para o ajuste da morfologia, inicialmente determinou-se o plano do colo anatômico do úmero. Para isso foram traçadas curvas na superfície da cabeça do úmero (Figura 11). A partir dos pontos de inflexão dessas curvas, define-se um plano médio, tendo esse plano como base, ajusta-se um outro plano de forma que a menor quantidade possível de pontos de inflexão fique abaixo dele. Esse plano foi definido, então, como o plano do colo anatômico do úmero (Figura 12). A superfície articular da cartilagem da cabeça do úmero foi definida como a metade de um elipsoide a partir de um plano paralelo ao plano do colo anatômico do úmero, a uma distância de $2 \mathrm{~mm}$, como ilustrado na

\section{Figura 13.}

Os dados utilizados para a reconstrução foram baseados em informações antropométricas da literatura ${ }^{111-113}$ e ajustados para melhor conformidade com a anatomia óssea, conforme representado nas Figuras 13 e 14.

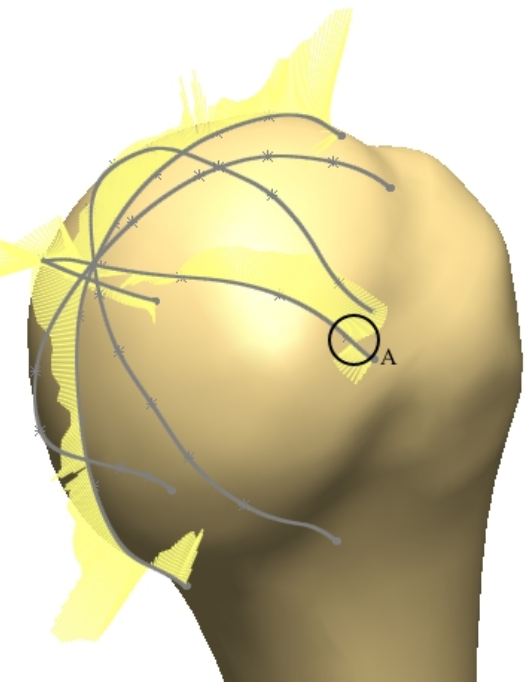

Figura 11 - Determinação do plano do colo anatômico do úmero. Em cinza, estão as curvas traçadas na superfície da cabeça do úmero e, em amarelo, suas curvaturas. $\mathrm{O}$ ponto A ilustra um dos pontos de inflexão utilizados para definir o plano do colo anatômico do úmero 

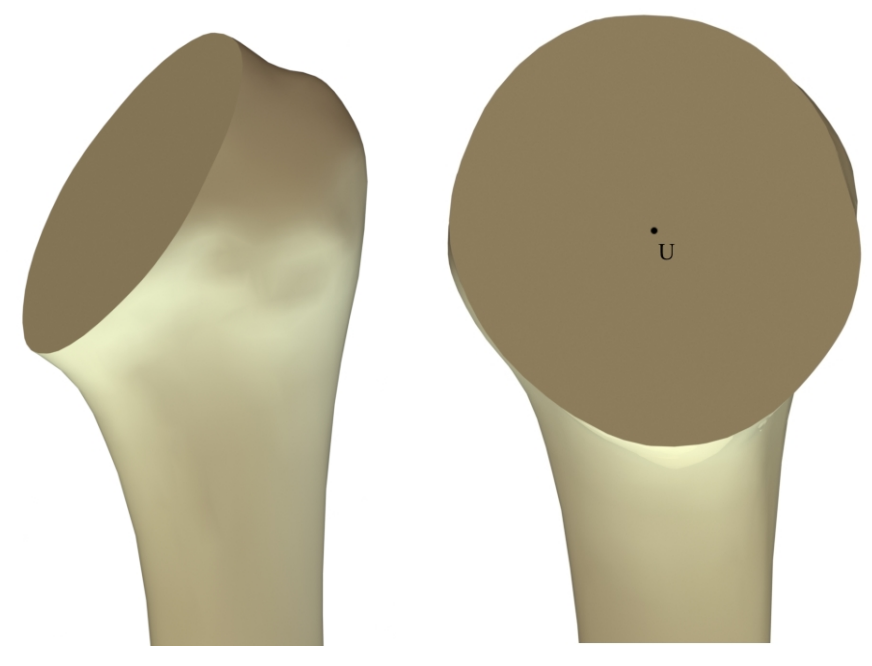

Figura 12 - Corte coincidente com o plano do colo anatômico do úmero. Ponto U - centroide do plano do colo anatômico do úmero

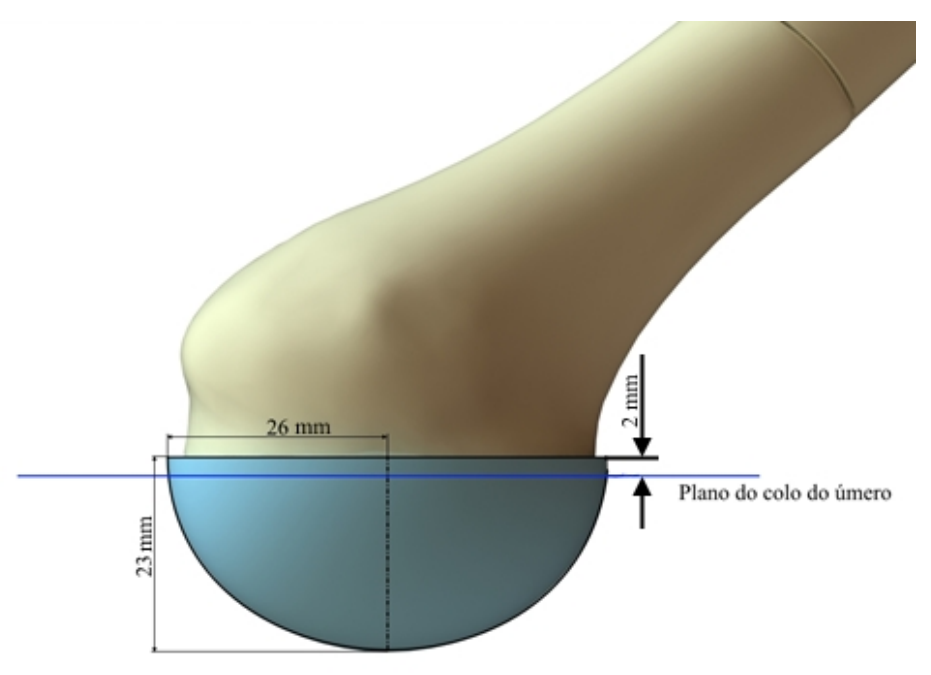

Figura 13 - Características geométricas da cartilagem da cabeça do úmero 


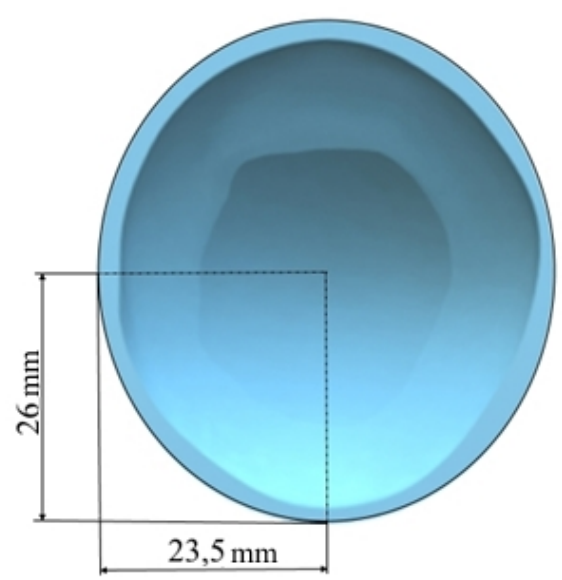

Figura 14 - Raios do elipsoide utilizados na reconstrução da cartilagem da cabeça do úmero

\subsection{Morfologia da cartilagem da cavidade glenoidal}

A imagem obtida da artro-RM determinou o contorno inicial da cartilagem da cavidade glenoidal. Esse contorno foi ajustado à superfície óssea da fossa glenoidal da escápula, conforme ilustrado na Figura 15. 

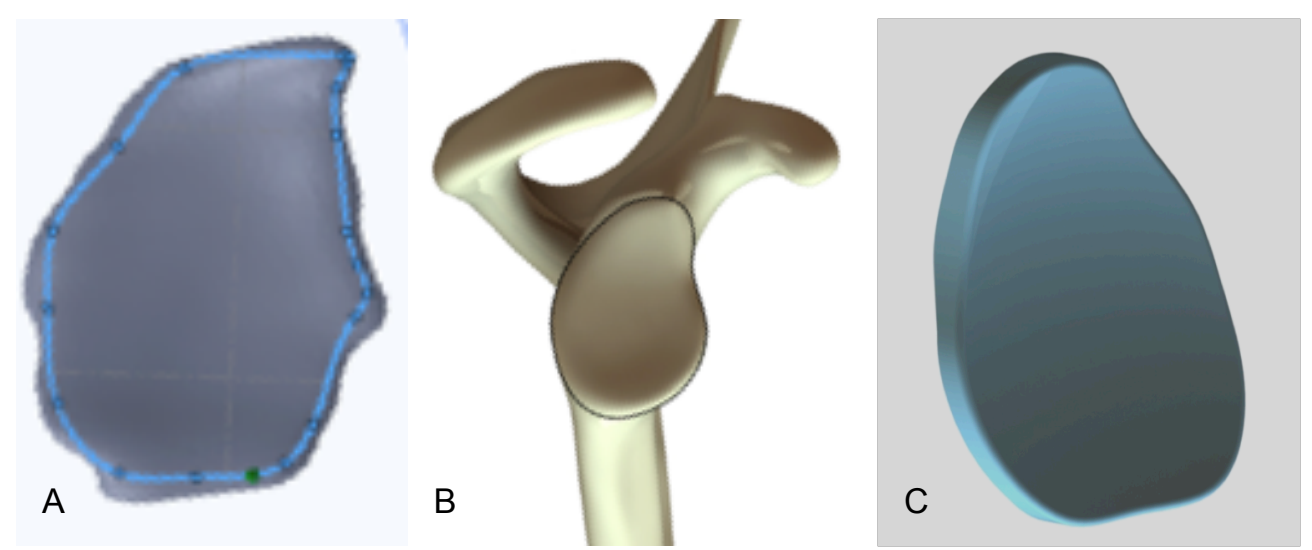

Figura 15 - A- Imagem bruta do contorno da cartilagem da cavidade glenoidal, a partir de pontos da artro-RM. B- Contorno ósseo no plano normal da fossa glenoidal. CRefinamento final da morfologia da cartilagem da cavidade glenoidal, após ajuste à morfologia do plano normal

A partir dos raios das superfícies óssea e articular da cartilagem da cavidade glenoidal obtida da artro-RM, foi determinado um raio médio (r_m), a partir de um mesmo centro, equidistante das duas faces. A espessura inicial da cartilagem, baseada em dados antropométricos ${ }^{111}$, foi determinada com início em r_m e incrementada, de forma equivalente, entre as faces ósseas e articular até que a superfície articular da cartilagem da cavidade glenoidal entre em contato com a superfície articular da cartilagem da cabeça do úmero na posição de $0^{\circ}$ de abdução (Figura 16). Desta forma, determina-se a espessura final da cartilagem e o raio final da superfície articular da cartilagem da cavidade glenoidal. 


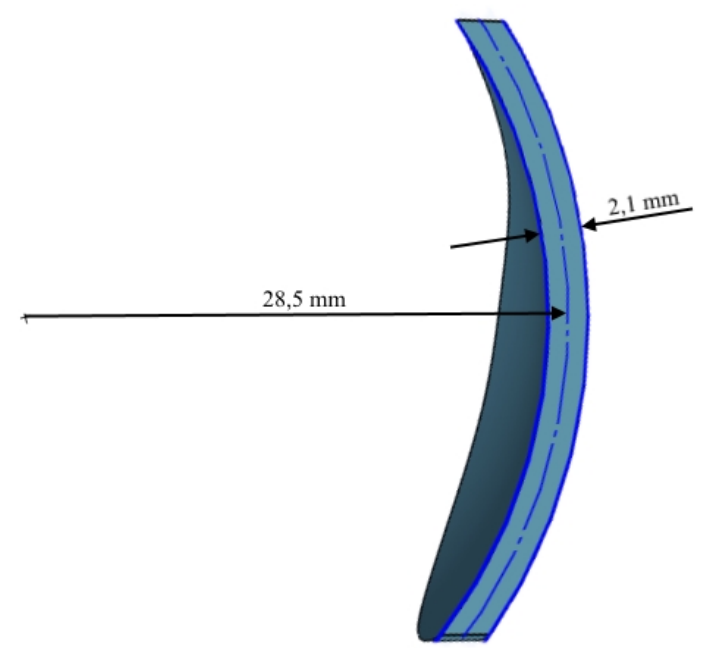

Figura 16 - Raio médio e espessura inicial da cartilagem da cavidade glenoidal

\subsection{Análise crítica dos resultados anatômicos}

Após a finalização do ajuste geométrico, as dimensões da extremidade proximal do úmero e da escápula foram comparadas com as informações antropométricas da literatura ${ }^{111-115}$. Os parâmetros utilizados foram: os raios da cabeça do úmero, o raio de curvatura da cavidade glenoidal, o ângulo cervicodiafisário do úmero e as dimensões da cavidade glenoidal.

A avaliação dos raios de curvatura das estruturas articulares foi realizada por uma análise de desvio padrão do resultado do sphere fitting, ou seja, se as estruturas representadas pelos pontos escolhidos nas superfícies correspondem de forma aceitável a uma esfera, como defendido por Soslowski et al. ${ }^{111}$. A avaliação da superfície articular da cabeça do úmero como elipsoide foi feita ao comparar as dimensões dos raios, nos três planos, com os dados da literatura ${ }^{112,114}$. 
A medição do ângulo cervicodiafisário foi realizada ao calcular o ângulo entre a linha do eixo da diáfise e uma linha perpendicular ao plano do colo anatômico do úmero ${ }^{114}$.

As dimensões da cavidade glenoidal foram comparadas com dados dos estudos de Ikemoto et al. ${ }^{115}$ e lannotti et al. ${ }^{114}$. Calculou-se a área total, as dimensões dos segmentos vertical, horizontal superior, médio e inferior, e a razão entre o segmento superior e inferior.

\subsubsection{Determinação das propriedades dos materiais}

O modelo numérico de elementos finitos foi desenvolvido no software Abaqus. Foram selecionados elementos tetraédricos de segunda ordem modificados C3D10M para as cartilagens, por serem elementos robustos e apropriados para problemas envolvendo contato. O comportamento material das cartilagens foi definido por uma lei de material hiperelástico Neo-Hookean: $E=70 M P a$ e $v=0,4^{116,117}$. Os ossos foram definidos como corpos rígidos e modelados com elementos triangulares $\mathrm{R} 3 \mathrm{D} 3^{106}$.

\subsubsection{Determinação das propriedades de contato}

Um modelo de contato sem atrito foi definido como condição mecânica na superfície $\operatorname{articular}^{106}$. Foram avaliadas a área de contato, a localização do contato e a pressão de contato. Um mapa com os resultados foi montado para cada posição analisada. 


\subsubsection{Determinação das condições de contorno}

A escápula foi definida como fixa, incapaz de realizar qualquer movimento. Somente o úmero apresentou movimento translacional, e seus graus de liberdade foram liberados gradualmente durante a simulação para facilitar a convergência do modelo. Inicia-se com a translação do úmero na direção normal à superfície articular da cartilagem da cavidade glenoidal, isto é, no eixo $Z$ do sistema local de coordenadas, seguido pela liberação do movimento do úmero nas direções vertical (eixo $\mathrm{Y}$ ) e anteroposterior (eixo $\mathrm{X}$ ). A rotação do úmero foi mantida fixa para garantir o equilíbrio, com consequente aparecimento de um vetor de momento reativo. Esse momento de reação deve tornar-se nulo ou suficientemente pequeno à medida que o sistema de esforços externos estejam equilibrados para a angulação da posição proposta.

\subsubsection{Determinação do carregamento das forças}

Os principais determinantes das forças atuantes na articulação glenoumeral corresponderam às forças exercidas pelos segmentos musculares. Foram desconsideradas as contribuições de estruturas que atuam de forma passiva no equilíbrio articular, como os ligamentos, a cápsula articular e o comportamento passivo dos músculos. Foram considerados neste estudo somente o comportamento ativo dos músculos deltoide, subescapular, supraespinal, infraespinal e redondo menor. 
Os pontos de inserção muscular e braços de alavanca foram baseados nas informações de Favre et al. ${ }^{90}$, e ajustados de acordo com o centro de rotação articular, as referências anatômicas da escápula, e as imagens dos footprints das inserções do manguito rotador obtidas na artro-RM, e três pontos de referência de inserções musculares na superfície óssea. As linhas de ação foram ajustadas para estarem em contato com a superfície óssea. As origens escapulares da musculatura do manguito rotador e músculo deltoide não foram representadas no modelo. Desta forma, a linha de ação foi direcionada de acordo com a escala de coordenadas desse modelo, as referências de Favre et al. ${ }^{90}$ e as referências anatômicas da escápula desse modelo.

Os músculos foram representados como cabos sem atrito, permanecendo sempre retesados e traçando uma trajetória que vai desde a origem muscular na escápula ou na clavícula até a inserção no úmero, ajustada pela técnica de "obstacle-set"86,88 para estar em contato com a superfície óssea ou de cartilagem. Desta forma, esses segmentos musculares envolvem essas estruturas, gerando, assim, uma força de coaptação muscular devido ao contato entre o músculo e o osso (wrapping). No modelo numérico, os músculos são representados pelo vetor da força exercida por eles em seus respectivos pontos de inserção, como ilustrado na Figura 17. 


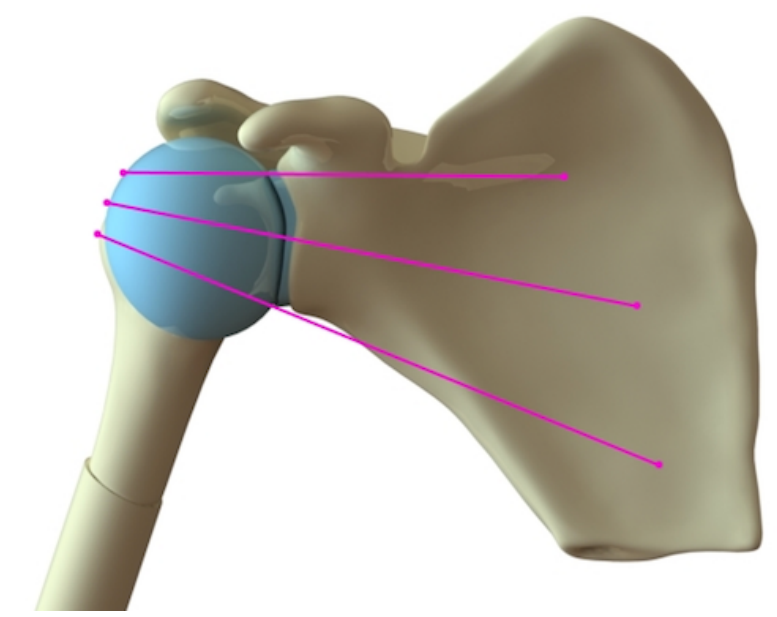

A

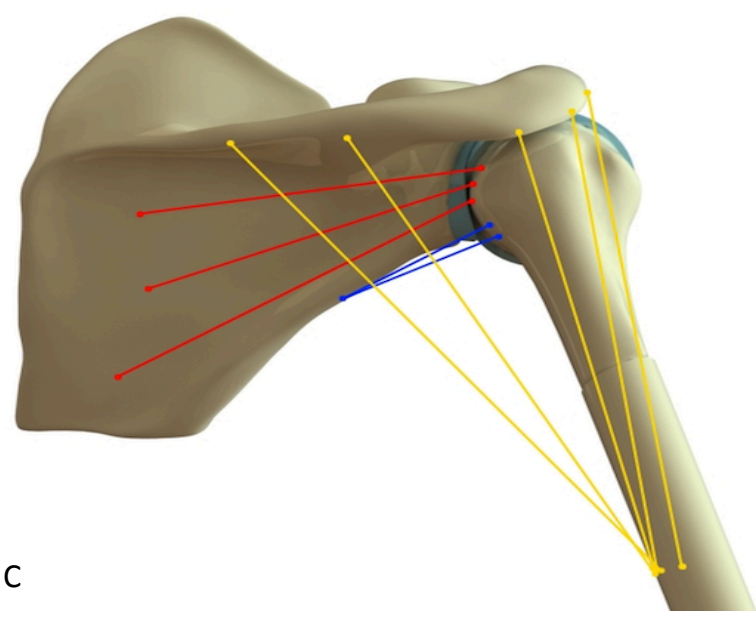

B

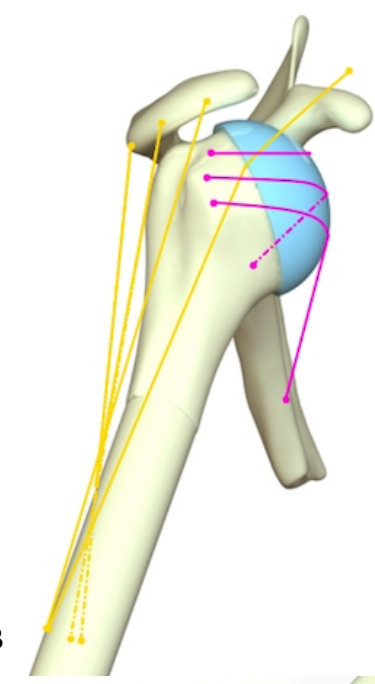

D

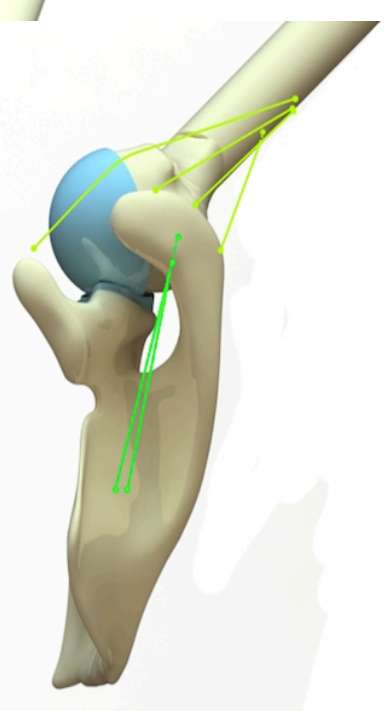

Figura 17 - llustrações do trajeto muscular na posição $60^{\circ}$ de abdução e $90^{\circ}$ de rotação lateral: subescapular (rosa), deltoide (amarelo), infraespinal (vermelho), redondo menor (azul) e supraespinal (verde). A. Vista anterior. B. Vista lateral. C. Vista posterior. D. Vista superior

Nesse modelo foram consideradas as seguintes forças que atuam no úmero:

- $\quad$ peso do braço $(\boldsymbol{p})$, 
- forças exercidas pelos segmentos musculares $\left(f_{m}\right)$,

- força devido ao contato muscular-ósseo (coaptação muscular) $\left(f_{r}\right)$ e

- força de reação devido ao contato articular $\left(\boldsymbol{r}_{\boldsymbol{a}}\right)$.

\subsection{Direção das forças}

A ação das forças dos músculos é no respectivo ponto de inserção no úmero, e sua direção foi determinada pelo trajeto muscular em cada posição de abdução, como ilustrado na Figura 18.

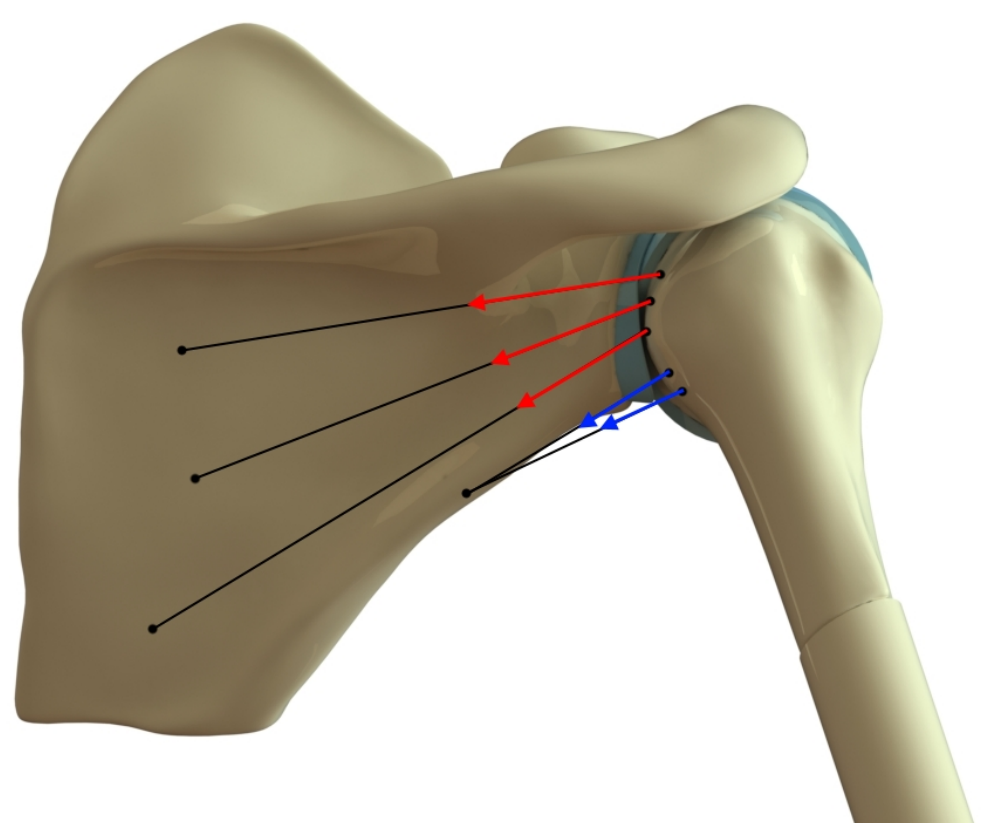

Figura 18 - Visão posterior da escápula. Os trajetos musculares dos músculos infraespinal e redondo menor são representados pela linha preta, enquanto que as direções das forças exercidas por esses músculos são representadas pelas setas vermelhas e azuis, respectivamente 
A direção do peso do braço foi definida na posição de 0 graus de abdução ao longo da diáfise do úmero e seu ponto de aplicação estará a $320 \mathrm{~mm}$ do centro da cabeça do úmero ${ }^{118}$, como na Figura 19.

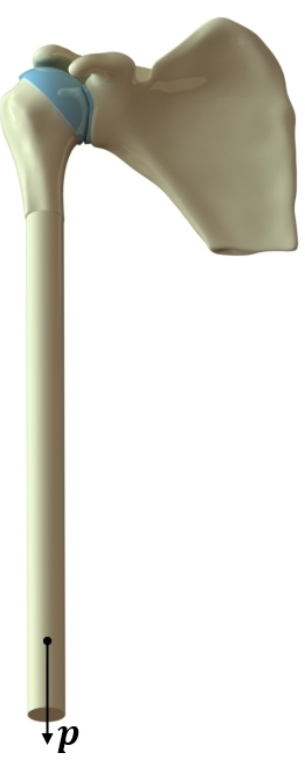

Figura 19 - Peso do braço na posição de 0 graus

Para determinar a direção do peso do braço nas outras posições de abdução foi necessário considerar o ritmo escapuloumeral, já que o movimento de abdução é uma combinação entre a angulação do úmero com relação a escápula e da escápula com relação ao plano sagital, como ilustrado na Figura 20. 


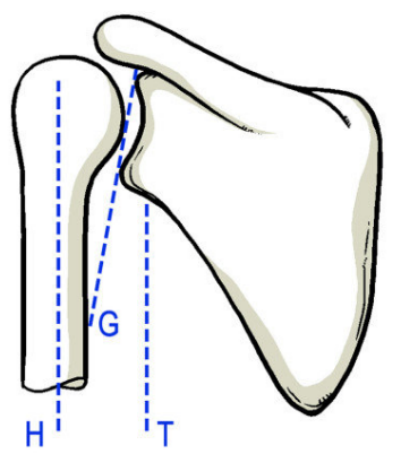

b

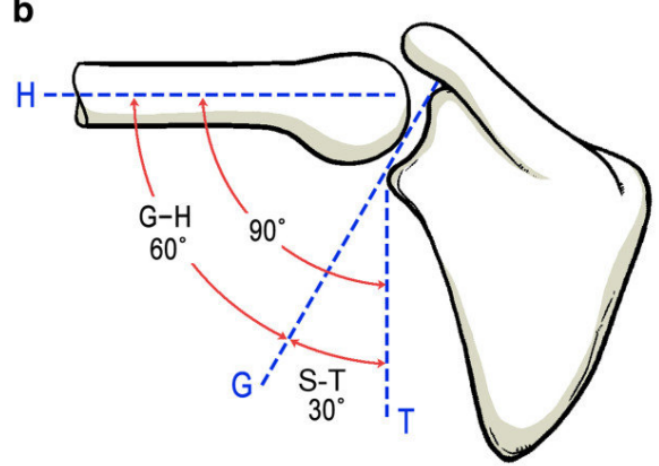

Figura 20 - Ritmo escapuloumeral com o ombro na posição de $0^{\circ}$ de abdução (a) e na posição de $90^{\circ}$ de abdução (b). As linhas $\mathrm{H}$ (eixo da diáfise do úmero), $\mathrm{G}$ (coincidente com o plano da cavidade glenoidal) e $\mathrm{T}$ (plano sagital), formam os ângulos glenoumeral (G-H) e escapulotorácico (S-T)

Para corrigir a direção do peso do braço mede-se o ângulo glenoumeral entre a posição de abdução $k$ e a posição inicial, em 0 graus, onde $k$ são as posições de abdução consideradas no modelo. Como a escápula é fixa em relação ao sistema de coordenadas, e portanto coincidente em ambas as posições, o ângulo glenoumeral é medido entre as retas que passam pelo centro aproximado da diáfise do úmero. Assim, o ângulo escapulotorácico é definido como a diferença entre o ângulo de abdução k e o ângulo glenoumeral dessa mesma posição.

Na posição de abdução $k$ é possível determinar a direção do peso do braço em uma posição $k\left(\boldsymbol{p}_{\boldsymbol{k}}\right)$ em seu respectivo ponto de aplicação $\left(\boldsymbol{x}_{\boldsymbol{p}_{\boldsymbol{k}}}\right)$. Considerando que a escápula em ambas as posições são coincidentes, o ângulo glenoumeral é medido entre as retas que passam pelo centro da diáfise do úmero na posição $\mathrm{k}$ e $\boldsymbol{p}_{\mathbf{0}}$, e o ângulo escapulotorácico será a diferença entre o ângulo de abdução $k$ e o ângulo glenoumeral desta mesma posição. 0 ângulo entre a reta $\boldsymbol{A}_{k}$ (paralela a $\boldsymbol{p}_{0}$ a partir de $\boldsymbol{x}_{p_{k}}$ ) a e a reta que passa pelo 
centro da diáfise do úmero na posição $k$ é o ângulo glenoumeral, Portanto, a direção de $\boldsymbol{p}_{\boldsymbol{k}}$ é definida pelo ângulo escapulotorácico a partir de $\boldsymbol{A}_{\boldsymbol{k}}$ (Figura 21).

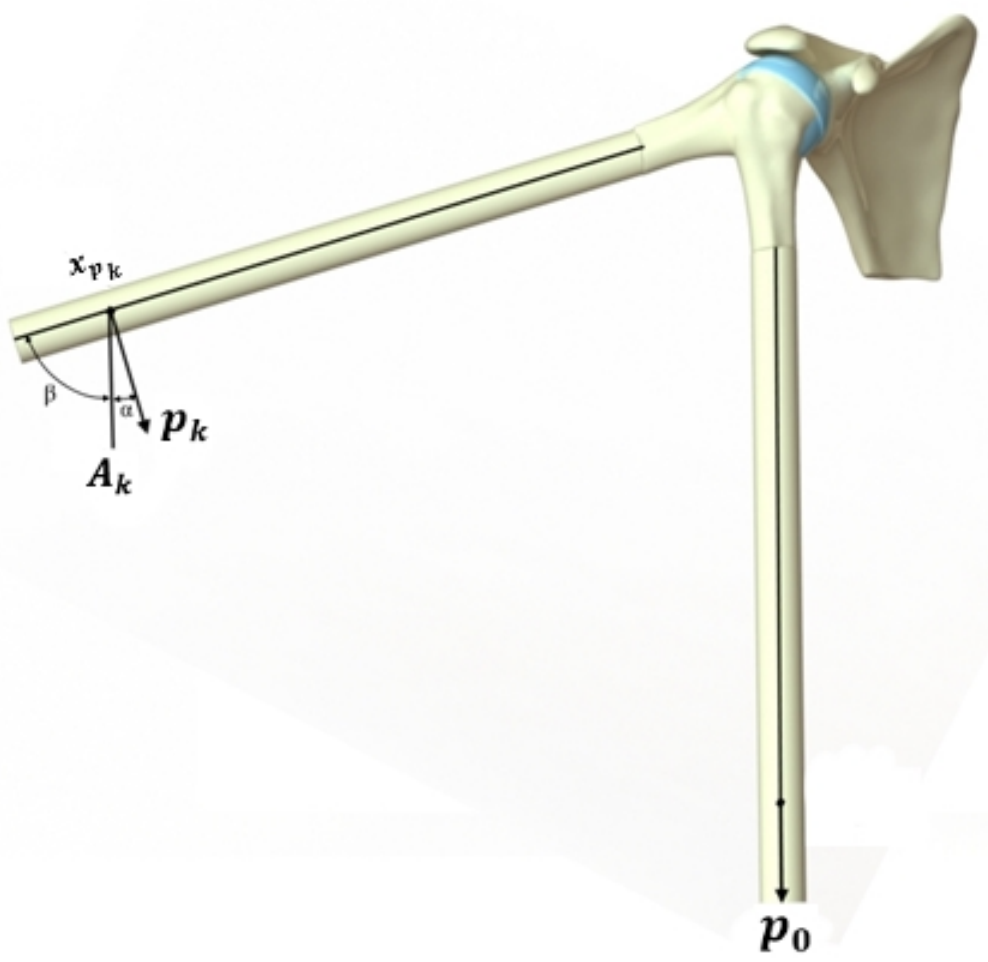

Figura 21 - Determinação da direção do peso do braço em uma posição k considerando que a escápula em ambas as posições são coincidentes

As direções das forças resultantes do contato dos músculos com a cabeça do úmero foram determinadas por meio de um modelo corda-polia sem atrito, como esquematizado na Figura 22. onde as forças $\boldsymbol{f}_{1}$ e $\boldsymbol{f}_{2}$ possuem a mesma amplitude $f$ mas direções unitárias distintas, $\boldsymbol{e}_{\mathbf{1}}$ e $\boldsymbol{e}_{2}$, respectivamente. Admitindo que o músculo se comporta como uma corda tensionada quando contraído, as forças $\boldsymbol{f}_{1}$ e $\boldsymbol{f}_{2}$ atuam nas regiões de inserção do úmero e da escápula, e $f$ é a magnitude dessa força. 


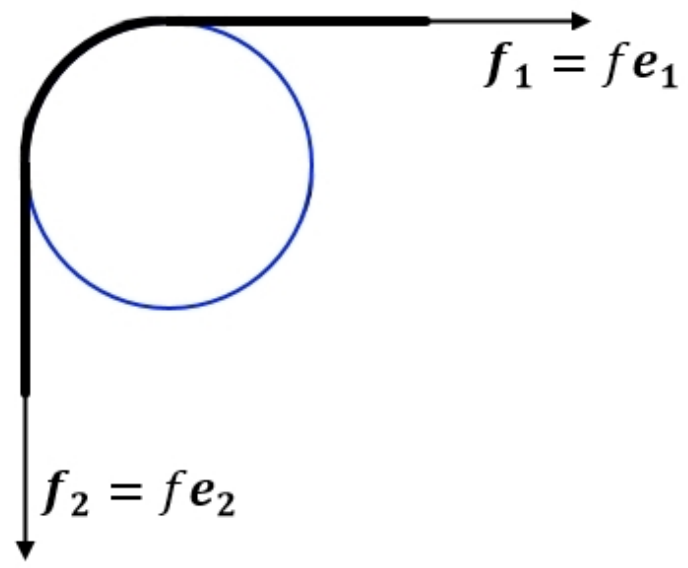

Figura 22 - Forças atuantes em um sistema corda-polia sem atrito

Para poder analisar corretamente o sistema acima, é necessário separálo em dois corpos distintos. Devido a terceira lei de Newton, ambos os corpos exercem uma força entre si, pois há um contato entre eles. Assim, há o aparecimento de uma força distribuída na região de contato, que foi representada por meio de uma força resultante $\boldsymbol{f}_{\boldsymbol{r}}$ em ambos os corpos, possuindo a mesma amplitude $f_{r}$, mas direções contrárias (Figura 23).
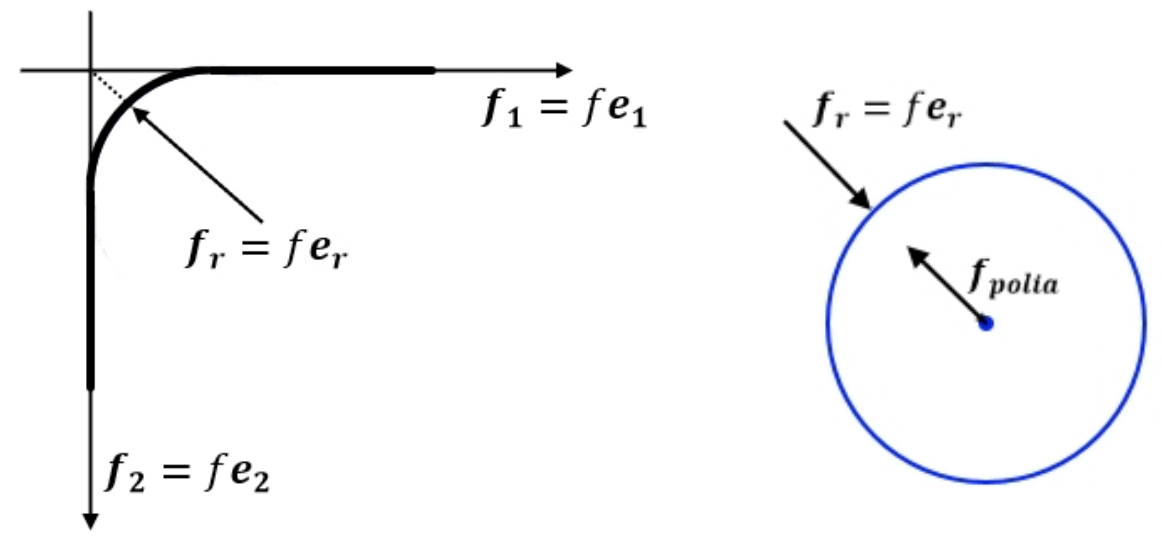

Figura 23 - Diagrama de corpo livre da corda (esquerda) e da polia (direita) 
Inicialmente, analisa-se as forças atuando na corda de modo que elas satisfaçam o equilíbrio deste corpo (Eq. 1):

$$
f_{1}+f_{2}+f_{r}=0
$$

Como as forças $\boldsymbol{f}_{1}$ e $\boldsymbol{f}_{2}$ tem direção e amplitude conhecidas, determinase a força de reação $\boldsymbol{f}_{\boldsymbol{r}}$ de amplitude $f_{r}$ e direção unitária $\boldsymbol{e}_{\boldsymbol{r}}$ por meio da Eq. 2. Essa foi a força aplicada na cabeça úmero pela contração do segmento muscular que a envolve:

$$
\boldsymbol{f}_{\boldsymbol{r}}=-\left(\boldsymbol{f}_{\mathbf{1}}+\boldsymbol{f}_{2}\right)=-f\left(\boldsymbol{e}_{\mathbf{1}}+\boldsymbol{e}_{2}\right)=-f \boldsymbol{d}_{\boldsymbol{r}}=f d_{r} \boldsymbol{e}_{\boldsymbol{r}}=f_{r} \boldsymbol{e}_{\boldsymbol{r}}
$$

Onde $d_{r}$ é a soma dos vetores unitários $\boldsymbol{e}_{1}$ e $\boldsymbol{e}_{2}$.

O ponto de aplicação $\boldsymbol{x}_{\boldsymbol{r}}$ da força $\boldsymbol{f}_{\boldsymbol{r}}$ é determinado por meio do modelo geométrico, admitindo que $\boldsymbol{f}_{r}$ passa pela bissetriz de $\boldsymbol{f}_{1}$ e $\boldsymbol{f}_{2}$ e é normal a superfície de contato (Figura 24). 


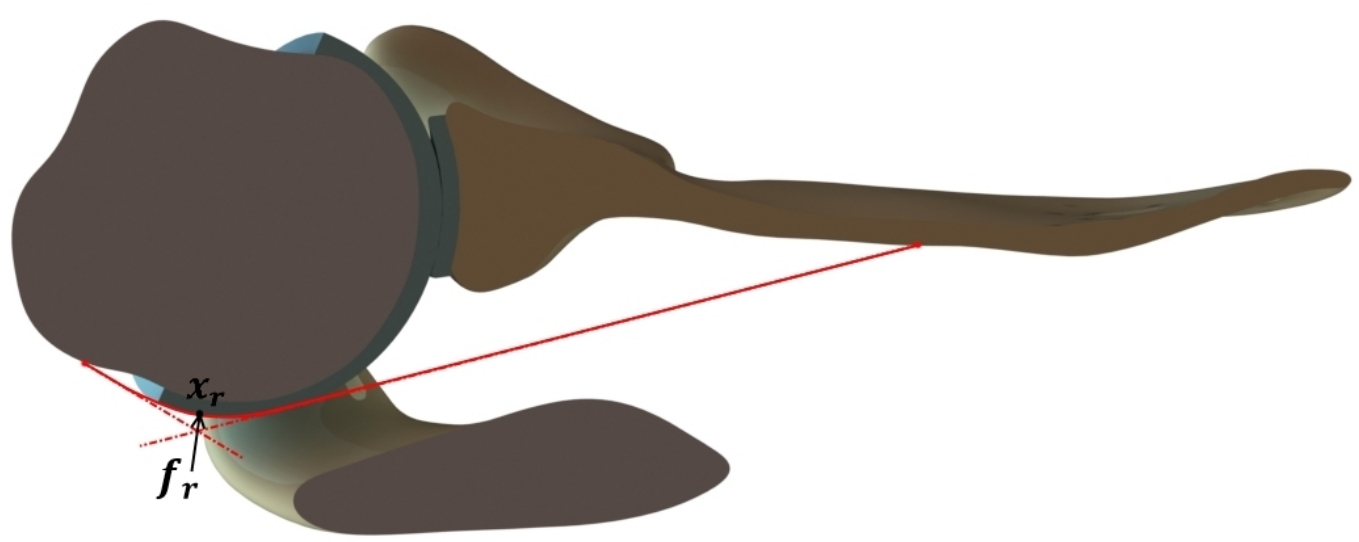

Figura 24 - Determinação do ponto x_r no modelo geométrico. As linhas em vermelho representam o trajeto muscular a partir dos pontos de inserção e são coincidentes com as direções de f_1 e f_2. Em preto o ponto de aplicação x_r e o vetor representando $\boldsymbol{f}_{\boldsymbol{r}}$

\subsection{Amplitude das forças}

A amplitude do peso do braço foi definida como $5 \%$ da massa corporal ${ }^{118}$ resultando no valor de $35 \mathrm{~N}$.

Para facilitar a análise das forças, admite-se que as amplitudes das forças musculares $\boldsymbol{f}_{\boldsymbol{m}_{\boldsymbol{i}}}$ são proporcionais à amplitude da força exercida por um músculo de referência. Neste caso, o grupo muscular de referência é o deltoide intermediário e a amplitude da sua força é denotada $f_{m_{u}}$. Assim, os demais segmentos musculares apresentam amplitudes na forma

$$
f_{m_{i}}=r_{m_{i}} f_{m_{u}}
$$

Onde $r_{m_{i}}$ é a proporção muscular de cada segmento. 
Para reduzir a quantidade de variáveis desconhecidas e facilitar a posterior determinação das mesmas, admite-se que a proporção muscular dos segmentos de um mesmo grupo muscular são iguais. Devido à grande área de inserção e às diferentes funções fisiológicas, os seis segmentos do deltoide são divididos em três grupos musculares: deltoide anterior, deltoide intermediário e deltoide posterior. Assim, tem-se uma redução de 16 para 7 variáveis, como ilustrado na Tabela 1.

Tabela 1 - Divisão dos grupos musculares em diferentes segmentos e a representação da proporção muscular de cada um

\begin{tabular}{|c|c|c|c|}
\hline Grupos musculares & Segmentos musculares & $r_{m_{i}}$ & $r_{m}$ \\
\hline Supraespinal & $\begin{array}{l}\text { Supraespinal anterior } \\
\text { Supraespinal posterior }\end{array}$ & $\begin{array}{l}r_{m_{1}} \\
r_{m_{2}}\end{array}$ & $r_{m_{S S P}}$ \\
\hline Subescapular & $\begin{array}{l}\text { Subescapular superior } \\
\text { Subescapular intermediário } \\
\text { Subescapular inferior }\end{array}$ & $\begin{array}{l}r_{m_{3}} \\
r_{m_{4}} \\
r_{m_{5}}\end{array}$ & $r_{m_{S S C}}$ \\
\hline Infraespinal & $\begin{array}{c}\text { Infraespinal superior } \\
\text { Infraespinal intermediário } \\
\text { Infraespinal inferior }\end{array}$ & $\begin{array}{l}r_{m_{6}} \\
r_{m_{7}} \\
r_{m_{8}}\end{array}$ & $r_{m_{I S P}}$ \\
\hline Redondo menor & $\begin{array}{l}\text { Redondo menor superior } \\
\text { Redondo menor inferior }\end{array}$ & $\begin{array}{l}r_{m_{9}} \\
r_{m_{10}}\end{array}$ & $r_{m_{T R M N}}$ \\
\hline \multirow{3}{*}{ Deltoide } & Deltoide anterior & $r_{m_{11}}$ & $r_{m_{D E L A}}$ \\
\hline & $\begin{array}{c}\text { Deltoide intermediário anterior } \\
\text { Deltoide intermediário intermediário } \\
\text { Deltoide intermediário posterior }\end{array}$ & $\begin{array}{l}r_{m_{12}} \\
r_{m_{13}} \\
r_{m_{14}}\end{array}$ & $r_{m_{D E L I}}$ \\
\hline & $\begin{array}{l}\text { Deltoide posterior lateral } \\
\text { Deltoide posterior medial }\end{array}$ & $r_{m_{15}}$ & $r_{m_{D E L P}}$ \\
\hline
\end{tabular}

A amplitude das forças de reação devido ao contato dos segmentos musculares que envolvem a cabeça do úmero foi obtida a partir da Eq. 2: 


$$
\boldsymbol{f}_{\boldsymbol{r}_{\boldsymbol{i}}}=f_{r_{i}} \boldsymbol{e}_{\boldsymbol{r}_{\boldsymbol{i}}}
$$

Em que:

$$
f_{r_{i}}=f_{m_{i}} d_{r_{i}} .
$$

Substituindo a Eq. 3 na Eq. 5:

$$
f_{r_{i}}=r_{m_{i}} f_{m_{u}} d_{r_{i}}
$$

Assim, a amplitude da força de reação devido ao contato de um determinado segmento que envolve a cabeça do úmero é uma função da proporção muscular $r_{m_{i}}$ deste segmento e da amplitude da força exercida pelo grupo muscular de referência $f_{m_{u}}$.

\subsection{Equilíbrio articular}

Para poder garantir a estabilização articular, é necessário que as forças atuando na articulação estejam em equilíbrio. Assim, o somatório das forças que atuam no úmero deve ser igual a zero (Eq. 7):

$$
\sum_{i=1}^{N} \boldsymbol{f}_{\boldsymbol{m}_{\boldsymbol{i}}}+\sum_{j=1}^{K} \boldsymbol{f}_{\boldsymbol{r}_{j}}+\boldsymbol{p}+\boldsymbol{r}_{\boldsymbol{a}}=\mathbf{0},
$$


$\mathrm{Na}$ Eq. 8 as forças são representadas por meio de sua amplitude e direção unitária:

$$
\sum_{i=1}^{N} f_{m_{i}} \boldsymbol{e}_{\boldsymbol{m}_{i}}+\sum_{j=1}^{K} f_{r_{j}} \boldsymbol{e}_{\boldsymbol{r}_{j}}+p \boldsymbol{e}_{\boldsymbol{p}}+r_{a} \boldsymbol{e}_{\boldsymbol{a}}=\mathbf{0}
$$

Reescrevendo e isolando a variável $f_{m_{u}}$, obtém-se:

$$
f_{m_{u}}\left(\sum_{i=1}^{N} r_{m_{i}} \boldsymbol{e}_{\boldsymbol{m}_{i}}+\sum_{j=1}^{K} r_{r_{j}} \boldsymbol{e}_{\boldsymbol{r}_{j}}\right)+p \boldsymbol{e}_{\boldsymbol{p}}+r_{a} \boldsymbol{e}_{\boldsymbol{a}}=\mathbf{0}
$$

Assim, da Eq. 9 consegue-se determinar a força de reação devido ao contato articular que atua no úmero, tal que:

$$
r_{a} \boldsymbol{e}_{\boldsymbol{a}}=-f_{m_{u}}\left(\sum_{i=1}^{N} r_{m_{i}} \boldsymbol{e}_{\boldsymbol{m}_{i}}+\sum_{j=1}^{K} r_{r_{j}} \boldsymbol{e}_{\boldsymbol{r}_{j}}\right)-p \boldsymbol{e}_{\boldsymbol{p}}
$$

Para garantir a estabilidade articular é necessário que os momentos gerados pelas forças descritas anteriormente também estejam em equilíbrio (Eq. 11):

$$
\sum_{i=1}^{N} \boldsymbol{m}_{\boldsymbol{m}_{\boldsymbol{i}}}+\sum_{j=1}^{K} \boldsymbol{m}_{\boldsymbol{r}_{\boldsymbol{j}}}+\boldsymbol{m}_{\boldsymbol{p}}+\boldsymbol{m}_{\boldsymbol{a}}=\mathbf{0}
$$

Onde $\boldsymbol{m}_{\boldsymbol{m}_{\boldsymbol{i}}}$ é o momento gerado pelos segmentos musculares $\boldsymbol{f}_{\boldsymbol{m}_{\boldsymbol{i}}} ; \boldsymbol{m}_{\boldsymbol{r}_{\boldsymbol{j}}}$ é o momento gerado pelas forças de reação $\boldsymbol{f}_{\boldsymbol{r}_{\boldsymbol{j}}}$ devido ao contato dos músculos que envolvem a cabeça do úmero; $\boldsymbol{m}_{\boldsymbol{p}}$ é o momento gerado pelo peso do 
braço; e $\boldsymbol{m}_{\boldsymbol{a}}$ é o momento gerado pela força reação $\boldsymbol{r}_{\boldsymbol{a}}$ devido ao contato articular. A determinação destes momentos é realizada por meio do produto vetorial entre seus respectivos braços de momento e forças.

Este sistema define as seis equações de equilíbrio estático nas três direções do sistema de coordenadas para o sistema articular quando submetido às forças já descritas anteriormente. Nota-se, entretanto, que para um determinado valor do peso $\boldsymbol{p}$, há treze variáveis desconhecidas: $f_{m_{u}}, r_{m_{S S P}}$, $r_{m_{S S C}}, r_{m_{I S P}}, r_{m_{T R M N}}, r_{m_{D E L A}}, r_{m_{D E L P}}, \boldsymbol{r}_{\boldsymbol{a}}(x, y, z)$ e $\boldsymbol{m}_{\boldsymbol{a}}(x, y, z)$. Como há mais variáveis do que equações de equilíbrio, não existe solução única para esse sistema, sendo necessário o desenvolvimento de um procedimento para se chegar a uma solução aproximada satisfatória.

\subsection{Método de solução das equações de equilíbrio}

Com o objetivo de obter a solução fisiologicamente mais adequada dentre as diferentes combinações de forças possíveis para alcançar equilíbrio do sistema articular, propôs-se formular um problema de extremização. Para tal definiu-se uma função objetivo a ser minimizada dentro de um conjunto de restrições.

Considera-se $\boldsymbol{r}_{\boldsymbol{m}} \in \boldsymbol{R}^{7}$ a variável vetorial contendo como componentes as incógnitas do problema: amplitude da força do grupo muscular de referência e coeficientes musculares dos correspondentes grupos musculares. 
$\boldsymbol{r}_{\boldsymbol{m}}=\left(f_{m_{u}, m_{S S P}}, r_{m_{S S C}}, r_{m_{I S P}}, r_{m_{T R M N}}, r_{m_{D E L A}}, r_{m_{D E L P}}\right)$.

Assim, o problema foi definido formalmente como:

$\min \varepsilon_{m}\left(\boldsymbol{r}_{\boldsymbol{m}}\right)$

sujeito às restrições:

$r_{a} \leq \alpha$

$\varepsilon_{f}=0$

$r_{m_{l}} \geq 0, \quad l=1 \ldots 7$

$r_{m_{D E L I}}=1$

Em que:

$\varepsilon_{f}=\left|\sum_{i=1}^{N} \boldsymbol{f}_{\boldsymbol{m}_{\boldsymbol{i}}}+\sum_{j=1}^{K} \boldsymbol{f}_{\boldsymbol{r}_{\boldsymbol{j}}}+\boldsymbol{p}+\boldsymbol{r}_{\boldsymbol{a}}\right|$

$\varepsilon_{m}=\frac{\left|\sum_{i=1}^{N} \boldsymbol{m}_{m_{i}}+\sum_{j=1}^{K} \boldsymbol{m}_{r_{j}}+\boldsymbol{m}_{p}+\boldsymbol{m}_{\boldsymbol{a}}\right|}{\left|\boldsymbol{m}_{\boldsymbol{p}}\right|}$

Em outras palavras, deseja-se encontrar a menor força que os músculos devem exercer para equilibrar a articulação glenoumeral (i) tal que o momento residual $\varepsilon_{m}$ seja menor que $1 \%$, respeitando as condições de equilíbrio de forças (ii) e considerando somente o comportamento ativo dos músculos (iii). 
Dada a natureza da função objetivo, com muitos mínimos locais dentro do espaço de busca, foi escolhido o método de otimização heurístico (algoritmo genético) MOGA-II disponível no código comercial ModeFRONTIER.

O cálculo de funções objetivo e restrição foi implementado num código em linguagem MatLab que está contido no ModeFRONTIER. As forças resultantes do processo de otimização são transferidas para o modelo de Elementos Finitos desenvolvido no Abaqus que permite a determinação das características mecânicas de contato entre as cartilagens deformáveis que compõem a articulação. Esta solução, entretanto, fornece uma força resultante de contato $\boldsymbol{r}_{\boldsymbol{a}}$ que, em geral, apresenta diferenças de valor e posicionamento com aquela presumida no MatLab. Isto obriga a realizar um processo iterativo de correção entre algoritmo de otimização e cálculo via Elementos Finitos, descrito na Figura 25. 


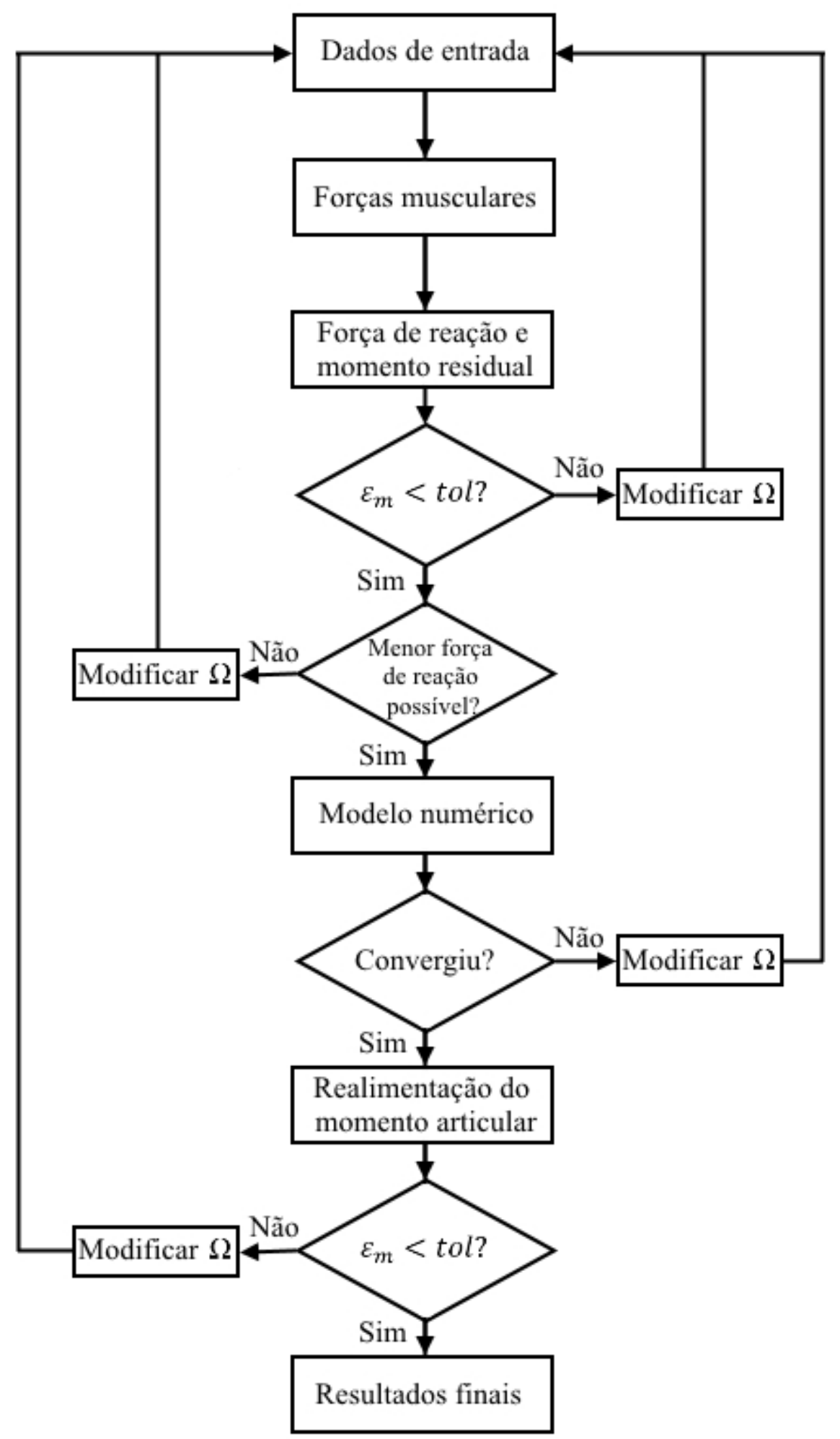

Figura 25 - Fluxograma da metodologia utilizada para a determinação da amplitude das forças exercidas pelos músculos 


\subsubsection{Análise crítica dos resultados e validação do modelo}

Como descrito nos tópicos anteriores, cada passo da construção do modelo teve a validação das características morfológicas feita por meio de comparação com dados de anatomia presentes na literatura.

A validação do ambiente fisiológico do modelo, ou seja, as características de cargas articulares, foi realizada ao confrontar-se o resultado do equilíbrio de forças, e suas repercussões biomecânicas nas diferentes posições, com os dados presentes na literatura ${ }^{60,61,90,118-136}$.

\subsection{Estudo da trilha da glenoide}

Após a construção e validação do modelo, pode-se avaliar a relação entre a cavidade glenoidal e a cabeça do úmero nas posições articulares propostas. Para essa medição foram definidos parâmetros, como medidas quantitativas da cavidade glenoidal, pontos de referência na extremidade proximal do úmero, os limites da trilha da glenoide e as características a serem estudadas.

\subsubsection{Comprimento anteroposterior da cavidade glenoidal}

A medida do comprimento anteroposterior da cavidade glenoidal foi baseada nos métodos de Omori et al. ${ }^{41}$ e Griffith et al. ${ }^{137}$. Inicialmente, definese o comprimento do eixo longo da cavidade glenoidal, que é medido do 
tubérculo supraglenoidal até a margem inferior da cavidade glenoidal, seguindo uma referência de $12 \mathrm{hs}$ a $6 \mathrm{hs}$. Então, o tamanho anteroposterior da cavidade glenoidal é definido por meio de uma linha perpendicular a seu eixo longo. $\mathrm{O}$ parâmetro de Omori et al. ${ }^{41}$ considera a medição pela linha perpendicular que passa no ponto médio superoinferior, enquanto que Griffith et al. ${ }^{137}$ utilizam a medida que corresponde ao comprimento máximo anteroposterior, usualmente na porção média da metade inferior da cavidade glenoidal (Figura 26). Esses valores foram expressos em arcos ao contornar as superfícies articulares.

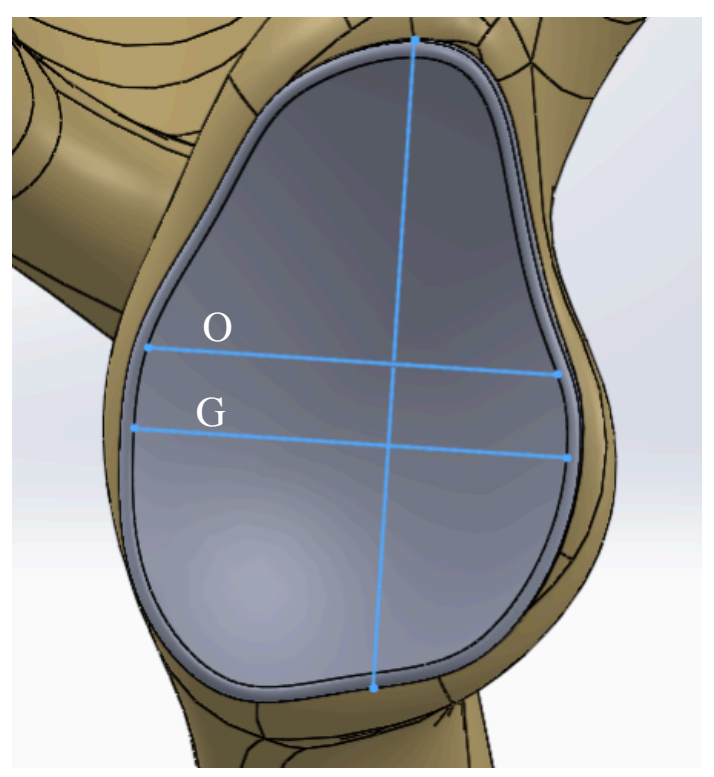

Figura 26 - Linhas de referência para medição do comprimento anteroposterior da cavidade glenoidal, a linha superior, "O", corresponde ao método de Omori e a linha inferior, "G", corresponde ao método de Griffith

Fonte: Omori et al. ${ }^{41}$ e Griffith et al. ${ }^{137}$ 


\subsubsection{Comprimento da trilha da glenoide}

Os pontos de referência para medição do comprimento da trilha da glenoide foram estipulados à semelhança do estudo de Omori et al. ${ }^{41}$ (Figura 27):

- Plano aproximado do colo anatômico do úmero: determinado a partir dos pontos de inflexão das curvas traçadas ao redor da cabeça do úmero;

- Ponto U: é o centroide da secção umeral do plano do colo anatômico do úmero;

- Ponto C: ponto central articular ósseo da cabeça do úmero, definido como a intersecção entre a cartilagem articular da cabeça do úmero e a linha perpendicular ao plano do colo anatômico que passe pelo ponto $U$.
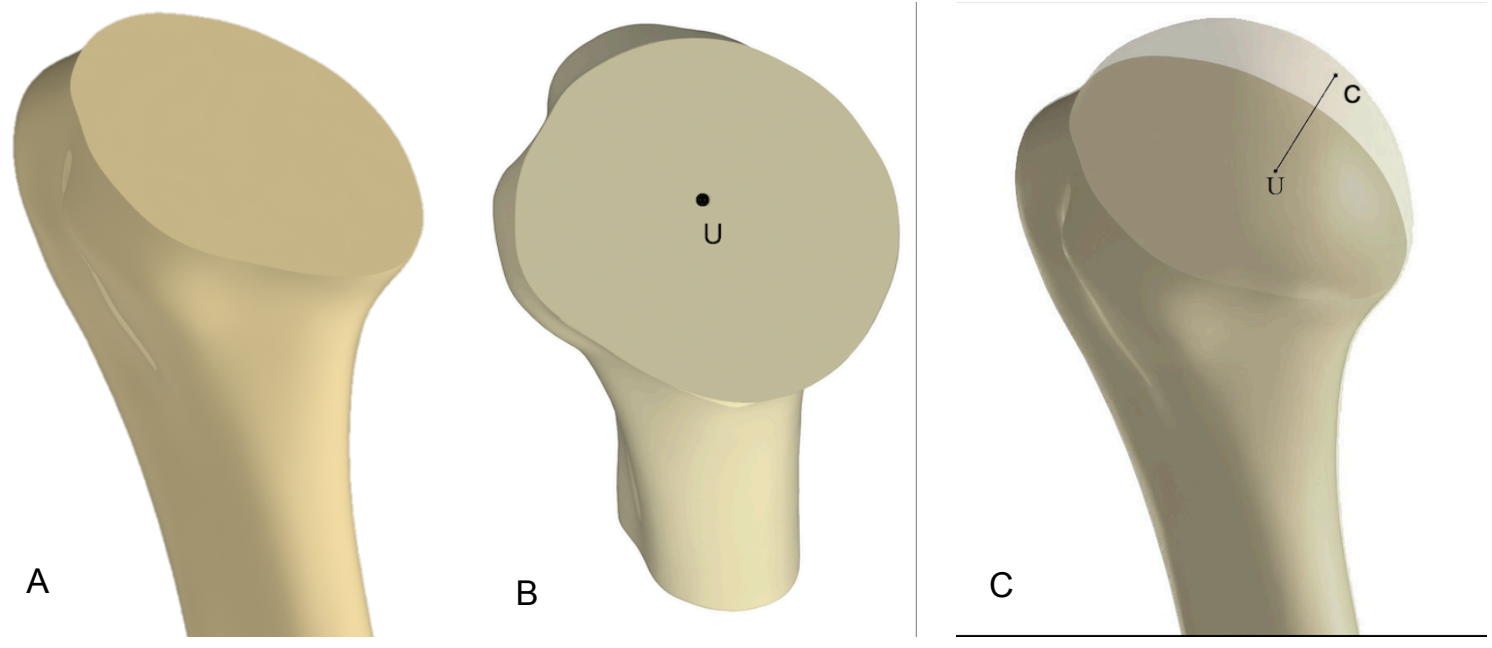
Figura 27- Pontos de referência para localização da trilha da glenoide. A. Plano do colo anatômico. B. Ponto central U, no plano do colo anatômico. C. Ponto central articular $C$, localizado na superfície articular da cabeça do úmero, em linha perpendicular ao ponto $\mathrm{U}$ e ao plano do colo anatômico

\subsubsection{Limites da trilha da glenoide}

O ponto mais medial do contato da cavidade glenoidal na cabeça do úmero após a ativação das forças articulares foi definido como Ponto M. Para cada grau de abdução foi definido um ponto $M$ correspondente, por exemplo: M30, M60, M90. A partir do Ponto $U$, do Ponto $C$ e de cada Ponto $M$ correspondente, foi definido um plano, denominado plano UCM, que orienta a medição do comprimento da trilha da glenoide para a respectiva posição (Figura 28).

Ao seguir-se o plano de orientação, o comprimento da trilha da glenoide no correspondente grau de abdução é a distância entre o ponto $M$ e o primeiro ponto de contato com a inserção do manguito rotador. A medição foi feita ao contornar-se a superfície articular, e não em linha reta (Figura 28). Também foi avaliada a distância de cada ponto $M$ até o ponto do limite da cartilagem da cabeça do úmero, como realizado por Yamamoto et al. $^{32}$.

Os valores foram aferidos com e sem a ativação das forças articulares e seus resultados, comparados. Como não é possível definir um ponto de contato articular sem a ativação das forças articulares, o ponto medial da linha de referência de Omori et al. e de Grifith et al. na cavidade glenoidal foi projetado na superfície articular da cabeça do úmero e entendido como o ponto de contato. A medição do comprimento da trilha também seguiu o plano definido UCM, até o ponto de contato com a inserção do manguito rotador e limite da 
cartilagem. Esse valor será dividido pelo valor correspondente de comprimento anteroposterior da cavidade glenoidal medido pelo método de Omori et al. ${ }^{\mathbf{4 1}}$ ou de Grifith et al. ${ }^{137}$.
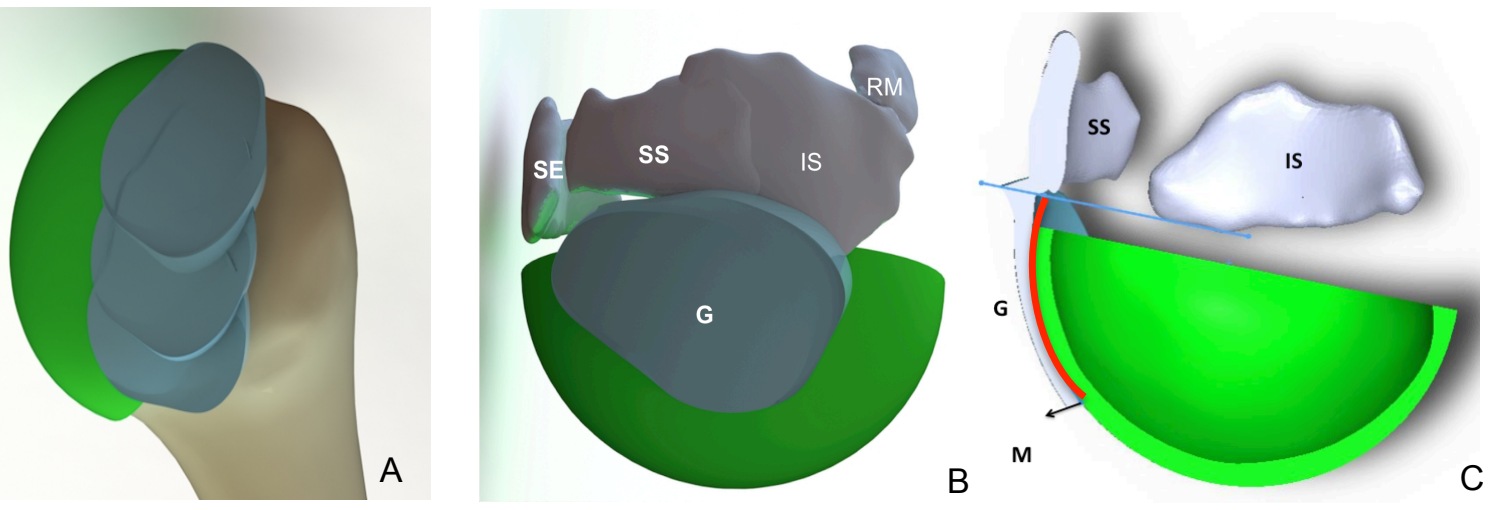

Figura 28 - Medidas de referência da trilha da glenoide. A- Posição relativa da cartilagem da cavidade glenoidal em cada grau de abdução. B- Detalhe das posições relativas da cartilagem da cabeça do úmero (em verde), da cartilagem da cavidade glenoidal, e das inserções do manguito rotador. C- Corte da cartilagem da cabeça do úmero (em verde) no plano de referência UCM; distância do ponto $M$ até a inserção do manguito rotador corresponde à extensão da trilha da glenoide (arco em vermelho). G-Cartilagem da cavidade glenoidal; SE-subescapular; SS-supraespinal; ISinfraespinal; RM-redondo menor

\subsubsection{Características avaliadas}

Foram avaliadas as seguintes características:

- Comprimento da trilha da glenoide, em $\mathrm{mm}=$ distância da borda medial do contato da cavidade glenoidal na cabeça do úmero (ponto 
M) até a inserção do manguito rotador e até o limite da cartilagem, medido a $60^{\circ}, 90^{\circ}$ e $120^{\circ}$ graus de abdução, a $90^{\circ}$ de rotação lateral;

- Razão da trilha, em \%, definida à semelhança do método de Yamamoto et al. ${ }^{32}$, corresponde à razão entre comprimento da trilha e o comprimento anteroposterior da cavidade glenoidal, medido tanto pela método de Omori et al. ${ }^{41}$ quanto pelo de Griffith et al. ${ }^{137}$ :

- $\quad$ Comparação dos resultados desses parâmetros antes (desativado) e após (ativado) o carregamento muscular;

- Área, localização e porcentagem do contato articular nos diferentes graus de abdução e rotação lateral, tanto na cartilagem da cabeça do úmero, quanto na da cavidade glenoidal;

- Distribuição da pressão na área de contato articular.

\subsection{Análise de dados}

A leitura (pós-processamento) dos dados foi realizada com o software do LEB-UFSC. O software foi utilizado para preparar o modelo e para visualizar os resultados da simulação numérica, incluindo a parte detalhada de cada estrutura que compõe o modelo. Foi possível, por exemplo, saber qual a variação de tensão de cada músculo ou a variação da pressão de contato de cada osso. Desta forma, foi feito um relatório gráfico com fotos e filmes das posições estudadas e das características da trilha da glenoide como já mencionadas. 


\section{$5 \quad$ RESULTADOS}

\subsection{Dados do voluntário}

O voluntário escolhido foi RMS, sexo masculino, 24 anos, 1,72m de altura, $70 \mathrm{Kg}$, índice de massa corpórea $(\mathrm{IMC})=23,66$, destro.

\subsection{Ajuste geométrico}

\subsubsection{Sphere fitting, centro de rotação e raios articulares}

Para determinar o ponto correspondente ao CR foram escolhidos 120 pontos, de forma manual e aleatória, na superfície articular da cavidade glenoidal. A Tabela 2 apresenta os resultados do sphere fitting utilizado para a definição do CR e para o trabalho geométrico das estruturas articulares.

Tabela 2 - Raio e número de pontos utilizados para o sphere fitting

\begin{tabular}{ccc}
\hline & Raio [mm] & Pontos \\
\hline Cabeça do úmero & 23,93 & 65 \\
Fossa glenoidal & 31,23 & 51 \\
Face óssea da cartilagem glenoidal & 30,08 & 120 \\
Face articular da cartilagem glenoidal & 26,90 & 83 \\
Face óssea da cartilagem umeral & 22,83 & 199 \\
Face articular da cartilagem da cabeça umeral & 25,46 & 228 \\
Centro de Rotação & 25,46 & 83 \\
\hline
\end{tabular}




\subsubsection{Espessura da cartilagem}

Os valores da espessura inicial, raio médio (r_m), e raios articular e ósseo da cartilagem da escápula estão apresentados na Tabela 3.

Tabela 3 - Características geométricas utilizadas como referência para a cartilagem da cavidade glenoidal

\begin{tabular}{cccc}
\hline Espessura inicial & Raio médio & Raio articular & Raio ósseo \\
\hline $2,1 \mathrm{~mm}$ & $28,5 \mathrm{~mm}$ & $27,45 \mathrm{~mm}$ & $29,55 \mathrm{~mm}$ \\
\hline
\end{tabular}

Uma leve alteração óssea da escápula fez-se necessária para que a cartilagem da cavidade glenoidal possuísse uma espessura mínima aceitável. Para isso, subtraiu-se uma pequena parte do tecido ósseo da fossa glenoidal. Após alteração óssea, houve adição de material de cartilagem a partir da face óssea da cartilagem da cavidade glenoidal, de modo que essa superfície fosse congruente à superfície da óssea da escápula. Os dados de espessura média, máxima e mínima para a cartilagem da cabeça do úmero e da escápula estão na tabela 4. As figuras 29 e 30 ilustram a distribuição de espessura ao longo das cartilagens articulares da cabeça do úmero e escápula.

Tabela 4 - Dados de espessura das cartilagens reconstruídas

\begin{tabular}{lccc}
\hline & Espessura média & Espessura máxima & Espessura mínima \\
\hline Úmeral & $1,96 \mathrm{~mm}$ & $3,25 \mathrm{~mm}$ & $0,72 \mathrm{~mm}$ \\
Glenoidal & $2,3 \mathrm{~mm}$ & $5,05 \mathrm{~mm}$ & $2,1 \mathrm{~mm}$ \\
\hline
\end{tabular}




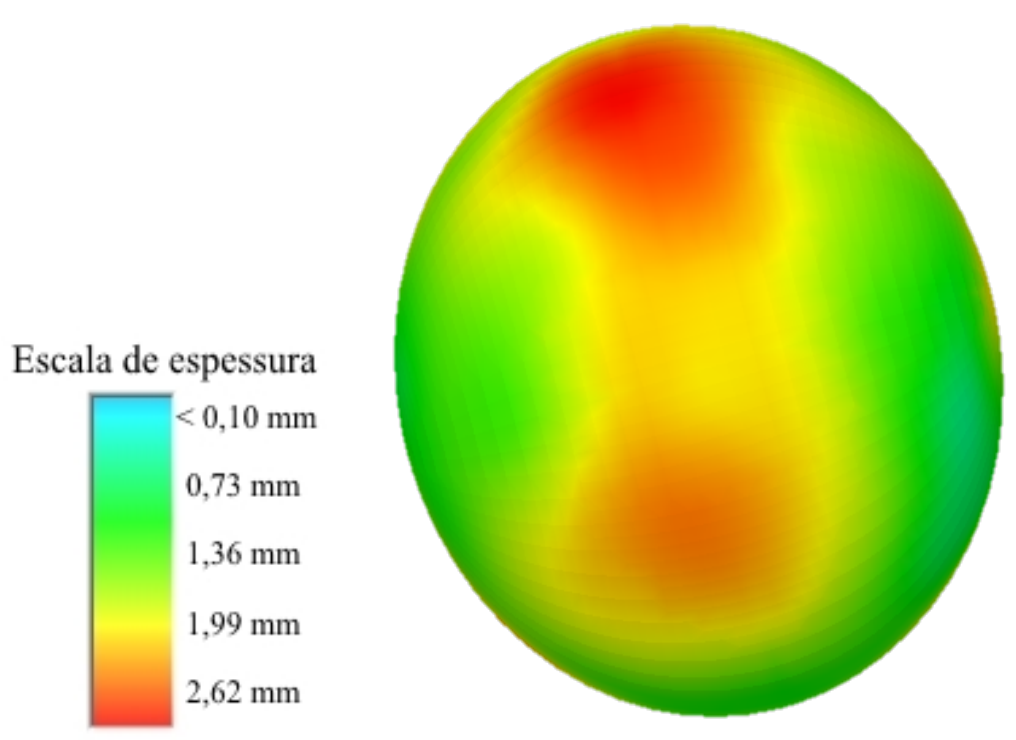

Figura 29 - Distribuição de espessura da cartilagem da cabeça do úmero

Escala de espessura

$\square 2,10 \mathrm{~mm}$
$2,54 \mathrm{~mm}$
$2,98 \mathrm{~mm}$
$3,42 \mathrm{~mm}$
$3,86 \mathrm{~mm}$

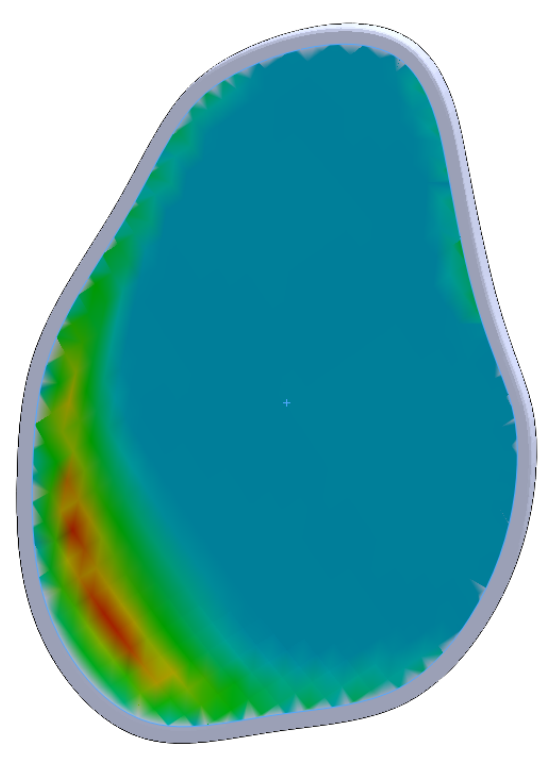

Figure 30 - Distribuição de espessura na cartilagem da cavidade glenoidal 


\subsection{Características da reconstrução geométrica}

\subsubsection{Esfericidade das estruturas articulares}

Os resultados dos desvios padrão do sphere fitting das estruturas articulares reproduzidas pelos exames de imagem está na Tabela 5.

Tabela 5 - Características da morfologia advinda dos exames de imagem. Desvios padrão das estruturas utilizadas para o sphere fitting; e $\mathrm{d} / \mathrm{R}$ : média das distâncias entre o centro da esfera e os pontos selecionados na superfície da estrutura (d) e o raio da esfera $(R)$

\begin{tabular}{lrr}
\hline \multicolumn{1}{c}{ Estrutura } & Desvio Padrão & \multicolumn{1}{c}{ d/R } \\
\hline Úmero & $1,70 \%$ & 1,000 \\
Face articular da cartilagem do úmero & $1,38 \%$ & 1,000 \\
Face óssea da cartilagem do úmero & $1,87 \%$ & 0,999 \\
Face articular da cartilagem glenoidal & $1,26 \%$ & 0,999 \\
Face óssea da cartilagem glenoidal & $0,94 \%$ & 0,999 \\
Fossa glenoidal da escápula & $0,85 \%$ & 0,999 \\
\hline
\end{tabular}

O resultado do desvio padrão da superfície articular da cartilagem da cabeça do úmero após ajustes geométricos que a tornaram um esferoide está na Tabela 6. 
Tabela 6 - Desvio padrão da superfície articular da cartilagem da cabeça do úmero reconstruída

\begin{tabular}{llrl}
\hline \multicolumn{2}{c}{ Estrutura } & Desvio Padrão & d/R \\
\hline $\begin{array}{l}\text { Superfície articular da } \\
\text { úmero após reconstrução }\end{array}$ & & $2,46 \%$ & 1,000 \\
\hline
\end{tabular}

\subsubsection{Anatomia da extremidade proximal do úmero}

As características geométricas da extremidade proximal do úmero deste modelo e de lanotti et al. ${ }^{114}$ estão indicadas na Tabela 7. A representação da morfologia do úmero encontrada no plano do colo anatômico do úmero está ilustrada na Figura 31.

Tabela 7 - Características geométricas da extremidade proximal do úmero deste modelo e do estudo de lannotti

\begin{tabular}{lcc}
\hline & Modelo numérico & lannotti et al. $^{114}$ \\
\hline Distância superior-inferior [mm] & 38,93 & $39 \pm 3,7$ \\
Distância anterior-posterior superior [mm] & 15,1 & $23 \pm 2,7$ \\
Distância anterior-posterior inferior [mm] & 22,88 & $29 \pm 3,1$ \\
Espessura da cabeça do úmero [mm] & 18,67 & $20 \pm 2,0$ \\
Ângulo cervicodiafisário (graus) & 130,01 & $135 \pm 5$ \\
\hline Fonte: lannotti et al. ${ }^{114}$ &
\end{tabular}




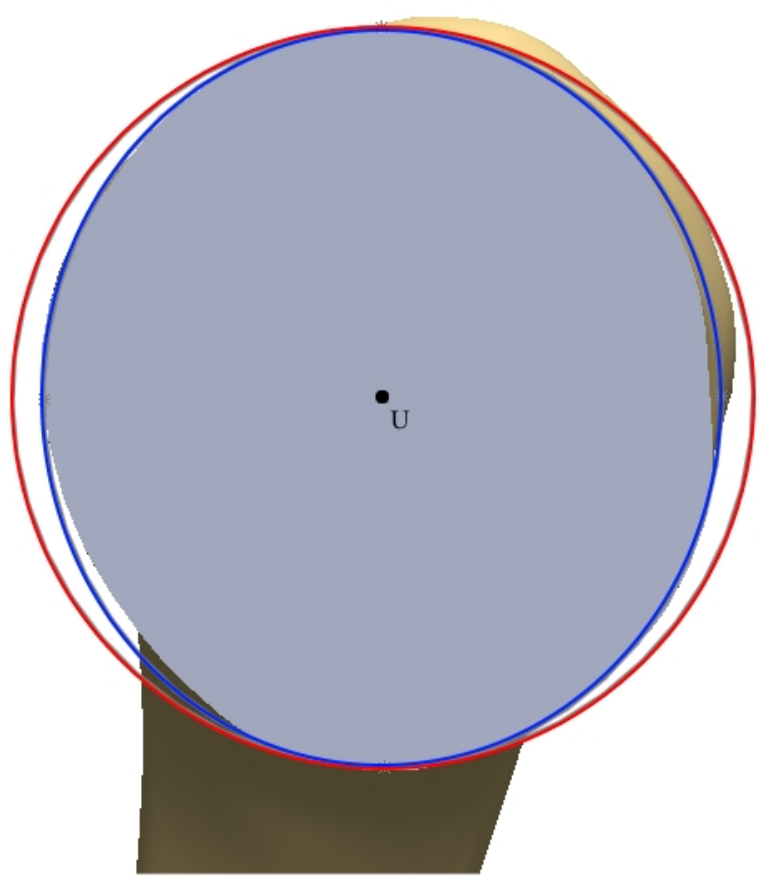

Figura 31 - Em vermelho, a circunferência traçada para representar o contorno na cabeça do úmero em um corte congruente ao plano do colo anatômico do úmero. Em azul, uma elipse com a mesma finalidade

\subsubsection{Raios articulares da cabeça do úmero}

Os raios da extremidade proximal do úmero e da cartilagem articular da cabeça do úmero encontrados neste modelo e em estudos antropométricos da literatura estão nas Tabelas 8 e 9. 
Tabela 8 - Resultado dos raios ósseos da extremidade proximal do úmero

\begin{tabular}{lcccc}
\hline \multicolumn{1}{c}{ Úmero } & $\begin{array}{c}\text { Modelo } \\
\text { numérico }\end{array}$ & $\begin{array}{c}\text { Soslowski et } \\
\text { al. }^{111}\end{array}$ & $\begin{array}{c}\text { Zumstein et } \\
\text { al. }^{112}\end{array}$ & $\begin{array}{c}\text { lannotti et } \\
\text { al. }^{114}\end{array}$ \\
\hline $\begin{array}{l}\text { Raio plano } \\
\text { coronal (mm) }\end{array}$ & $18,65 / 24,13$ & - & $23,5 \pm 4,9$ & $25 \pm 2,1$ \\
$\begin{array}{l}\text { Raio plano } \\
\text { axial (mm) } \\
\text { Raio plano } \\
\text { transversal } \\
\text { (mm) }\end{array}$ & $23,81 / 22,00$ & - & - & $23 \pm 2,5$ \\
$\begin{array}{l}\text { Sphere fitting } \\
(\mathrm{mm})\end{array}$ & $18,76 / 21,56$ & - & $24,7 \pm 4,7$ & - \\
\hline
\end{tabular}

Tabela 9 - Resultado dos raios articulares e dados de espessura da cartilagem da cabeça do úmero

\begin{tabular}{|c|c|c|c|c|}
\hline Cartilagem úmero & $\begin{array}{l}\text { Modelo } \\
\text { Numérico }\end{array}$ & $\begin{array}{l}\text { Soslowski } \\
\text { et al. }{ }^{111}\end{array}$ & $\begin{array}{l}\text { Zumstein et } \\
\text { al. }^{112}\end{array}$ & $\begin{array}{l}\text { lannotti } \\
\text { et al. }{ }^{114}\end{array}$ \\
\hline Raio plano coronal (mm) & $23 / 26$ & - & - & $25,4 \pm 4,3$ \\
\hline Raio plano axial (mm) & $26 / 23,5$ & - & - & - \\
\hline $\begin{array}{l}\text { Raio plano transversal } \\
(\mathrm{mm})\end{array}$ & $23 / 23,5$ & - & - & $24 \pm 5,4$ \\
\hline Sphere fitting (mm) & 25,18 & $26,85 \pm 1,41$ & - & - \\
\hline Espessura média (mm) & 1,96 & $1,44 \pm 0,3$ & $1,74(\mathrm{DV}=0,45)$ & - \\
\hline Espessura mínima (mm) & 0,72 & $0,65 \pm 0,32$ & 0,92 & - \\
\hline Espessura máxima (mm) & 3,25 & $2,03 \pm 0,66$ & 3,32 & - \\
\hline
\end{tabular}

\subsubsection{Anatomia da cavidade glenoidal}


As dimensões da cavidade glenoidal de acordo com os parâmetros dos estudos de Ikemoto et al. ${ }^{115}$ e lanotti et al. ${ }^{114}$ estão expostas respectivamente nas Tabelas 10 e 11.

Tabela 10 - Dimensões da cavidade glenoidal segundo parâmetros de Ikemoto e sua comparação

\begin{tabular}{ccc}
\hline Parâmetro & Modelo numérico & Ikemoto et al. ${ }^{115}$ \\
\hline Área total & $753,94 \mathrm{~mm}^{2}$ & $730 \mathrm{~mm}^{2}$ \\
Área parcial & $121,95 \mathrm{~mm}^{2}$ & $58,59 \mathrm{~mm}^{2}$ \\
SV & $38,93 \mathrm{~mm}$ & $37,67 \mathrm{~mm}$ \\
SHS & $17,87 \mathrm{~mm}$ & $18,27 \mathrm{~mm}$ \\
SHM & $26,67 \mathrm{~mm}$ & $23,94 \mathrm{~mm}$ \\
SHI & $24,44 \mathrm{~mm}$ & $24,21 \mathrm{~mm}$ \\
SHla & $5,85 \mathrm{~mm}$ & $2,92 \mathrm{~mm}$ \\
SHS/SHI & 0,73 & 0,76 \\
\hline
\end{tabular}

Fonte: Ikemoto et al. ${ }^{115}$

Tabela 11 - Dimensões da cavidade glenoidal segundo parâmetros de lannotti e sua comparação

Modelo numérico lannotti et al.

\begin{tabular}{lll}
\hline Distância superior-inferior [mm] & 38,93 & $39 \pm 3,7$ \\
Distância anterior-posterior superior [mm] & 17,87 & $23 \pm 2,7$ \\
Distância anterior-posterior inferior [mm] & 30,29 & $29 \pm 3,1$
\end{tabular}

Fonte: lannotti et al. ${ }^{114}$ 


\subsection{Rítmo escapuloumeral}

A Tabela 12 ilustra os ângulos glenoumeral e escapulotorácico nas posições de $60^{\circ}, 90^{\circ}$ e $120^{\circ}$ de abdução.

Tabela 12 - Ângulo glenoumeral e ângulo escapulotorácico encontrado nas diferentes posições de abdução

\begin{tabular}{lcc}
\hline Posição & $\begin{array}{c}\text { Ângulo } \\
\text { glenoumeral }\end{array}$ & $\begin{array}{c}\text { Ângulo } \\
\text { escapulotorácico }\end{array}$ \\
\hline 60 graus & $45,59^{\circ}$ & $14,41^{\circ}$ \\
90 graus & $73,61^{\circ}$ & $16,09^{\circ}$ \\
120 graus & $89,62^{\circ}$ & $31,38^{\circ}$ \\
\hline
\end{tabular}

\subsection{Dados de força de reação articular e ativação muscular}

A Tabela 13 demonstra os resultados das forças e momentos de reação articular, da força de cada grupo muscular e do momento residual, que foram encontrados após o processo iterativo do algoritmo de equilíbrio das forças articulares, para cada posição. A Figura 32 apresenta os gráficos dos valores das forças de reação articular e de cada grupo muscular nas 3 posições estudadas. A Figura 33 apresenta um gráfico com os valores das forças de todos os segmentos musculares para cada posição articular. A Figura 34 apresenta, para cada posição, a contribuição proporcional de cada músculo para atingir o equilíbrio de forças. 
Tabela 13 - Dados da força e momento do peso do braço para cada posição, e correspondente valores das forças de reação articular e musculares encontradas para a estabilização do modelo

\begin{tabular}{lccc}
\hline & $\mathbf{6 0}$ graus & $\mathbf{9 0}$ graus & $\mathbf{1 2 0}$ graus \\
\cline { 2 - 4 } Peso do braço (N) & $\mathbf{3 5}$ & $\mathbf{3 5}$ & $\mathbf{3 5}$ \\
Momento do braço (N.mm) & $\mathbf{9 7 8 1 , 8 2}$ & $\mathbf{1 1 3 4 3 , 5 1}$ & $\mathbf{9 7 8 4 , 6 6}$ \\
\hline Força de reação articular (N) & 666,06 & 690,17 & 549,24 \\
Momento articular (N.mm) & 828,28 & 988,11 & 637,25 \\
& & & \\
Supraespinal (N) & 174,34 & 1,22 & 21,13 \\
Subescapular (N) & 317,19 & 416,74 & 289,68 \\
Infraespinal (N) & 90,30 & 102,22 & 22,65 \\
Redondo menor (N) & 6,46 & 0,29 & 4,03 \\
Deltoide anterior (N) & 6,24 & 2,65 & 33,06 \\
Deltoide médio (N) & 223,52 & 207,77 & 99,00 \\
Deltoide posterior (N) & 57,07 & 99,83 & 122,35 \\
Deltoide (N) & 281,07 & 305,23 & 250,35 \\
Momento residual (N.mm) & 19,44 & 49,93 & 30,69 \\
Momento residual (\%) & $0,20 \%$ & $0,44 \%$ & $0,31 \%$ \\
\hline
\end{tabular}




\section{Resultados}

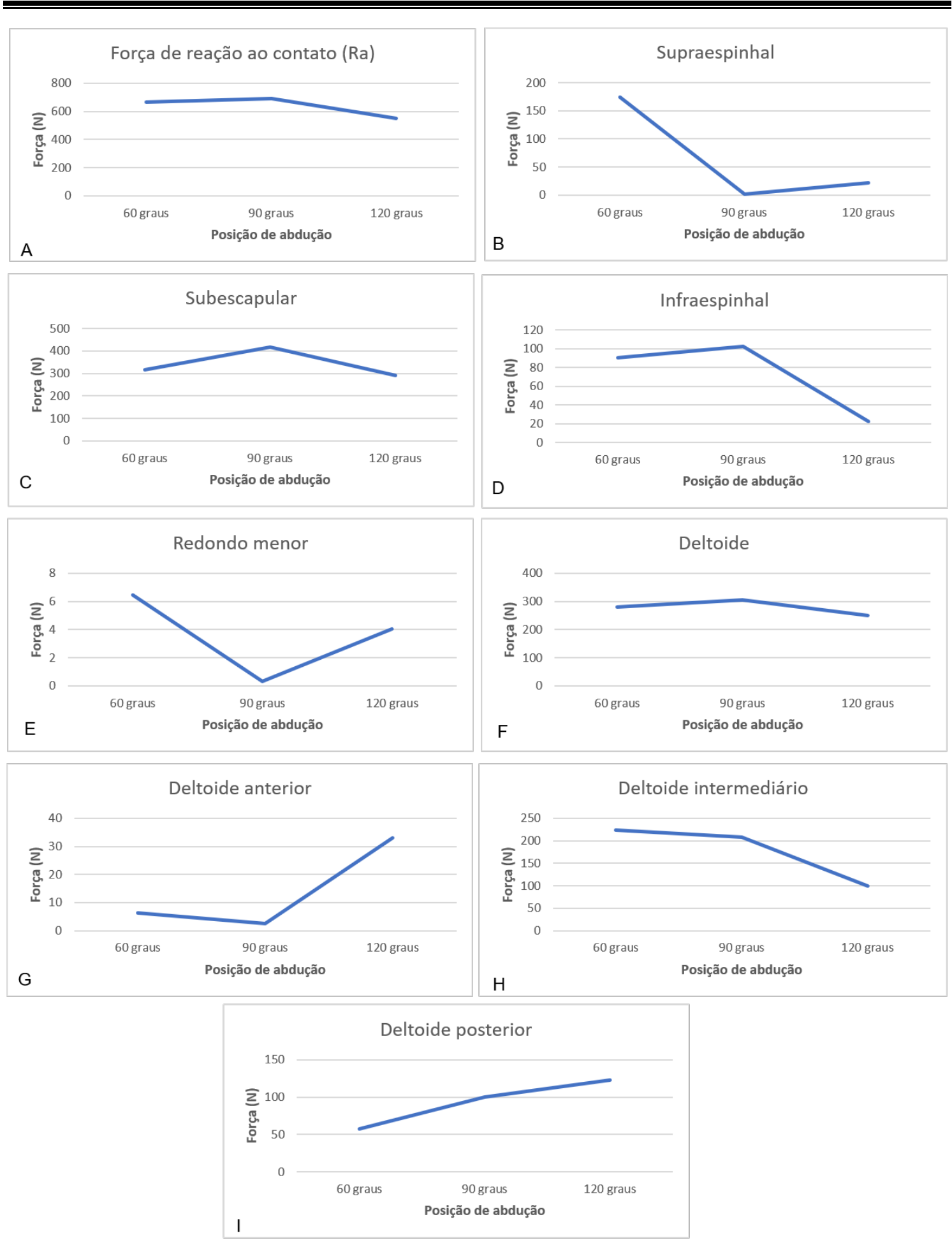

Figura 32 - A. Gráfico indicando valores de força de reação e força muscular por segmento muscular: B. Supraespinal, C. Subescapular; D. Infraespinal; E. Redondo menor; F. Deltoide; G. Deltoide anterior; H. Deltoide intermediário e; I. Deltoide posterior 


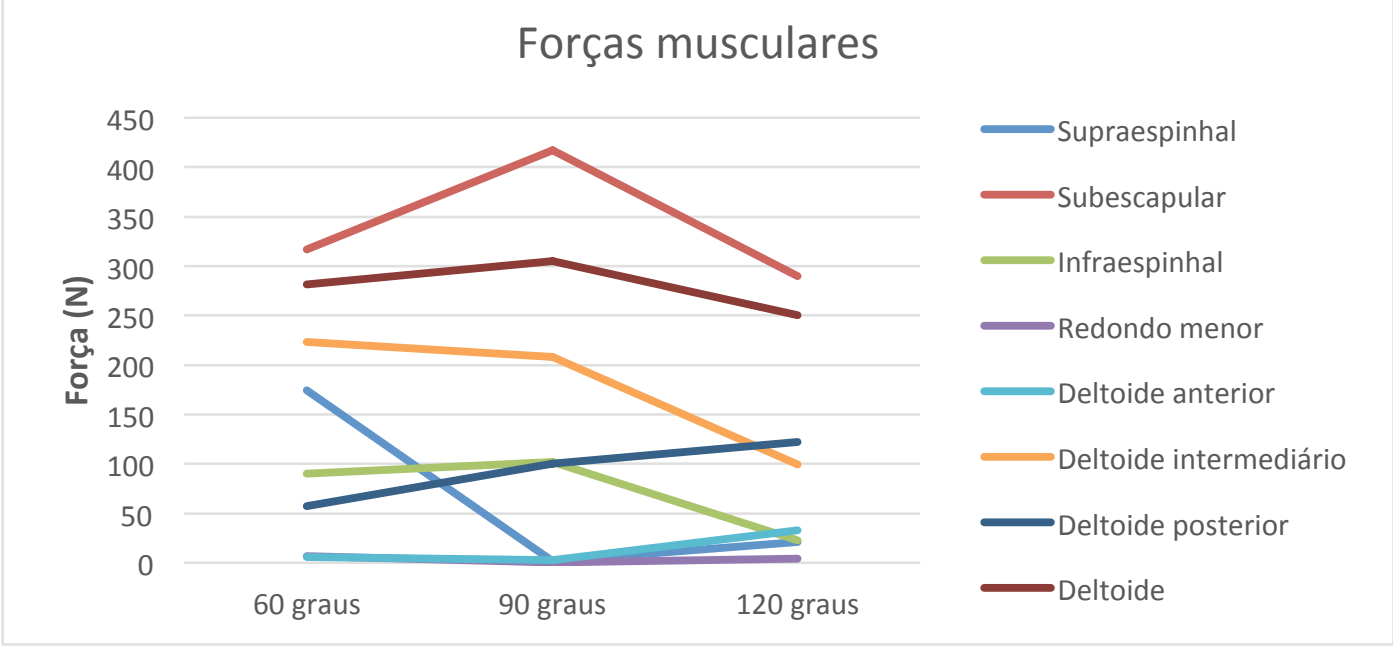

Figura 33 - Gráfico dos valores das forças musculares por posição articular
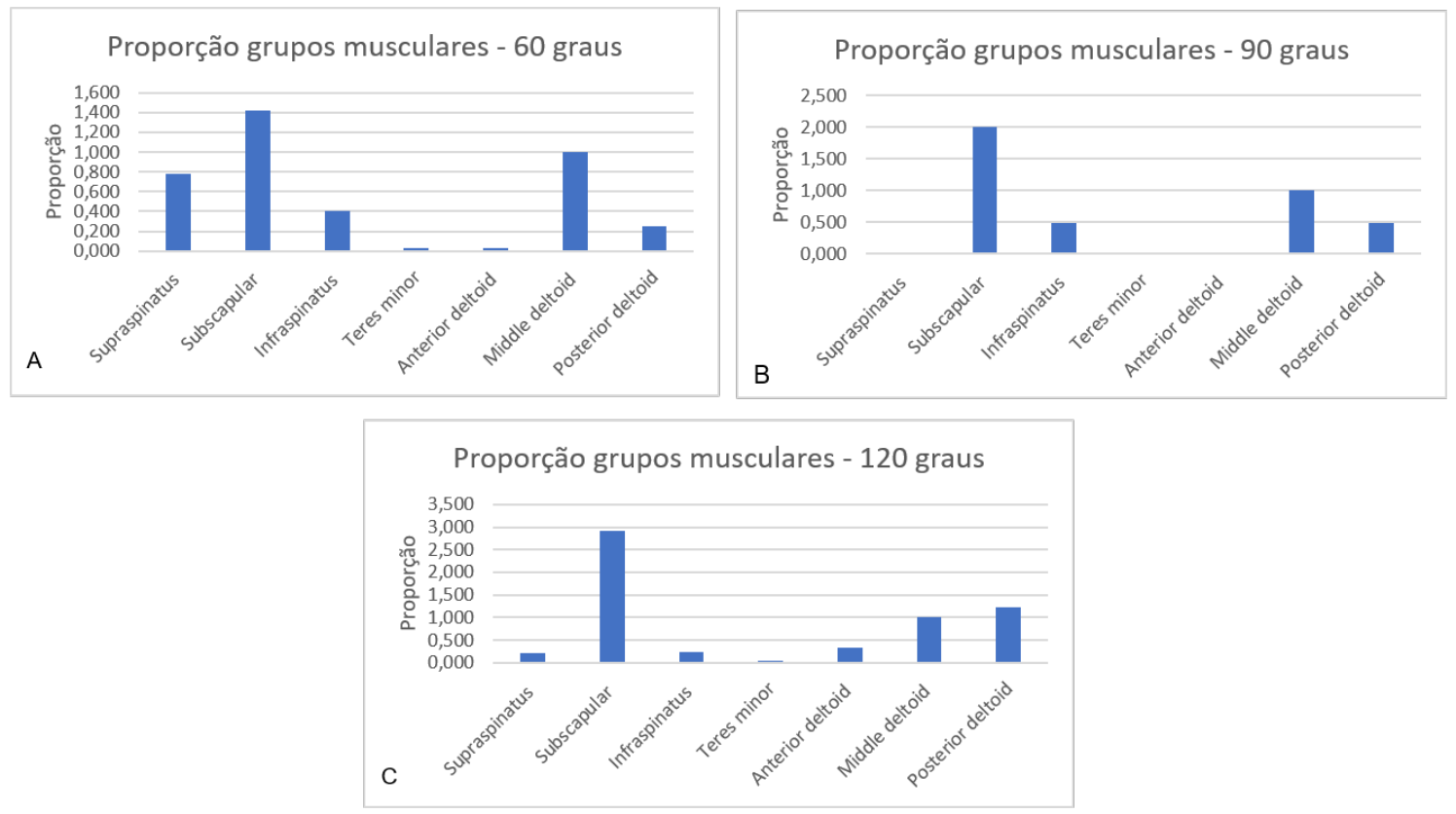

Figura 34 - Gráfico indicando valores proporcionais de contribuição de força muscular dos segmentos musculares por posição. A. $60^{\circ} ; \mathrm{B} ; 90^{\circ}$; C. $120^{\circ}$ 


\subsection{Translação da cabeça do úmero}

Os resultados da translação da cabeça do úmero nos eixos horizontal, vertical e axial, após o carregamento de forças articular, estão representados na Tabela 14.

Tabela 14 - Translação do CR de acordo com a posição e o eixo. Eixo X: posterior (+) e anterior (-); eixo Y: superior (+) e inferior (-); eixo Z: medial $(+)$ e lateral $(-)$; e total (deslocamento 3D)

\begin{tabular}{lcccc}
\hline & $\mathbf{X}$ & $\mathbf{Y}$ & $\mathbf{Z}$ & Total $(\mathbf{m m})$ \\
\hline $\mathbf{6 0}$ graus & $-1,68$ & 0,579 & 0,51 & 1,849 \\
$\mathbf{9 0}$ graus & $-3,387$ & $-0,171$ & 0,553 & 3,436 \\
$\mathbf{1 2 0}$ graus & $-1,989$ & $-2,219$ & 0,767 & 3,077 \\
\hline
\end{tabular}

\subsection{Características do contato articular}

A tabela 15 apresenta dados de pressão, área de contato e porcentagem de contato nas cartilagens da cabeça do úmero e da cavidade glenoidal de acordo com a posição articular. A Figura 35 ilustra a localização e distribuição de pressão de contato articular na cabeça do úmero e na cavidade glenoidal. 
Tabela 15 - Características do contato articular nas posições $60^{\circ}, 90^{\circ}$ e $120^{\circ}$

\begin{tabular}{lccc}
\hline & $\mathbf{6 0}$ graus & $\mathbf{9 0}$ graus & $\mathbf{1 2 0}$ graus \\
\hline Pressão de contato máxima (MPa) & 3,35 & 3,61 & 2,86 \\
Área de contato $\left(\mathbf{m m}^{2}\right)$ & 396,40 & 385,36 & 335,53 \\
Área de contato glenoide (\%) & $65,41 \%$ & $63,59 \%$ & $55,37 \%$ \\
Área de contato úmero (\%) & $10,81 \%$ & $10,51 \%$ & $9,15 \%$ \\
\hline
\end{tabular}


Resultados

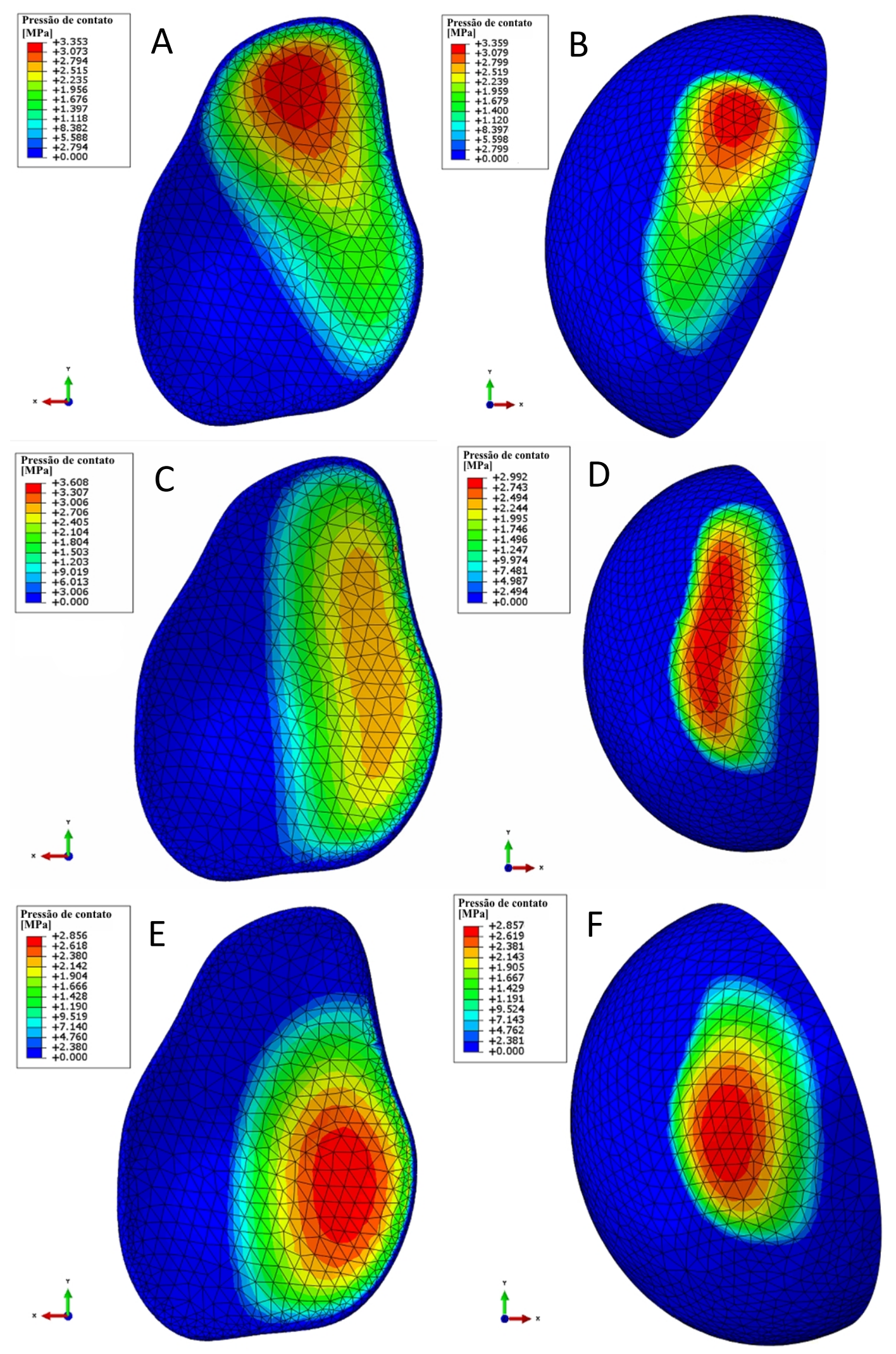


Figura 35 - Distribuição de pressão na superfície articular da cavidade glenoidal e da região posterior da cabeça do úmero de acordo com grau de abdução. A, B- $60^{\circ}$; C, D- $90^{\circ}$; E, F- $120^{\circ}$

\subsection{Trilha da glenoide}

As Tabelas 16 a 19 demonstram os resultados dos valores de referência, cálculo da trilha da glenoide por posição e por método de aferição, comparação entre os dados obtidos com o modelo desativado (sem influência de forças) e ativado (após equilíbrio de forças) e comparação com os dados da literatura. A Figura 36 ilustra a morfologia da trilha da glenoide obtida neste estudo.

Tabela 16 - Dados dos valores de referência para o cálculo da trilha da glenoide e valores da trilha da glenoide por posição

\begin{tabular}{lccc}
\hline & $\mathbf{6 0}$ graus & $\mathbf{9 0}$ graus & $\mathbf{1 2 0}$ graus \\
\hline Arco de contato (mm) & 17,03 & 18,62 & 23,24 \\
\hline Distância anteroposterior Griffith $(\mathbf{m m})$ & 23,61 & 23,61 & 23,61 \\
Distância anteroposterior Omori $(\mathbf{m m})$ & 22,28 & 22,28 & 22,28 \\
Trilha da glenoide Griffith (em \%) & $72,13 \%$ & $78,86 \%$ & $98,43 \%$ \\
Trilha da glenoide Omori (em \%) & $76,44 \%$ & $83,57 \%$ & $104,31 \%$ \\
\hline
\end{tabular}


Tabela 17 - Comparação dos valores de comprimento (em $\mathrm{mm}$ ) do ponto medial de contato até a inserção do manguito rotador e correspondente valor da trilha da glenoide (em \%) por posição articular, antes e depois do carregamento das forças

\begin{tabular}{lcccccccc} 
& \multicolumn{2}{c}{$\mathbf{6 0}^{\circ}$} & & \multicolumn{2}{c}{$\mathbf{9 0}^{\circ}$} & & \multicolumn{2}{c}{$\mathbf{1 2 0}^{\circ}$} \\
\cline { 2 - 3 } \cline { 7 - 8 } \cline { 7 - 8 } Contato Omori & $25,68 \mathrm{~mm}$ & $17,03 \mathrm{~mm}$ & & $19,66 \mathrm{~mm}$ & $18,62 \mathrm{~mm}$ & & $22,98 \mathrm{~mm}$ & $23,24 \mathrm{~mm}$ \\
Contato Griffith & $16,88 \mathrm{~mm}$ & $17,03 \mathrm{~mm}$ & & $20,27 \mathrm{~mm}$ & $18,62 \mathrm{~mm}$ & & $24,41 \mathrm{~mm}$ & $23,24 \mathrm{~mm}$ \\
Trilha Omori & $115,26 \%$ & $76,44 \%$ & & $88,24 \%$ & $83,57 \%$ & & $103,14 \%$ & $104,31 \%$ \\
Trilha Griffith & $71,50 \%$ & $72,13 \%$ & & $85,85 \%$ & $78,86 \%$ & & $103,39 \%$ & $98,43 \%$
\end{tabular}

Tabela 18 - Resultado do comprimento (em $\mathrm{mm}$ ) e da razão (em \%) da trilha da glenoide (ponto $M$ até a cartilagem ou inserção do manguito rotador) desse modelo, com e sem ativação das forças musculares, segundo os parâmetros de Yamamoto, e sua comparação

Razão da trilha

Posição articular e referência da medida

$45^{\circ}$ até cartilagem

$60^{\circ}$ até cartilagem

$90^{\circ}$ até cartilagem

$90^{\circ}$ até manguito

$120^{\circ}$ até manguito

\begin{tabular}{cccccc} 
Yamamoto & $\begin{array}{c}\text { Modelo } \\
\text { desativado }\end{array}$ & $\begin{array}{c}\text { Modelo } \\
\text { ativado }\end{array}$ & Yamamoto & $\begin{array}{c}\text { Modelo } \\
\text { desativado }\end{array}$ & $\begin{array}{c}\text { Modelo } \\
\text { ativado }\end{array}$ \\
\hline $71 \% \pm 27 \%$ & - & - & $16,2 \pm 6.2 \mathrm{~mm}$ & - & - \\
- & $61,88 \%$ & $69,42 \%$ & - & $14,61 \mathrm{~mm}$ & $16,39 \mathrm{~mm}$ \\
$69 \% \pm 16 \%$ & $85,85 \%$ & $78.86 \%$ & $15,8 \pm 2,5 \mathrm{~mm}$ & $20,27 \mathrm{~mm}$ & $18,62 \mathrm{~mm}$ \\
$84 \% \pm 14 \%$ & $85,85 \%$ & $78,86 \%$ & $18,4 \pm 2,5 \mathrm{~mm}$ & $20,27 \mathrm{~mm}$ & $18,62 \mathrm{~mm}$ \\
- & $88,39 \%$ & $84,33 \%$ & - & $20,87 \mathrm{~mm}$ & $19,91 \mathrm{~mm}$
\end{tabular}

Fonte: Yamamoto et al. ${ }^{32}$

Tabela 19 - Resultado do comprimento (em $\mathrm{mm}$ ) e da razão (em \%) da trilha da glenoide desse modelo, com e sem ativação das forças musculares, segundo os parâmetros de Omori, e sua comparação

\begin{tabular}{|c|c|c|c|c|c|c|}
\hline \multirow[b]{2}{*}{ Posição articular } & \multicolumn{3}{|c|}{ Razão da Trilha } & \multicolumn{3}{|c|}{ Comprimento da trilha } \\
\hline & Omori & $\begin{array}{c}\text { Modelo } \\
\text { desativado }\end{array}$ & $\begin{array}{l}\text { Modelo } \\
\text { ativado }\end{array}$ & Omori & $\begin{array}{c}\text { Modelo } \\
\text { desativado }\end{array}$ & $\begin{array}{l}\text { Modelo } \\
\text { ativado }\end{array}$ \\
\hline $60^{\circ}$ & $89 \% \pm 14 \%$ & $115,26 \%$ & $76,44 \%$ & $20,7 \pm 4,5 \mathrm{~mm}$ & $25,68 \mathrm{~mm}$ & $17,03 \mathrm{~mm}$ \\
\hline $90^{\circ}$ & $83 \% \pm 12 \%$ & $88,24 \%$ & $83,57 \%$ & $19,4 \pm 3,9 \mathrm{~mm}$ & $19,66 \mathrm{~mm}$ & $18,62 \mathrm{~mm}$ \\
\hline $120^{\circ}$ & $82 \% \pm 10 \%$ & $104,31 \%$ & $103,39 \%$ & $18,9 \pm 2,7 \mathrm{~mm}$ & $22,98 \mathrm{~mm}$ & $23,24 \mathrm{~mm}$ \\
\hline
\end{tabular}

Fonte: Omori et al. ${ }^{41}$ 

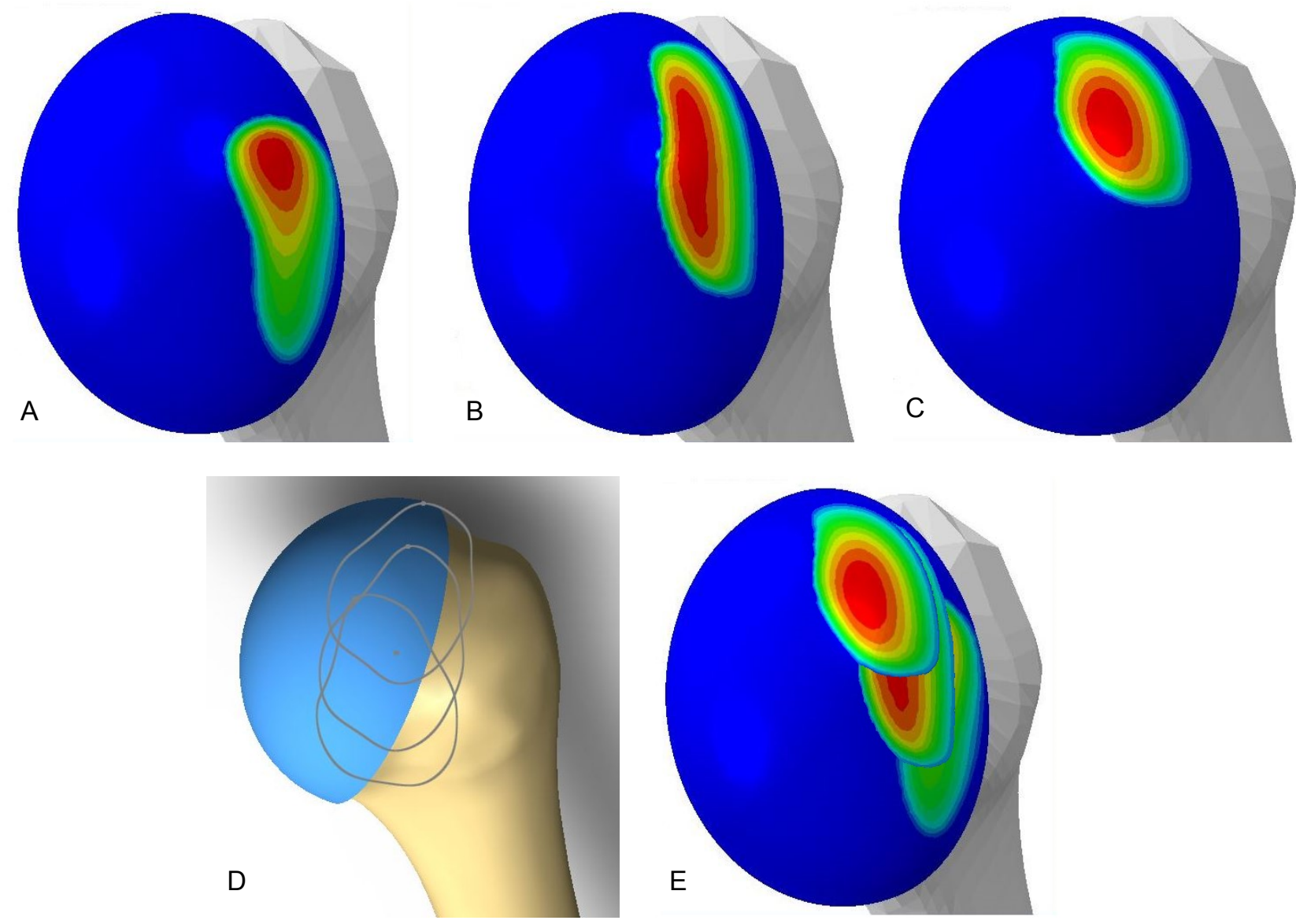

Figura 36 - llustrações do conceito de trilha da glenoide ${ }^{32}$. Contato que a cavidade glenoidal promove na superfície articular da cabeça do úmero a $90^{\circ}$ de rotação lateral e diferentes graus de abdução: A. $60^{\circ}$; B. $90^{\circ}$; C. $120^{\circ}$; D. Contorno da silhueta da cavidade glenoidal em relação ao úmero em cada posição articular; E. Trajeto do contato das 3 posições ilustrando topografia da trilha da glenoide 


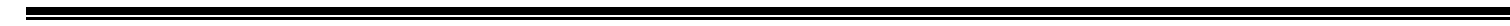

6. DISCUSSÃO 
6

DISCUSSÃO

O tratamento cirúrgico da instabilidade glenoumeral anterior é um tema extensamente estudado na história da medicina. A técnica de Bankart, descrita em 1923 e publicada em $1938^{21}$, foi um marco para o tratamento dessa entidade e, com seu subsequente desenvolvimento técnico e tecnológico, tornou-se um dos procedimentos mais realizados pelo cirurgião de ombro, com resultados muito satisfatórios ${ }^{30,47,51}$. Porém, como em qualquer outro procedimento extensamente realizado, existem falhas e complicações. As taxas publicadas de incidência de luxação recorrente após este reparo capsulolabral anterior variam de $0 \%$ a $30 \%{ }^{8,9,30,47,51,55,57}$.

O estudo dos fatores preditivos de falha da cirurgia de Barkart é um tema recorrente na literatura ${ }^{13,17,18,27,30,39,47,51,52,138}$. A importância de explorar os fatores de risco para a falha do reparo capsulolabral na instabilidade glenoumeral anterior encontra-se na necessidade de evitar cirurgias de revisão, que são tecnicamente mais difíceis ${ }^{13,138-140}$, e no impacto econômico proporcionado pelo afastamento do paciente de suas atividades laborais ${ }^{7}$. Dentre os fatores preditivos de falha, a presença de lesões ósseas é um dos principais temas estudados ${ }^{13,28-30,35,40,48-50,53,54,56,58,59}$, cerca de $70 \%$ dos pacientes com recidiva pós-operatória apresentam alguma lesão óssea significativa $^{141}$. Com o objetivo de entender melhor os mecanismos de falha envolvidos nas lesões ósseas, novos conceitos estão sendo desenvolvidos. Em 2007, uma corrente de estudo foi iniciada por Yamamoto et al. ${ }^{32}$, o conceito da trilha da glenoide. 
Como forma de caracterizar a trilha da glenoide, foram feitos estudos em cadáveres por meio de representações tridimensionais de exames de imagens $^{32,40,41}$. Porém, esses estudos apresentam a limitação de não contemplar forças fisiológicas atuantes na articulação glenoumeral durante o arco de movimento, o que pode modificar os achados de contato entre as superfícies articulares ${ }^{67,142}$. Ensaios biomecânicos em cadáveres apresentam limitações por conta de deterioração tecidual, diminuto número de músculos avaliados e imprecisões na avaliação das força por sensores, o que dificulta previsões globais ${ }^{67,120,124,142}$. Já a avaliação dos parâmetros biomecânicos in vivo apresenta restrições técnicas e éticas importantes.

Modelos numéricos podem solucionar muitos desses desafios já que, de forma não invasiva, possibilitam aplicar forças em diversos graus e direções e prever os desdobramentos biomecânicos de forma impossível de serem avaliados experimentalmente ${ }^{107}$. A simulação numérica mostra-se uma ferramenta muito útil nos estudos biomecânicos por apresentar melhor custoefetividade do que estudos laboratoriais, clínicos ou feitos em animais ${ }^{42}$. Porém, é muito difícil de ser feita com qualidade e, para isso, é fundamental que a construção do modelo seja direcionada para obter-se a melhor resposta para o questionamento científico em questão, além de simular de forma acurada as situações encontradas na realidade ${ }^{43}$.

A Figura 37 ilustra o aumento expressivo do interesse em modelos numéricos do ombro, como demonstrado pelo crescimento exponencial do número de publicações baseadas nessa ferramenta, principalmente a partir do ano $2000^{43,107,143}$. Esse fenômeno foi impulsionado pelo crescente interesse da indústria de artroplastias (próteses) por informações biomecânicas ${ }^{144}$ além dos 
recentes avanços tecnológicos e aprendizado técnico que possibilitaram soluções aos desafios proporcionados pela anatomia e biomecânica do ombro, visto que apresenta grande liberdade de movimento, pouca estabilidade estática e complexa estabilidade dinâmica.

Grande parte destes modelos numéricos reproduz um ambiente anatômico e biomecânico fidedigno, porém, para uma análise criteriosa sobre o contato articular, como a da trilha da glenoide, é preciso agregar uma tecnologia que observe de forma assertiva o efeito das forças em superfícies de morfologia heterogênea. A técnica de elementos finitos acrescenta ao modelo numérico a capacidade de obter-se esses resultados em estruturas com detalhamento anatômico e funcional complexo ${ }^{45,46,72}$.

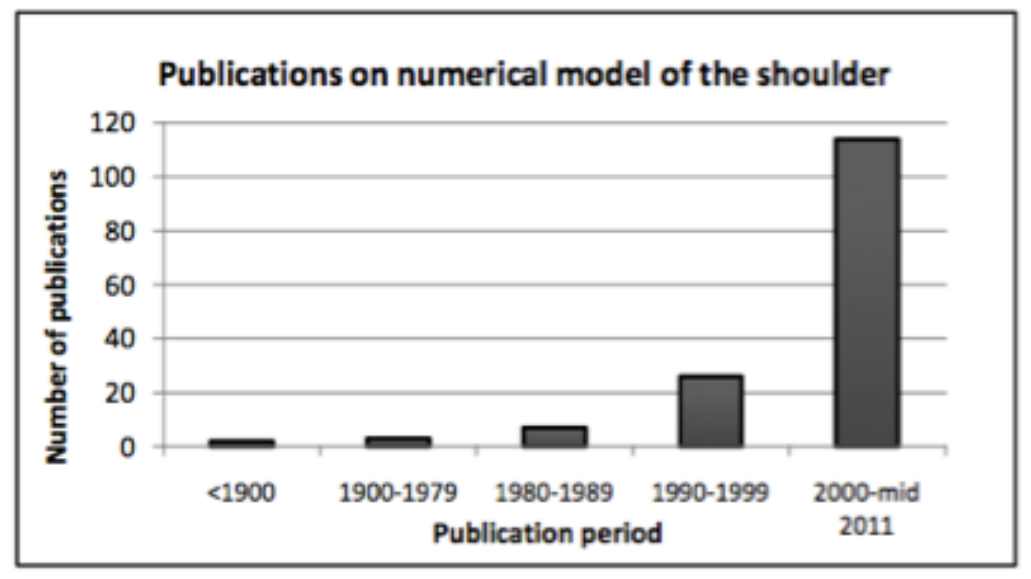

Figura 37 - Índice de publicações internacionais baseadas em modelos

Fonte: $\quad$ Favre P., $2011^{143}$ numéricos de ombro por período

O chamado Método dos Elementos Finitos, ou MEF, foi originalmente criado por Turner em 1956 para solução de equações relacionadas a biomecânica, engenharia civil e aeronáutica ${ }^{45}$. Os diversos tipos de problemas físicos encontrados nas ciências e nas engenharias, como tensão ou 
deformação, são descritos matematicamente na forma de equações diferenciais ordinárias e parciais ${ }^{44,45,72}$. A solução exata dessas equações usualmente é fruto de método de solução analítica de equações algébricas e diferenciais aplicados a geometrias e condições de contorno particulares e bem conhecidos. Já a obtenção dessas soluções analíticas exatas para geometrias e condições de contorno muito complexas é impraticável, ou impossível, em alguns casos.

Para solucionar essa questão, o MEF, com a ajuda de computadores, utiliza padrões numéricos que levam a soluções aproximadas do problema real. Inicialmente, é feito um protótipo virtual que represente a geometria do objeto a ser estudado, fisicamente, esse objeto é chamado de corpo contínuo e é composto por infinitos pontos. Para entender o que acontece com esse corpo contínuo a partir da aplicação de determinadas condições de contorno sobre ele, é necessário que se saiba como esses pontos interagem entre si. Através da metodologia de elementos finitos, o corpo contínuo é discretizado, ou seja, é divido em um número finito de elementos ${ }^{72}$. Esses elementos possuem geometria e propriedades mecânicas conhecidas e são ligados entre si por áreas denominadas de nós ${ }^{45}$. Quanto maior a quantidade de elementos, mais fidedigna é a representação e maior o custo computacional agregado à simulação. Agora, em vez de analisar o corpo contínuo com infinitas variáveis desconhecidas, analisa-se o comportamento de uma quantidade finita de elementos e como eles interagem entre si, dessa forma, consegue-se um resultado aproximado do problema real ${ }^{45,75}$.

A aplicação do MEF em estudos biomecânicos de ortopedia foi iniciada em $1972^{46}$, e, em 1983, já era considerado um método estabelecido com bons 
resultados, apesar do reconhecimento de algumas de suas limitações ${ }^{73}$. Desde então, com a evolução tecnológica, houve um grande aumento de sua validação, aceitação e utilização ${ }^{43,44,77,78}$. O método tem como vantagens o fato de ser não invasivo o que possibilita a análise de situações alvo e obtenção de resultados de momento ou após repetições de movimentos durante um tempo determinado ${ }^{44}$. Desta forma é possível observar resultados de inúmeras variáveis de uma forma dinâmica, precisa e temporal.

O estudo das estruturas biológicas (osso, ligamento, cartilagem, músculos, entre outros) por meio de elementos finitos aumentou nas últimas décadas por conta de soluções matemáticas que contemplam a não linearidade e complexidade da deformação de tais estruturas, ou seja, por meio de fórmulas matemáticas que traduzem as características biomecânicas de cada estrutura $^{116,117}$, isso possibilita uma boa representação das condições encontradas in vivo. Este método provou ser útil para o estudo do comportamento de qualquer unidade funcional, a despeito de sua complexidade geométrica, porém sua aplicação na rotina clínica ainda é comprometida devido ao tempo e o custo para sua aplicação. Atualmente, mostra-se uma poderosa ferramenta no campo da cirurgia ortopédica, principalmente das artroplastias, ao aprimorar o entendimento da biomecânica tanto em situações de normalidade como patológicas ${ }^{44,75}$, ao contribuir para um melhor entendimento de cinemática e, por ser interativo, ao possibilitar a observação de situações mutáveis como simulações de transferência de tendão ${ }^{145}$, colocação de próteses ${ }^{74,77,136}$, ou ainda o comportamento biomecânico de lesões ósseas ${ }^{106}$.

Desta forma, com a ajuda do MEF, refinados modelos numéricos de 
diversas articulações podem ser construídos com base em suposições sobre suas relações geométricas e estimativas de dinâmicas envolvidas (Figura 38). Como método de avaliação da trilha da glenoide, nosso estudo propôs o desenvolvimento de um modelo numérico músculo esquelético 3D com utilização do MEF, a fim de representar as características biomecânicas fisiológicas presentes no arco de movimento de abdução e rotação lateral. Ao reproduzir um ambiente que simula de forma mais verossímil as condições de contato articular, é possível avaliar as características da trilha da glenoide em uma situação mais próxima do real.
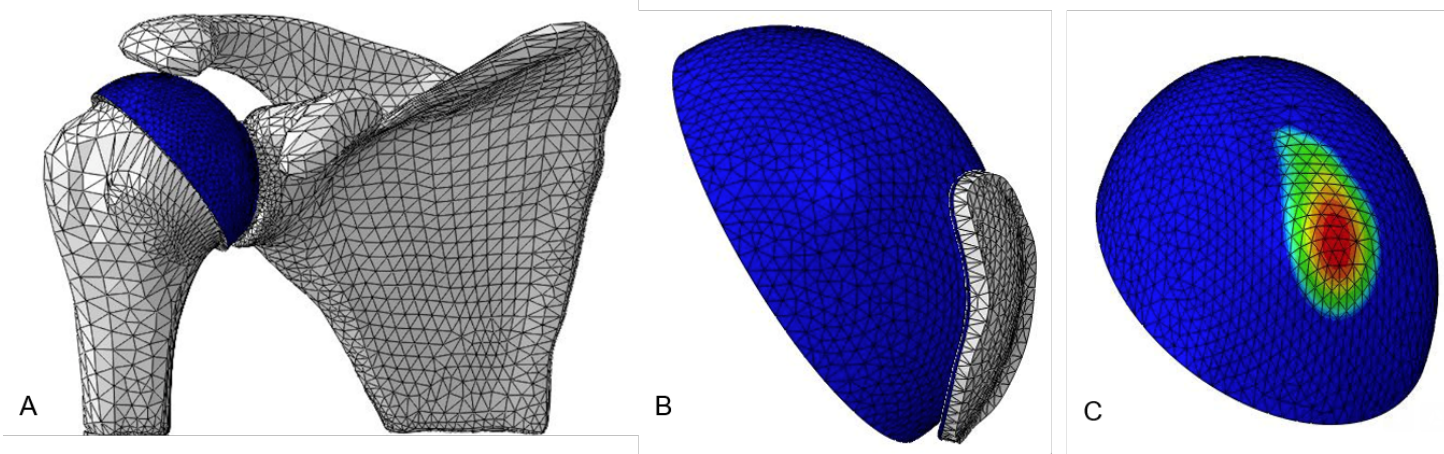

Figura 38 - Modelo numérico da articulação glenoumeral com uso do MEF. A. Aspecto final do modelo a $0^{\circ}$ de abdução. B. Detalhes das malhas de elementos finitos das cartilagens articulares da cavidade glenoidal e da cabeça do úmero. C. Detalhes da área e pressão de contato promovida pela cavidade glenoidal na superfície articular da cabeça do úmero

Para a construção do modelo pode-se usar informações geométricas e funcionais advindas de bancos de dados antropométricos ou dados individualizados de exames, como RM, TC, EMG e radioscopia. Idealmente, os modelos devem ser dimensionados com base em parâmetros recolhidos individualmente $e^{75,76,78}$. O uso dos métodos de imagens facilita a validação de 
hipóteses matemáticas do modelo, tais como o CR da articulação glenoumeral e os braços de alavanca da musculatura.

O desenvolvimento de nosso modelo baseou-se em informações de imagens artrográficas de artro-TC e artro-RM. Esse fato é uma grande vantagem deste modelo ${ }^{78,146}$, pois o detalhamento geométrico alcançado é superior às suposições teóricas e às aproximações feitas por modelos construídos com base em banco de dados antropométricos ${ }^{83,85,88-90}$. Outra vantagem é que a representação das diversas posições articulares foi orientada pela disposição dos ossos encontrada na artro-TC. Esse fato contribui para uma representação mais fidedigna da posição relativa entre os ossos ao minimizar erros matemáticos advindos de suposições teóricas. O grande investimento na precisão geométrica e de posicionamento relativo do úmero e escápula é fruto da demanda para caracterizar o contato articular e a trilha da glenoide da forma mais fiel possível.

A escolha do voluntário seguiu um critério antropométrico que o aproximasse de um representante médio da população em risco de luxação glenoumeral. A taxa de maior prevalência ocorre no sexo masculino, em faixa de idade entre 25 e 30 anos $^{7,10,57}$. Nosso voluntário encontra-se de acordo com os dados antropométricos dessa faixa de idade e sexo ${ }^{108}$. A escolha da lateralidade deveu-se à maior prevalência de luxações ocorrerem em ombro dominante, e o mesmo ser o ombro direito ${ }^{7,57}$. Para diminuir o risco de alterações anatômicas individuais, o histórico pessoal de lesão no ombro direito foi um critério de exclusão.

Existem vários fatores biomecânicos que determinam a dinâmica e resultados dos modelos numéricos, os principais são: o centro de rotação, o 
sistema de coordenadas, as estruturas representadas, suas respectivas características, as condições de contato e de limite. Na literatura, um grande número de modelos numéricos apresentam simplificações a fim de diminuir a complexidade da análise, ao reduzir o número de variáveis possíveis ${ }^{83-}$ 91,95,107,119, são exemplos de simplificações: restringir movimentos translacionais, desconsiderar a participação de certos grupamentos musculares e a adoção de CR fixo ao considerar a articulação do ombro como bolasoquete. Essas medidas, apesar de serem úteis por tornar factíveis as análises complexas, podem alterar as forças de reação e de tensão articular, além de interferir na análise da deformação tecidual, da área e da pressão articular.

As estruturas representadas no modelo sólido são: o úmero e a cavidade glenoidal, com suas respectivas cartilagens, e os músculos deltoide, supraespinal, infraespinal, subescapular e redondo menor. Para um primeiro modelo, consideramos serem estas as estruturas mais determinantes para a análise do contato articular ${ }^{95,99,101}$. A capsula articular, ligamentos e lábio glenoidal não são representados neste modelo, a adição dessas estruturas seria muito trabalhosa pois, além de sua representação individualizada pelos exames de imagem ser difícil e seu refinamento geométrico ser dispendioso, aumenta-se a complexidade matemática da análise ${ }^{98,102-104}$. O mesmo raciocínio serve para outros grupamentos musculares que não são essenciais para a estabilização do modelo numérico de ombro ${ }^{147}$. Para o objetivo deste estudo, entendemos que a vantagem biomecânica de se representar essas estruturas não se justificaria frente à complexidade que agregaria à análise, por conta disso, optou-se por essa simplificação. 
O centro de rotação da articulação é um ponto chave para as aferições biomecânicas, a localização desse ponto tem influência na cinemática e na distribuição de forças articulares e musculares. Existem diversas técnicas de aferição do $\mathrm{CR}$, tanto de pontos fixos como dinâmicos, todas apresentam vantagens e limitações ${ }^{91,110,148-150}$. Uma grande parte dos modelos numéricos de ombro utiliza a técnica de sphere fitting, descrito por Meskers et al. ${ }^{110}$, que parte de uma simplificação da dinâmica articular como sendo bola-soquete. De acordo com essa técnica, o CR coincide com o centro geométrico articular, que é o centro de uma esfera encaixada na cavidade glenoidal que tenha o diâmetro da cabeça do úmero. Para determinar o centro, utiliza-se uma seleção de pontos da superfície dessa esfera e, pela melhor intersecção de retas que passem por esses pontos, define-se o centro geométrico.

Essa técnica tem a vantagem de facilitar os cálculos e previsões do modelo, diminuindo a complexidade de variáveis de força, já que trabalha com um ponto de referência fixo. A desvantagem deste método é que a simplificação feita por assumir que a articulação funciona como bola-soquete, ou seja, com um CR fixo, diminui a influência de movimentos de translação que ocorrem entre a cabeça do úmero e a escápula decorrentes da não confluência entre as superfícies articulares, Portanto, a mudança dinâmica da posição desse centro não é contemplada, o que pode alterar os resultados do modelo. Apesar da desvantagem teórica, estudos demonstraram que a técnica de cálculo de CR fixo pode ser equivalente às técnicas de centros dinâmicos em modelos numéricos estáveis ${ }^{150,151}$, este modelo utilizou a técnica de sphere fitting para definir um CR fixo. A análise do desvio padrão dos raios utilizados pelo sphere fitting, tanto para a face articular da cabeça do úmero quanto da 
cavidade glenoidal, demonstrou ser possível considerar essas superfícies de forma esférica com desvios padrão menores que $2 \%$, ou seja, as referências utilizadas neste modelo permitem um cálculo preciso do CR pela técnica do sphere fitting.

Como ponto de referência para os subsequentes ajustes é necessário definir um sistema de coordenadas, essas coordenadas correlacionam a posição 3D de cada ponto do modelo, o que possibilita fazer os ajustes necessários, medições de forças e inter-relações entre os diversos pontos. 0 sistema preconizado pela International Society of Biomechanics (ISB) para uma padronização dos modelos numéricos utiliza como referência o $C R$ e os epicôndilos medial e lateral ${ }^{152}$, porém a escolha do sistema de coordenadas pode ser individualizada de acordo com o objetivo do modelo. Nosso estudo optou por definir os eixos de referência no centro de rotação do úmero de acordo com os planos cardinais mediolateral, superoinferior e anteroposterior a partir de linha normal à superfície articular da cavidade glenoidal. Essa opção foi escolhida por facilitar a posterior liberação dos graus de liberdade da translação do úmero nesses eixos e também para facilitar o estudo da capacidade de estabilização dos segmentos musculares a partir da direção das forças exercidas por eles. Outra vantagem dessa escolha foi a possibilidade de utilizar a referência de Favre $\mathbf{P}^{143}$ para definir o trajeto e braço de alavanca dos grupos musculares por tratar-se da mesma origem de sistema de coordenadas.

Alguns problemas podem surgir da tradução das informações dos exames de imagem para a construção de modelos sólidos. As estruturas sólidas são reconstruídas individualmente, mas mantém sua relação espacial, imprecisões 
nas fases de aquisição de dados e de reconstrução podem levar a erros de dimensão das estruturas. Como se trata de ambiente 3D, podem ocorrer intersecções de estruturas em um mesmo ponto, o que não corresponde à realidade. Para solucionar esses erros, um trabalho de ajuste geométrico fazse necessário.

O refinamento geométrico pode ser feito por meio de diversas técnicas, isoladas ou combinadas, técnicas que utilizem valores médios ajudam a reduzir essas imprecisões e chegar a um valor mais perto do real. Alguns autores ${ }^{95,119}$ trabalham com a hipótese de que o espaço entre os ossos observado nas imagens da TC é preenchido por cartilagem, assim a espessura de cada cartilagem seria determinada como sendo a metade da lacuna entre a cabeça do úmero à fossa glenoidal da escápula. Já outros estudos utilizam-se integralmente de dados da literatura para definir esses parâmetros, como curvatura e espessura da cartilagem ${ }^{88,106}$. Em outros casos, prefere-se utilizar o sphere fitting para esse ajuste ${ }^{143}$, por meio de seleção de uma certa quantidade de pontos na superfície, sendo o mínimo recomendado de 40 pontos ${ }^{110}$, porém utilizar integralmente a técnica de sphere fitting pode representar uma limitação, ao admitir-se a cartilagem da cavidade glenoidal como perfeitamente congruente à da cabeça do úmero ${ }^{112}$.

Nosso trabalho considerou as superfícies articulares das cartilagens como não perfeitamente congruentes ${ }^{61,112}$; a da cavidade glenoidal foi idealizada como esférica ${ }^{111,119,143}$ e a da cabeça do úmero como uma elipsoide $8,61,112,114$. A definição da superfície articular da cabeça do úmero como uma elipsoide a partir de plano a $2 \mathrm{~mm}$ do plano do colo do úmero deveu-se à melhor conformidade anatômica encontrada por esse método. A determinação da 
espessura média baseou-se no estudo de Soslowsky et al. ${ }^{111}$, e os raios articulares da cartilagem da cabeça do úmero foram baseados no trabalho de Zumstein et al. ${ }^{112}$. Esses valores foram corrigidos para o melhor ajuste aos parâmetros anatômicos do modelo. O ajuste da espessura e raio de curvatura da cartilagem da cavidade glenoidal utilizou o sphere fiitting e a referência de distância entre os ossos encontrados na artro-TC. Neste trabalho, a quantidade de pontos selecionados para o sphere fitting foi maior por entendermos que quanto maior a quantidade de pontos, mais fidedigna é a representação. Entendemos que desta forma, diferentemente desses outros estudos, respeitamos os parâmetros anatômicos individuais do voluntário, sem desconsiderar os parâmetros antropométricos e a anatomia incongruente dos raios de curvatura.

As características biomecânicas das estruturas do ombro foram baseadas em dados da literatura ${ }^{106,116,117}$. Essa escolha deve-se à incapacidade prática de realizar um ensaio biomecânico no mesmo voluntário, já que se trata de modelo vivo, e por já existir um banco de dados validado das propriedades biomecânicas dessas estruturas ${ }^{106,116,117}$. As estruturas ósseas foram reconstruídas pelo padrão de reconstrução do software Abaqus, que são elementos R3D3 (sigla de "R" para rígido, "3D" para tridimensional e "3" para triangular). Neste modelo, os ossos possuem um comportamento de corpo rígido, essa escolha foi feita devido à grande diferença de rigidez existente entre as estruturas ósseas e cartilaginosas e também devido ao foco do estudo ser a análise das características mecânicas do contato articular entre as cartilagens $^{106,153}$. Além disso, essa medida demonstrou uma redução no custo computacional da análise sem prejuízo significativo da distribuição de cargas 
quando comparado com outros parâmetros ${ }^{106,153}$. A cartilagem foi reconstruída com elementos C3D10M (sigla de "C" para contínuo, "3D" para tridimensional, "10"para o número de nós, e "M" para modificado), que são robustos e apropriados para problemas envolvendo contato. O comportamento material das cartilagens foi definido como sendo hiperelástico Neo-Hookean, que representa materiais que são submetidos a grandes deformações e que apresentam uma relação tensão-deformação não linear, característica que possibilita deformações dessa estrutura de forma condizente com o mecanismo de contato fisiológico do ombro ${ }^{116,117}$.

O ventre muscular, considerado uma linha de força entre suas inserções, teve sua linha de ação ajustada para estar em contato com a superfície óssea. Devido à representação em diferentes sistemas de coordenadas, esse ajuste foi feito manualmente, com a alocação dos pontos de referência em contato com a superfície óssea. Os casos em que ocorreram passagem da linha de ação através de estruturas anatômicas foram corrigidos pela técnica de obstacle-set ${ }^{86,88}$, desta forma, esses segmentos musculares envolvem essas estruturas, gerando, assim, uma força de contato entre o músculo e o osso (wrapping).

Os pontos de origem e inserção musculares seguiram as referências de posicionamento e de braço de alavanca da literatura, e foram ajustados à anatomia particular deste modelo. Escolheu-se como entrada a referência de Favre et al. ${ }^{90}$, por conta da semelhança metodológica do traçado muscular e da proporção da área seccional entre os grupamentos musculares, além de considerarmos o mesmo ponto de CR. O ajuste dos braços de alavanca levou em conta o $\mathrm{CR}$, as referências anatômicas particulares das áreas de inserções 
deste modelo, obtidas da artro-RM, e três pontos referência de inserção muscular na superfície óssea, que guiaram as subsequentes inserções. Desta forma, buscamos o melhor posicionamento do ponto de origem e inserção que reproduzisse o valor desses braços de alavanca ajustados para a morfologia e dimensões do modelo.

Com relação às condições de limite estabelecidas, a escápula foi definida fixa, não sendo capaz de realizar qualquer movimento, e somente o úmero é capaz de realizar movimento translacional. Essa característica facilita os cálculos por diminuir variáveis de interferência da escápula na translação. A rotação da escápula pode alterar o braço de alavanca da musculatura e, portanto, interferir na estabilidade do modelo e nos resultados de contato $\operatorname{articular}^{91}$. O ritmo escapuloumeral foi calculado de acordo de acordo com a posição relativa entre a escápula e o úmero, estimada na artro-TC em cada posição (Tabela 12). O modelo numérico não contempla a interferência de forças de atrito nas características de contato, essa simplificação é realizada em outros modelos numéricos com a justificativa de diminuir a complexidade da análise ${ }^{106}$.

Sobre os graus de liberdade de movimento do úmero, permite-se a translação no eixo vertical, horizontal e axial, mas a rotação é fixa. Para isso, os graus de liberdade do úmero são liberados de forma gradual durante a simulação, a fim de facilitar a convergência do modelo, a escolha por não permitir a rotação do úmero foi devido à complexidade que seria agregada à análise. Essas medidas possibilitaram a construção de um modelo estável e que contempla o grau de liberdade translacional, isso traz uma importante vantagem biomecânica para nosso modelo, já que uma grande parte dos 
modelos numéricos não contemplam graus de liberdade translacionais ${ }^{83-89,91}$ o que pode ter influência na trilha da glenoide. A desvantagem é que o modelo se baseou em um CR fixo, considerou a escápula fixa, simplificações que podem interferir na aferição da translação.

O processo de validação é uma etapa importante para confirmar se as informações do modelo numérico são confiáveis ${ }^{43,44,78,79,107}$, pode ser feita por meio de comparações dos resultados encontrados com os de ensaios biomecânicos in vivo ou em cadáveres, ou comparando os dados de estudos reconhecidamente confiáveis. A escolha das variáveis de comparação do processo de validação é individualizada para cada modelo de acordo com o tipo de construção e de seu objetivo. Após o modelo estar propriamente validado, poderemos assumir que os achados encontrados pelo modelo possam corresponder, de forma aceitável, a achados in vivo. Desta forma, é possível considerar que as características da trilha da glenoide encontradas nas diversas posições articulares deste modelo sejam uma boa aproximação da realidade. O processo de validação deste modelo seguiu duas etapas: validação das características anatômicas e validação das forças fisiológicas atuantes. 


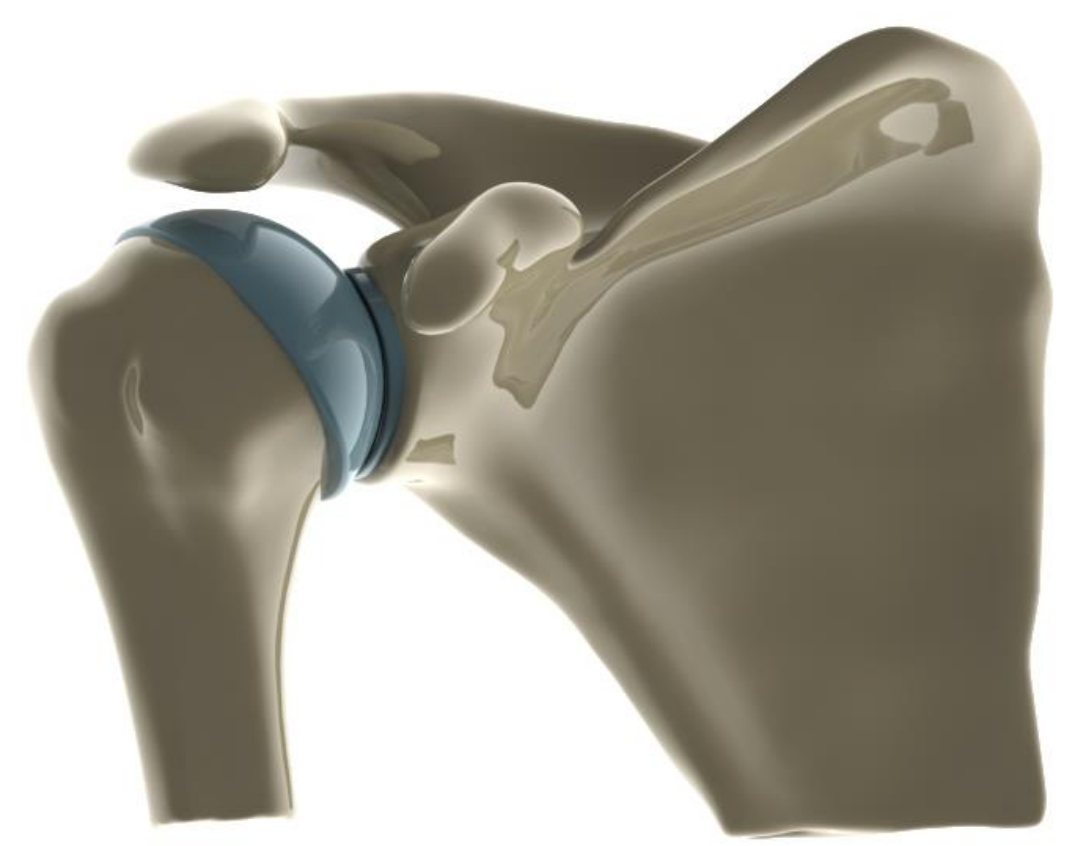

Figura 39 - Aspecto final da anatomia do modelo numérico em CAD após trabalho geométrico na posição de $0^{\circ}$ de abdução

A análise crítica das características geométricas demonstrou que nosso modelo reproduz de forma aceitável uma anatomia padrão (Figura 39), já que os achados são comparáveis às medidas encontradas nos estudos anatômicos da literatura ${ }^{60,61,111-115,127}$. Como ponto de partida, verificou-se se as superfícies ósseas e cartilaginosas obtidas pelos exames de imagem que poderiam ser representadas como superfícies esféricas, para isso foi feita uma análise de desvio padrão dos seus raios de curvatura utilizados pela técnica de sphere fitting. O resultado do raio da face articular da cartilagem da cavidade glenoidal de $27,45 \mathrm{~mm}$, apresentado na Tabela 3 , foi semelhante ao de Soslowsky et al. ${ }^{111}$, que encontrou valor de $26,37 \pm 2,42 \mathrm{~mm}$, o que demonstra ser possível a posterior representação dessas superfícies de forma esférica, com desvios padrão menores que $2 \%$, como defendido por Soslowsky et al. ${ }^{111}$. 
Seguiu-se o ajuste da morfologia da escápula, especialmente a cavidade glenoidal, principal região de interesse para o estudo, realizada pelo sphere fitting da fossa glenoidal. De acordo com Zumstein et al. ${ }^{112}$, a fossa glenoidal apresenta superfície elipsoide, assim como a cabeça do úmero, e apresenta diferença de $12 \mathrm{~mm}$ entre os raios de curvatura nos planos coronal e transversal, porém, os resultados de Soslowsky et al. ${ }^{111}$ mostraram que existe a possibilidade de se encaixar uma esfera nessa superfície com um desvio padrão menor que $1 \%$. Optou-se por representar a superfície articular da cavidade glenoidal como uma superfície esférica, devido, principalmente, à falta de referências geométricas para a construção de uma superfície elipsoide e à boa aproximação de sua anatomia a uma superfície esférica, como demonstrado pela tabela 5 .

As tabelas 10 e 11 mostram boa correlação entre as dimensões da cavidade glenoidal e os dados antropométricos da literatura. Ikemoto et al. ${ }^{115}$ avaliaram as dimensões da cavidade glenoidal encontrando valores máximos, mínimos e médios de diversos segmentos, da área da fossa da cavidade glenoidal e também de um índice de normalidade da cavidade glenoidal entre o segmento superior e o inferior. A Tabela 10 demonstra que os resultados estão de acordo com os resultados antropométricos de Ikemoto et al. ${ }^{115}$, com destaque para o índice de normalidade da cavidade glenoidal, considerado de 0,76 (0.66 a 0.86), que foi de 0,73 neste estudo. Já a Tabela 11, mostra boa correlação entre as dimensões da fossa glenoidal com os achados de lanotti et al. ${ }^{114}$, exceto pelo segmento superior, que é menor. As A Figura 15 ilustra que a morfologia da cartilagem da cavidade glenoidal apresenta uma forma de pêra, assim como descrito por lannotti et al. ${ }^{114}$. A área superficial dessa 
cartilagem, de $606 \mathrm{~mm}^{2}$, e a espessura média de 2,3mm, determinada juntamente com a da cartilagem da cabeça do úmero, apresentam valores condizentes com os da literatura ${ }^{111,113}$.

Com relação às dimensões do úmero, o ângulo cervicodiafisário deste modelo foi de $130,1^{\circ}$ e está coerente com os dados encontrados na literatura, esse valor está no limite inferior da média encontrada por lannotti et al. ${ }^{114}, 135$ $\pm 5^{\circ}$, e dentro da faixa de variação de $120^{\circ}$ a $145^{\circ}$. A análise da versão umeral não foi possível por conta dos estudos de imagem não contemplarem os epicôndilos, o que é uma limitação desta análise.

Com relação à superfície articular da cartilagem da cabeça do úmero, optou-se por representá-la como uma superfície elipsoide, diferentemente da cavidade glenoidal. Essa escolha foi feita pois os resultados de contato entre as superfícies articulares demonstraram ser mais homogêneos do que sua representação por uma superfície esférica, além da vantagem de representarse de forma mais fidedigna a não conformidade da articulação glenoumeral $^{112,127}$. Ao analisarmos a anatomia da cabeça do úmero a partir de um corte coincidente ao plano do colo anatômico do úmero, percebe-se que sua região periférica realmente se assemelha a uma elipse, como ilustrado na Figura 31. As Tabelas 8 e 9 demonstram que a análise comparativa dos raios de curvatura, tanto da face óssea quanto da articular da cartilagem da cabeça do úmero, têm boa correlação com os dados antropométricos, principalmente dos estudos que não consideram a cabeça do úmero como esférica.

A espessura da cartilagem da cavidade glenoidal foi determinada juntamente com a espessura da cartilagem da cabeça do úmero, de forma que 
a espessura média de ambas as cartilagens estivessem dentro dos valores apresentados por Zumstein, et al. ${ }^{113}$. Considerou-se também a distância entre a cabeça do úmero e a fossa glenoidal da escápula na posição de 0 graus de abdução encontrada pelos exames de imagem, por representar o intervalo entre os ossos que seria preenchido por cartilagem ${ }^{95,119}$. A espessura média da cartilagem da cavidade glenoidal $(2,3 \mathrm{~mm})$ está um pouco acima do valor apresentado por Zumstein et al. ${ }^{113}$. É válido notar que a distância mínima entre a superfície óssea da cabeça do úmero e a superfície óssea da fossa glenoidal da escápula, encontrada nos exames de imagem, foi de $2,21 \mathrm{~mm}$. A espessura da cabeça do úmero, como definida por lannotti et al. ${ }^{114}$, foi de $18 \mathrm{~mm}$ no limite inferior da média encontrada pelos autores, que é igual a $20 \pm$ 2,0 mm, e dentro da variação de $15 \mathrm{~mm}$ a $24 \mathrm{~mm}$. A distribuição da espessura da cartilagem ilustra maior espessura na periferia da cavidade glenoidal, e maior espessura na área central na cabeça do úmero, achado que vai ao encontro das características de distribuição de espessura da literatura ${ }^{60,113}$.

As cartilagens glenoumerais apresentam uma superfície articular não congruente ("mismatch") e são mais semelhantes a um elipsoide do que a uma esfera $^{61,112,114}$. Apesar disso, muitos dos modelos descritos na literatura simplificam essas superfícies como esféricas e congruentes ${ }^{95,106,119}$ tendo como justificativa os resultados apresentados por Soslowsky et al. ${ }^{111}$. Sabe-se que essas simplificações podem levar a representações que comprometam os resultados obtidos e uma representação criteriosa torna-se mais relevante no estudo das características de contato $\operatorname{articular}^{90,119,120}$. Neste modelo existe uma diferença entre os raios ósseos de cerca de $7 \mathrm{~mm}$, e ao final do trabalho geométrico, verificou-se que as superfícies articulares das cartilagens deste 
modelo não são congruentes, já que a esfera que melhor se encaixa na fossa glenoidal da escápula é de cerca de $27 \mathrm{~mm}$, enquanto os raios da elipsoide da cabeça do úmero variam entre $23 \mathrm{~mm}$ e $26 \mathrm{~mm}$. Esse fato confere uma maior fidelidade a este modelo em comparação com a real fisiologia $\operatorname{articular}^{61,112}$.

A validação do ambiente biomecânico do modelo baseou-se na comparação de dados de área e localização do contato, de força de reação articular e forças musculares com dados da literatura e de análises numéricas mais recentes do ombro ${ }^{60,61,90,118-135}$. Apesar de serem parâmetros importantes para evidenciar que o modelo se encontra equilibrado e reproduzindo o padrão de ativação muscular e força de reação articular verossímil, diferenças metodológicas prejudicam a comparação do ambiente biomecânico entre os estudos da literatura.

Existem particularidades do nosso modelo que dificultam essa comparação, como a avaliação em $90^{\circ}$ de rotação lateral, a presença de forças de coaptação muscular (wrapping) e a translação em 3 planos. Não obstante, a observação de que existe um comportamento similar desses parâmetros, mesmo com a mudança de posição articular, corrobora para a conclusão de que o modelo se comporta de forma estável e dentro de uma realidade fisiológica aceitável. A melhor forma de validação seria um ensaio biomecânico com o mesmo substrato anatômico utilizado para o modelo, como explicado anteriormente, essa análise é tecnicamente impossível de ser feita em nosso estudo por se tratar de informações obtidas de voluntário vivo. Outra maneira seria por meio da introdução de sensores em artroscopias e a posterior reprodução da posição articular proposta, porém limitações éticas e a indisponibilidade técnica impossibilitam essa alternativa. 
A validação das forças musculares estimadas ainda é uma questão desafiadora dos modelos músculo esqueléticos. As primeiras tentativas eram compostas por comparações das forças musculares calculadas com resultados de $E M G^{83}$ ou por meio de temporização muscular, que considera o deslocamento dos ventres musculares em função do tempo ${ }^{154}$, porém, esses métodos não se mostraram bons indicadores da magnitude de força muscular. Estudos mais recentes propuseram algoritmos de cálculo de força muscular e também parâmetros de atividade muscular específicas de acordo com a posição ${ }^{119,121,143}$. Embora existam diferenças metodológicas, a comparação desses dados com os do nosso estudo mostra que existe semelhanças no comportamento de ativação muscular. O padrão basal levemente superior das atividades das forças musculares pode ser explicado pelo fato deste modelo contemplar as forças de coaptação muscular e de não simplificar a anatomia como bola-soquete, o que subestima a ação estabilizadora da musculatura $^{119,120}$.

O subescapular, considerado o principal estabilizador anterior dinâmico ${ }^{130,131}$, é o músculo mais ativo deste modelo durante todo a arco de movimento. Entendemos que esse fato ocorre devido à necessidade de uma maior ação de estabilização anterior para que a equação de equilíbrio de forças gere resultante em direção à fossa glenoidal. Essa ação do subescapular tornase mais relevante por conta da posição estudada, em $90^{\circ}$ de rotação lateral, que tende a aumentar a força de coaptação muscular desse músculo e também da ausência de estabilizadores estáticos, como o lábio glenoidal e a cápsula anteroinferior, que torna sua ativação ainda mais necessária para a estabilização do modelo, principalmente a partir de $90^{\circ}$ de abdução ${ }^{132,133,142}$. 
Esses achados estão de acordo com a teórica vantagem biomecânica da cirurgia de Latarjet que, ao interpor o tendão conjunto após a fixação do enxerto de coracoide, potencializa a ação do subescapular como estabilizador anterior dinâmico, principalmente na abdução em $90^{\circ}$ de rotação lateral ${ }^{23,155-}$ 157

Com relação aos outros tendões, a literatura ${ }^{90,121,134,135}$ defende que o supraespinal tem ação significativa nos primeiros graus de abdução e diminui drasticamente sua atividade a partir de $90^{\circ}$, fato que ocorre neste modelo em que o músculo deltoide segue a ativação padrão ${ }^{8,121,128,134,136}$, mantendo-se ativo como um todo para manter a abdução nas 3 posições estudadas, com predomínio da porção intermédia. Porém, após $90^{\circ}$ de abdução, o deltoide intermediário diminui sua atividade, enquanto as outras porções ficam mais ativas. Isso está de acordo com a mudança da linha de ação do deltoide intermédio que ocorre a partir de $90^{\circ}$ de abdução, de compressão para cisalhamento, que faz a estabilidade depender mais das suas outras porções e do manguito rotador ${ }^{121,128}$. Também em concordância com a literatura, os músculos infraespinal e redondo menor estão ativos, com força de estabilização principalmente até $90^{\circ}$ de abdução, quando essa necessidade $\operatorname{diminui}^{121}$.

A análise de comportamento da força de reação articular e pressão de contato na literatura é controversa. Sarshari et al. ${ }^{124}$ avaliaram o comportamento de diversos modelos numéricos da literatura e observaram que os modelos apresentam aumento da força de reação e pressão de contato articular até $90^{\circ}$ de abdução, mas divergem quanto ao comportamento além desse grau. A maioria desses estudos demonstrou comportamento de redução 
da força de reação a partir dos $90^{\circ}$ de abdução, fato que vai ao encontro de nossos achados ${ }^{124}$. Os índices de força de reação articular deste modelo estão levemente superiores à média da literatura ${ }^{124}$, o que pode ser explicado por este modelo considerar a ação de coaptação muscular e necessitar da estabilizar uma articulação não congruente ${ }^{119,120}$. A estabilidade do sistema, demonstrada pela resultante de forças, que aponta medialmente em direção à cavidade glenoidal ${ }^{91}$, foi alcançada somente por ação muscular, o que sugere que o modelo conseguiu uma resposta satisfatória para a equação de equilíbrio e corrobora com a teoria de que uma boa coordenação da atividade muscular garante a estabilidade $\operatorname{articular}^{61,107}$.

Com relação à área de contato articular, existe divergência na literatura entre os estudos feitos em cadáveres e os feitos por simulações numéricas, os quais apresentam menores valores ${ }^{124}$ Essa diferença pode ser justificada pela discriminação mais acurada do contato entre superfícies pelos modelos numéricos. A comparação da área de contato deste modelo condiz com os achados de outras simulações numéricas ${ }^{60,122}$ e com o fato de a área em rotação lateral ser menor do que em rotação neutra ${ }^{122}$. Este modelo mostra que ocorre diminuição da área de contato articular com a progressão do grau de abdução em $90^{\circ}$ de rotação lateral.

O aumento do grau de abdução também demonstrou que a área de contato desloca-se de anterossuperior para anteroinferior na cavidade glenoidal, e de posteroinferior para posterossuperior na cabeça do úmero, o que tem boa correlação com a literatura ${ }^{60,123,125}$. Esse achado corrobora com o conceito da trilha da glenoide e com o fato da maioria dos casos de instabilidade glenoumeral anterior ocorrer na região anteroinferior. Vale 
destacar que o fato da análise de contato deste modelo considerar a cartilagem e realizar análise em rotação lateral justifica o achado de contato mais anterior na cavidade glenoidal do que alguns estudos da literatura ${ }^{124,126}$, como defendido por Massimini et al. ${ }^{123}$.

A análise da pressão máxima de contato deste estudo demonstra um leve aumento de até $90^{\circ}$ de abdução, que regride consideravelmente em $120^{\circ}$ de abdução, o que é condizente com o comportamento das forças musculares para a estabilização do modelo nessas posições como demonstrado em alguns estudos $^{61,124}$. Conzen et al. $^{127}$ referem que a pressão máxima de contato articular a $90^{\circ}$ de abdução e $90^{\circ}$ de rotação lateral é de $5,1 \mathrm{Mpa}$, o que reforça que este modelo apresenta comportamento fisiológico para essa posição.

A variabilidade do comportamento da translação do úmero presente na literatura compromete uma validação criteriosa ${ }^{124}$. Apesar disso, os valores da translação deste modelo, expostos na Tabela 14, mostram-se similares, tanto na direção quanto na magnitude, aos reportados na literatura. Para cada posição articular, o valor total da translação, distribuída nos 3 planos, não ultrapassou $4 \mathrm{~mm}$, o que condiz com os achados da literatura em ambiente $3 D^{91}$. Este modelo demonstra que o úmero, em rotação lateral, realiza translação superior nos graus iniciais de abdução e que inverte essa tendência a partir de $90^{\circ}$, quando realiza translação inferior de cerca de $2,3 \mathrm{~mm}$ até $120^{\circ}$, comportamento que reproduz achados de diversas análises ${ }^{90,118,119,124,129}$. O comportamento da translação no eixo horizontal também demonstrou uma correlação com a literatura ${ }^{123-125}$ ao constatar a translação anterior progressiva de $60^{\circ}$ a $90^{\circ}$, que regride em $120^{\circ}$ até aproximadamente a mesma posição encontrada a $60^{\circ}$. A análise do eixo $Z$ evidencia translação medial levemente 
progressiva com o aumento do grau de abdução, o que está de acordo com o comportamento das forças articulares e a anatomia elipsoide da cartilagem da cabeça do úmero ${ }^{124}$.

Frente a essas análises comparativas da anatomia e fisiologia mecânica concluímos que este modelo numérico apresenta um ambiente de forças biomecânicas que condiz com uma resposta verossímil e, desta forma, a análise da trilha da glenoide mostra-se confiável para o objetivo proposto.

A escolha dos parâmetros de medição da trilha da glenoide deste estudo seguiu as sugestões presentes nos estudos sobre a trilha da glenoide na literatura ${ }^{32,41}$. Desta forma, a comparação entre os resultados é mais direta, porém, a medição da dimensão da trilha deste estudo seguiu pontos de referência $3 \mathrm{D}$, como o plano $U C M$, o que a torna mais acurada do que a utilização de parâmetros bidimensionais. Além disso, a aferição do comprimento anteroposterior da cavidade glenoidal utilizou também o método de Griffith et al. ${ }^{137}$, por considerarmos ser este o comprimento máximo anteroposterior, diferentemente do parâmetro de Omori et al. ${ }^{41}$, que consideraram a distância da linha anteroposterior perpendicular ao ponto médio da linha de referência superoinferior, como ilustrado na Figura 26.

Ikemoto et al. ${ }^{115}$, após analisar 93 peças cadavéricas, concluíram que os valores mensurados no seguimento médio e inferior da cavidade glenoidal são estatisticamente iguais, porém, nossa análise mostrou que existe uma diferença significativa do cálculo da trilha da glenoide com pequenas alterações no denominador, que corresponde ao comprimento anteroposterior da cavidade glenoidal. Consideramos que o comprimento máximo anteroposterior da cavidade glenoidal, como expresso pela técnica de Griffith et al. $^{137}$, diminui 
influências de variações morfológicas da cavidade glenoidal, e representa um parâmetro mais confiável para ser usado como referência.

Neste estudo, a trilha da glenoide correspondeu a um valor de $70 \%$ a $80 \%$ do comprimento máximo anteroposterior da cavidade glenoidal na faixa entre $60^{\circ}$ a $90^{\circ}$ de abdução, valor levemente abaixo do encontrado na literatura ${ }^{32,41}$. Entendemos que o motivo do valor em $120^{\circ}$ de abdução estar consideravelmente maior deve-se ao fato de que nessa posição o plano de medição UCM atravessa a cavidade glenoidal de forma oblíqua, além de percorrer uma área que tem a inserção do manguito mais afastada do limite da cartilagem articular. De forma semelhante, não existe diferença entre os valores da trilha medidos até o manguito ou até o limite da cartilagem em $90^{\circ}$ de abdução por conta do plano de medição UCM transpassar um ponto mais inferior na cabeça do úmero, no qual a inserção do manguito rotador coincide com o limite da cartilagem. Esses achados expõem a necessidade de uma melhor definição e padronização dos parâmetros de medição da trilha da glenoide.

Yamamoto et al. ${ }^{32}$ introduziram o conceito de trilha da glenoide em estudo que definiu uma razão de contato articular entre a cabeça do úmero e a cavidade glenoidal, o comprimento desse contato foi considerado a distância entre a borda medial do contato que a cavidade glenoidal promove na cabeça do úmero até a inserção do manguito rotador. Essa medida correspondeu, em $90^{\circ}$ de abdução e $90^{\circ}$ de rotação lateral, a $84 \%$ do comprimento anteroposterior da cavidade glenoidal, com uma variação de $\pm 14 \%$. Para as outras posições, como as de $0^{\circ}$ e $45^{\circ}$ de abdução em relação ao tronco, o autor considerou o comprimento da trilha até a borda da cartilagem. 
A análise de Yamamoto et al. ${ }^{32}$ foi feita em peças cadavéricas que, apesar da manutenção do lábio glenoidal, durante seu preparo tiveram a desinserção da cápsula posterior, supraespinal, infraespinal e redondo menor, o que é uma desvantagem desta análise por desconsiderar a influência das forças de coaptação muscular (wrapping) que podem modificar a região do contato articular. Para a estabilização das peças, utilizou-se força de contato empírica de $22 \mathrm{~N}$ promovida por cabos e polias inseridas em pontos aleatórios. Entendemos que esse ambiente não reproduz de maneira fidedigna as características fisiológicas de forças de contato articular e reações musculares. As marcações dos limites de contato foram realizadas por meio de perfurações com fios de Kirshner, muitas vezes sem visualização direta, método que é pouco preciso.

Nosso estudo tem a vantagem de levar em consideração a influência das forças musculares e articulares de uma maneira mais controlada e próxima à condição fisiológica real. Além disso, a medição digital do contato pelo modelo numérico é muito mais precisa do que a marcação e a medição manual feita por Yamamoto et al. ${ }^{32}$, além do fato da pressão de contato identificar o ponto final do contato articular de uma forma mais assertiva.

Nossa análise mostra que 0 valor da trilha da glenoide em $90^{\circ}$ de abdução, segundo parâmetros de Yamamoto et al. $^{32}$, é de $86 \%$ do comprimento máximo anteroposterior da cavidade glenoidal quando o modelo não apresenta o carregamento das forças, e de $79 \%$ após a ativação muscular. A comparação com as outras medidas realizadas por Yamamoto et al. ${ }^{32}$ demonstra que os valores obtidos, tanto antes como depois da ativação muscular, apresentam-se dentro da variação prevista pelo autor. Esses 
achados ilustram a importância de considerar a influência das forças articulares na análise do contato articular, já que o valor da trilha do modelo sem as forças assemelha-se ao encontrado por Yamamoto et al. $^{32}$, mas fica $7 \%$ menor quando as forças são ativadas.

Omori et al. ${ }^{41}$ estudaram a trilha da glenoide por meio de análise que utilizou sobreposição de imagens de modelos sólidos reconstruídos a partir de exames de RM nas posições de $60^{\circ}, 90^{\circ}, 120^{\circ}$ e $150^{\circ}$ graus de abdução. As cartilagens articulares não foram reconstruídas por Omori et al. ${ }^{41}$, que levaram em conta somente as estruturas ósseas para a análise do contato articular. Entendemos isso como uma limitação do estudo, já que o contato articular não é realizado na superfície óssea, mas entre as superfícies articulares da cartilagem da cabeça do úmero e da escápula. Além disso, Omori et al. ${ }^{41}$ utilizaram as projeções brutas dos exames de imagem sem o devido refinamento geométrico, o que pode gerar imprecisões na geometria e, por consequência, na análise das dimensões da trilha da glenoide. Outra limitação é o fato das representações dos modelos sólidos serem obtidas em posição estática supina, que não apresenta interferência do peso do braço e de forças fisiológicas de estabilização atuantes em posição ortostática. Por fim, Omori et al. ${ }^{41}$ realizaram a medição do comprimento da trilha seguindo parâmetro linear bidimensional, e não tridimensional, o que pode gerar imprecisões.

Entendemos que nossa análise supre algumas das limitações da análise de Omori et al. ${ }^{41}$ por considerarmos para o contato articular a cartilagem com ajuste geométrico, o peso do braço, e a influência de forças e pressões articulares para definir o ponto limite do contato articular, e não a sobreposição de imagens. Além disso, a tecnologia de elementos finitos agrega à análise a 
vantagem de verificar a deformação da superfície de contato, em condições fisiológicas de pressão e estresse articular, com as mesmas características da cartilagem articular. Esses fatores permitem uma avaliação muito mais precisa do que a realizada por Omori et al. ${ }^{41}$.

A semelhança da metodologia para a aquisição dos modelos sólidos e dos pontos de referência usados para a medição das dimensões da trilha da glenoide torna a comparação dos resultados entre nosso estudo e o de Omori et al. $^{41}$ mais relevante. Os resultados obtidos por nosso modelo após o carregamento de forças mostra um comportamento diferente do apresentado por Omori et al. ${ }^{41}$. Apesar de existir concordância do resultado em $90^{\circ}$ de abdução, nota-se que a trilha em $60^{\circ}$ de abdução está no limite inferior, e a trilha em $120^{\circ}$ de abdução está acima da variação encontrada por Omori et al. ${ }^{41}$. Neste modelo, a trilha aumenta progressivamente de valor, de $60^{\circ}$ a $120^{\circ}$ de abdução, enquanto que Omori et al. ${ }^{41}$ apresentam o valor da trilha em $60^{\circ}$ de abdução maior do que em $90^{\circ}$ e, após esse grau, o valor permanece estável. Entendemos que as diferenças metodológicas já ilustradas podem explicar essa diferença ao modificarem o ponto de contato mais medial e, por conseguinte, os valores da trilha da glenoide. O valor da trilha da glenoide acima de $100 \%$ em $120^{\circ}$ de abdução, como explicado previamente, deve-se à orientação do plano de referência da medição nessa posição.

A diferença entre as dimensões da trilha da glenoide medidas antes e após o carregamento das forças articulares evidencia o quão importante é essa influência na análise do contato articular. Entendemos que a resultante de forças articulares e a liberdade de movimentos de translação proporcionada por este modelo promovem uma avaliação mais precisa e próxima da real fisiologia 
do contato articular, negligenciar essas características pode modificar o ponto mais medial de contato articular e subestimar o efeito desestabilizador de algumas lesões ósseas. As lesões de Hill-Sachs, que antes estavam dentro da trilha, apresentam-se fora da mesma nos casos em que a trilha da glenoide diminui após o carregamento das forças, o que pode levar a escolhas terapêuticas equivocadas e falhas cirúrgicas. Conclui-se que não se deve tomar decisões com base em avaliações que não contemplaram as forças articulares, principalmente em relação a lesões de Hill-Sachs que estão dentro da trilha, mas próximas ao limite de contato ${ }^{39,67}$.

A linha de pesquisa sobre a trilha da glenoide vem se desenvolvendo há pouco mais de uma década. Yamamoto et al. ${ }^{32}$ e Omori et al. ${ }^{41}$ realizaram estudos com o objetivo de encontrar uma medida padrão para guiar a conduta terapêutica da instabilidade glenoumeral anterior. Essas tentativas esbarram nas limitações do método de aferição proposto, na variação inter e intraobservador da análise dos exames de imagem e, principalmente, na influência de características individuais do paciente como frouxidão ligamentar, cinemática escapular e variações anatômicas ${ }^{64-67}$.

Este estudo propôs uma nova forma de aferição da trilha da glenoide. Embora não exista uma forma de medição padronizada da mesma, foi seguido o preconizado em estudos prévios ${ }^{32,41}$. Evidenciou-se que o valor da trilha da glenoide, apesar de ter semelhanças com os valores aferidos em outros estudos, não é bom para ser usado como referência universal para a tomada de decisão terapêutica para a instabilidade glenoumeral anterior. Mesmo que ocorra uma padronização da forma de medição da trilha da glenoide, o valor 
ainda sofrerá interferência de fatores individuais, como os descritos acima, o que compromete seu uso como medida padrão ${ }^{67}$.

Não obstante a medida, mesmo com as limitações descritas, tem se mostrado uma boa referência para a tomada de decisão terapêutica da instabilidade glenoumeral anterior, como evidenciado em estudos clínicos ${ }^{37,67-}$ 70. Além disso, consideramos importante o conceito teórico de que uma vez que a borda medial da lesão de Hill-Sachs ultrapasse o limite medial de contato articular proporcionado pela cavidade glenoidal na cabeça do úmero, o encaixe ósseo irá ocorrer, o que inviabilizaria a cirurgia de Bankart ${ }^{34}$. Neste modelo, pode-se verificar que as áreas que estão fora da trilha da glenoide não apresentam qualquer área de pressão ou contato articular, e uma lesão de HillSachs localizada nessa área levará à perda de sustentação, encaixe ósseo e falha da cirurgia de reparo capsulolabral. Este estudo identificou que, para cada posição, a área de contato que a cavidade glenoidal promove na cartilagem da cabeça do úmero (área da trilha da glenoide) corresponde a cerca de $10 \%$ do total da área desta cartilagem. Em outras palavras, é grande a área em que a uma lesão de Hill-Sachs estaria fora da trilha da glenoide, em um ombro com a cavidade glenoidal íntegra. Consideramos essas evidências muito importantes para ratificar o conceito da trilha da glenoide.

Este estudo apresenta algumas limitações, a construção do modelo baseia-se em informações obtidas de um único voluntário, o que compromete a reprodutibilidade externa de nossos achados. Mesmo que a escolha do voluntário tenha seguido um critério antropométrico que mais o aproximasse de um representante médio da população em risco de luxação glenoumeral, e ajustes geométricos tenham sido realizados, essa escolha propicia erros de 
generalização por conta de possíveis variações anatômicas. A escolha do número de voluntários foi limitada pelo custo de recursos e tempo que a análise de modelo numérico com o MEF demanda, o uso de mais voluntários em posteriores estudos pode ajudar a minimizar esse tipo de problema.

Outra limitação é o fato de o modelo ter seguido referências de exames de imagem obtidas na posição supina. Mesmo sendo feitas correções, a referência de posição entre os ossos promovida pela artro-TC em posição supina pode não corresponder ao encontrado em posição ortostática, isso pode alterar a cinemática da escápula e interferir na avaliação dos resultados reproduzidos na posição vertical que sofre influências da gravidade. Outra limitação que devemos destacar é que a aquisição das imagens artrográficas pode não ter reproduzido fielmente a posição almejada, e pequenas distorções podem ter ocorrido pela incapacidade do voluntário de manter a posição proposta, seja devido ao desconforto da posição ou ao tempo de aquisição das imagens. Esse fato torna-se mais relevante quando estudamos a trilha da glenoide, aferida a $90^{\circ}$ de rotação lateral, pois uma pequena mudança na rotação pode interferir na medição da trilha.

Neste modelo, não foram consideradas ações da cápsula articular, do lábio glenoidal e de grupamentos musculares como o peitoral maior, o bíceps braquial, o trapézio e o latíssimo do dorso. Embora nesta primeira análise a simplificação do modelo tenha sido necessária para chegarmos a um modelo numérico factível, a ausência dessas estruturas e suas influências nas forças de reação articular, forças musculares e estabilidade do modelo não pode ser desconsiderada. Em um segundo momento, esperamos aprimorar este modelo ao incluir essas estruturas e avaliar a sua repercussão biomecânica. 
Este estudo não permite a validação dos coeficientes de materiais e forças de contato em modelo biomecânico por utilizar voluntário vivo, por conta disso, precisamos utilizar dados da literatura que aproximassem essas características. Essas informações, por mais que tenham sido obtidas em estudos com boa casuística e estejam de acordo com consensos biomecânicos, podem não representar as características particulares do voluntário e assim alterar a representação da realidade individualizada.

Por fim, mesmo com avanços tecnológicos significativos nas representações de forças musculares, a validação dos dados de reação articular e forças musculares nas diversas posições do ombro é muito difícil, principalmente em uma articulação de movimento extremamente complexo como é a cintura escapular. Por mais que a representação musculoesquelética tenha avançado, é muito difícil representar todas as forças fisiológicas atuantes em um ombro real e em posições de interesse particulares.

Como pontos positivos podemos destacar o desenvolvimento de um modelo numérico validado de elementos finitos do ombro. Trata-se de um modelo articular que contempla as principais estruturas da cintura escapular com suas correspondentes características biomecânicas e liberdade de movimentos de translação em três eixos. Até o presente momento não temos conhecimento de nenhum modelo numérico de ombro com essas características desenvolvido no Brasil, assim como não temos ciência de estudo na literatura que tenha utilizado um modelo numérico com MEF para analisar o contato articular e as características da trilha da glenoide.

No futuro, este primeiro modelo pode ter o detalhamento anatômico e funcional das estruturas aprimorado. Outras estruturas não contempladas neste 
modelo podem ser posteriormente inseridas, e seus efeitos, globais ou individualizados, poderão ser observados, assim como a representação de outras posições articulares obtidas na artro-TC, como em $30^{\circ}, 150^{\circ}$ e abdução máxima. A representação de movimento dinâmico também poderá ser desenvolvida tendo como referência as posições quasi-estáticas utilizadas neste estudo. O refinamento e o aumento da complexidade do modelo poderão proporcionar um melhor entendimento do funcionamento de um ombro normal ou patológico, além de verificar repercussões de lesões de estruturas ou de cirurgias durante um período de tempo definido.

Este modelo também permite estudos futuros em ciência básica. Pode ser utilizado para aprimorar entendimentos da biomecânica do ombro, como prever a repercussão de lesões de determinadas estruturas na estabilidade e na biomecânica do ombro ao longo do tempo. Pode-se, por exemplo, liberar a rotação do úmero para a análise de translação, desligar a ação de um ou mais músculos do manguito rotador ${ }^{100,101,128}$, representar diversos tipos de lesões ósseas ${ }^{50,106}$, ou verificar se o encaixe ósseo acontece de acordo com os preceitos da trilha da glenoide. Pode-se também utilizar o modelo para comparar resultados de cirurgias, como Bankart e Latarjet, ao longo do tempo, em modelos com lesões de Hill-Sachs dentro ou fora da trilha. Além disso, os dados da trilha da glenoide em diversas posições articulares podem sugerir protocolos de análise pré-operatórias ${ }^{67}$ e contribuir para identificar melhores posições para estudos radiológicos ${ }^{158}$.

Por fim, como último ponto positivo destaca-se a proposta de um novo método de avaliação do estudo da trilha da glenoide, realizado em situação mais próxima a forças articulares encontradas in vivo. Até agora os estudos se 
limitaram a informações obtidas por meio de estudos em cadáveres ou pela interposição de imagens em posições estáticas obtidas de estudos de imagem. Este estudo demonstrou que a aferição do índice da trilha da glenoide sofre influência das forças articulares glenoumerais, que devem ser consideradas para a análise. 


\section{CONCLUSÕES}




\section{CONCLUSÕES}

O modelo numérico de elementos finitos desenvolvido neste estudo reproduz de forma verossímil o contato articular da articulação glenoumeral sobre a influência das principais forças biomecânicas atuantes no ombro.

A análise do contato articular do modelo desenvolvido contribui para a evolução do conceito da trilha da glenoide e o ratifica. 
8. REFERÊNCIAS 


\section{REFERENCIAS}

1. Hovelius L. Incidence of shoulder dislocation in Sweden. Clin Orthop Relat Res. 1982;35(166):127-31.

2. Matsen FA 3rd, Zuckerman JD. Anterior glenohumeral instability. Clin Sports Med. 1983;2(2):319-38.

3. Rockwood CA WM. Subluxations and dislocation about the glenohumeral joint. In: Rockwood CA Jr, Green DP, Bucholz W, Heckman JD (editors). Fractures in adults. 4ed. Philadelphia: Lippincott-Raven; 1996. p. 1215.

4. Marx RG, McCarty EC, Montemurno TD, Altchek DW, Craig E V, Warren RF. Development of arthrosis following dislocation of the shoulder: a case-control study. J Shoulder Elb Surg. 2002;11(1):1-5.

5. Hovelius L, Saeboe M. Neer Award 2008: arthropathy after primary anterior shoulder dislocation-223 shoulders prospectively followed up for twenty-five years. J Shoulder Elb Surg. 2009;18(3):339-47.

6. Cetik O, Uslu M, Ozsar BK. The relationship between Hill-Sachs lesion and recurrent anterior shoulder dislocation. Acta Orthop Belg. 2007;73(2):175-8.

7. Zacchilli MA, Owens BD. Epidemiology of shoulder dislocations presenting to emergency departments in the United States. J Bone Joint Surg Am. 2010;92(3):542-9.

8. Matsen F, Wirth M, Lippitt S, Rockwood C. Rockwood and Matsen's The Shoulder. 4ed. Philadelphia: Saunders-Elsevier; 2009, p. 714-5. 
9. An VV, Sivakumar BS, Phan K, Trantalis J. A systematic review and meta-analysis of clinical and patient-reported outcomes following two procedures for recurrent traumatic anterior instability of the shoulder: Latarjet procedure vs. Bankart repair. J Shoulder Elb Surg. 2016;25(5):853-63.

10. Kardouni JR, Mckinnon CJ, Seitz AL. Incidence of shoulder dislocations and the rate of recurrent instability in soldiers. Med Sci Sports Exerc. 2016;48(11):2150-6.

11. Crall TS, Bishop JA, Guttman D, Kocher M, Bozic K, Lubowitz JH. Costeffectiveness analysis of primary arthroscopic stabilization versus nonoperative treatment for first-time anterior glenohumeral dislocations. Arthroscopy. 2012;28(12):1755-65.

12. Lau BC, Conway D, Curran PF, Feeley BT, Pandya NK. Bipolar bone loss in patients with anterior shoulder dislocation: a comparison of adolescents versus adult patients. Arthroscopy. 2017;33(10):1755-61.

13. Randelli P, Ragone V, Carminati S, Cabitza P. Risk factors for recurrence after Bankart repair a systematic review. Knee Surg Sports Traumatol Arthrosc. 2012;20(11):2129-38.

14. McLaughlin HL, Cavallaro WU. Primary anterior dislocation of the shoulder. Am J Surg. 1950;80(6):615-21.

15. Kralinger FS, Golser K, Wischatta R, Wambacher M, Sperner G. Predicting recurrence after primary anterior shoulder dislocation. $A m \mathrm{~J}$ Sports Med. 2002;30(1):116-20. 
16. Arciero RA, Wheeler JH, Ryan JB, McBride JT. Arthroscopic Bankart repair versus nonoperative treatment for acute, initial anterior shoulder dislocations. Am J Sports Med. 1994;22(5):589-94.

17. Donohue MA, Mauntel TC, Dickens JF. Recurrent shoulder instability after primary bankart repair. Sports Med Arthrosc. 2017;25(3):123-30.

18. Balg $F$, Boileau P. The instability severity index score. A simple preoperative score to select patients for arthroscopic or open shoulder stabilisation. J Bone Joint Surg Br. 2007;89(11):1470-7.

19. Perthes G. Uber Operationen bei habitueller Schulterluxation. Dtsch Z Chir. 1906;85:199-222.

20. Eden R. Zur Operation der habituellen Schulterluxation unter Mitteilung eines neuen verfahrens bei Abriß am inneren Pfannenrande. Dtsch Z Chir. 1918;144(3-4):269-80.

21. Bankart A. The pathology and treatment of recurrent dislocation of the shoulder joint. Br J Surg. 1938;(26):23-9.

22. Hybinette $S$. De la transplantation d'un fragment osseux pour remedier aux luxations recidivantes de l'épaule: constations et resultats operatoires. Acta Chir Scand. 1932;(71):411-45.

23. Latarjet M. A propos du traitement des luxations récidivantes de lépaule. Lyon Chir. 1954;49(8):994-7.

24. Helfet AJ. Coracoid transplantation for recurring dislocation of the shoulder. J Bone Joint Surg Br. 1958;40(2):198-202.

25. Howell SM, Galinat BJ, Surface ACA. The glenoid-labral socket. A constrained articular surface. Clin Orthop Relat Res. 1989;(243):122-5. 
26. Hill $H$, Sachs $M$. The grooved defect of humeral head: A frequently unrecognized complication of dislocations of the shoulder joint. Radiology. 1940;35(6):690-700.

27. Hawkins RH, Hawkins RJ. Failed anterior reconstruction for shoulder instability. J Bone Joint Surg Br. 1985;67(5):709-14.

28. Bigliani LU, Newton PM, Steinmann SP, Connor PM, Mcllveen SJ. Glenoid rim lesions associated with recurrent anterior dislocation of the shoulder. Am J Sports Med. 1998;26(1):41-5.

29. Itoi E, Lee SB, Berglund LJ, Berge LL, An KN. The effect of a glenoid defect on anteroinferior stability of the shoulder after Bankart repair: a cadaveric study. J Bone Joint Surg Am. 2000;82(1):35-46.

30. Burkhart SS, De Beer JF. Traumatic glenohumeral bone defects and their relationship to failure of arthroscopic Bankart repairs: significance of the inverted-pear glenoid and the humeral engaging Hill-Sachs lesion. Arthroscopy. 2000;16(7):677-94.

31. Burkhart SS, Debeer JF, Tehrany AM, Parten PM. Quantifying glenoid bone loss arthroscopically in shoulder instability. Arthroscopy. 2002;18(5):488-91.

32. Yamamoto $\mathrm{N}$, Itoi $\mathrm{E}$, Abe $\mathrm{H}$, Minagawa $\mathrm{H}$, Seki $\mathrm{N}$, Shimada $\mathrm{Y}$, et al. Contact between the glenoid and the humeral head in abduction, external rotation, and horizontal extension: a new concept of glenoid track. $J$ Shoulder Elbow Surg. 2007;16(5):649-56.

33. Di Giacomo G, De Vita A, Costantini A, de Gasperis N, Scarso P. Management of humeral head deficiencies and glenoid track. Curr Rev Musculoskelet Med. 2014; 7(1):6-11. 
34. Di Giacomo G, Itoi E, Burkhart SS. Evolving concept of bipolar bone loss and the Hill-Sachs lesion: from "engaging/non-engaging" lesion to "ontrack/off-track" lesion. Arthroscopy. 2014;30(1):90-8.

35. Yates JB, Choudhry MN, Waseem M. Managing Bony Defects of the Shoulder Joint that Occur in Association with Dislocation. Open Orthop J. 2017; $11: 1245-57$.

36. Momaya AM, Tokish JM. Applying the glenoid track concept in the management of patients with anterior shoulder instability. Curr Rev Musculoskelet Med. 2017;10(4):463-468.

37. Locher J, Wilken F, Beitzel K, Buchmann S, Longo UG, Denaro V, et al. Hill-sachs off-track lesions as risk factor for recurrence of instability after arthroscopic bankart repair. Arthroscopy. 2016;32(10):1993-9.

38. Itoi E. "On-track" and "off-track" shoulder lesions. EFORT Open Rev. 2017;2(8):343-51.

39. Nakagawa S, Hanai H, Mae T, Hayashida K, Yoneda M. Bipolar bone loss in male athletes with traumatic anterior shoulder instability: an evaluation using a new scoring system. Orthop $J$ Sport Med. 2018;6(7):232596711878242.

40. Kurokawa D, Yamamoto N, Nagamoto H, Omori Y, Tanaka M, Sano H, Itoi E. The prevalence of a large Hill-Sachs lesion that needs to be treated. J Shoulder Elbow Surg. 2013;22(9):1285-9.

41. Omori Y, Yamamoto N, Koishi H, Futai K, Goto A, Sugamoto K, Itoi E. Measurement of the glenoid track in vivo as investigated by $3-$ dimensional motion analysis using open MRI. Am J Sports Med. 2014;42(6):1290-5. 
42. Huiskes R, Hollister SJ. From structure to process, from organ to cell: recent developments of FE-analysis in orthopaedic biomechanics. $J$ Biomech Eng. 1993;115(4B):520-7.

43. Viceconti M, Olsen S, Nolte L-P, Burton K. Extracting clinically relevant data from finite element simulations. Clin Biomech (Bristol, Avon). 2005;20(5):451-4.

44. Herrera A, Ibarz E, Cegoñino J, Lobo-Escolar A, Puértolas S, López E, Mateo J, Gracia L. Applications of finite element simulation in orthopedic and trauma surgery. World J Orthop. 2012;3(4):25-41.

45. Turner MJ, Clough RW, Martins HC, Topp LJ. Stiffness and deflection analysis of complex structures. J Aeronaut Sci. 1956;23(9):805-23. (MJ T)

46. Brekelmans WA, Poort HW, Slooff TJ. A new method to analyse the mechanical behaviour of skeletal parts. Acta Orthop Scand. 1972;43(5):301-17.

47. Rowe CR, Patel D, Southmayd WW. The Bankart procedure: a long-term end-result study. J Bone Joint Surg Am. 1978;60(1):1-16.

48. Doneux S. P, Miyazaki AN, Lemos PEG, Souza AS, Checchia SL. Tratamento da luxacao recidivante anterior de ombro: Uso de enxerto osseo na deficiencia da glenoide. Rev Bras Ortop. 1997;32(9):675-82.

49. Checchia SL, Santos PD, Miyazaki AN, Fernandes A, Leite M, Simmer Filho J, Menezes MVC. Tratamento cirúrgico da luxação recidivante anterior do ombro em pacientes convulsivos. Rev Bras Ortop. 2000;35(9):340-6. 
50. Greis PE, Scuderi MG, Mohr A, Bachus KN, Burks RT. Glenohumeral articular contact areas and pressures following labral and osseous injury to the anteroinferior quadrant of the glenoid. J Shoulder Elbow Surg. 2002;11(5):442-51.

51. Tauber M, Resch H, Forstner R, Raffl M, Schauer J. Reasons for failure after surgical repair of anterior shoulder instability. J Shoulder Elbow Surg. 2004;13(3):279-85.

52. Boileau P, Villalba M, Héry J-Y, Balg F, Ahrens P, Neyton L. Risk factors for recurrence of shoulder instability after arthroscopic Bankart repair. $J$ Bone Joint Surg Am. 2006;88(8):1755-63.

53. Pagnani MJ. Open capsular repair without bone block for recurrent anterior shoulder instability in patients with and without bony defects of the glenoid and/or humeral head. Am J Sports Med. 2008;36(9):1805-12

54. Yamamoto N, Itoi E, Abe H, Kikuchi K, Seki N, Minagawa H, Tuoheti Y. Effect of an anterior glenoid defect on anterior shoulder stability: a cadaveric study. Am J Sports Med. 2009;37(5):949-54.

55. Hovelius L, Vikerfors O, Olofsson A, Svensson O, Rahme H. BristowLatarjet and Bankart: a comparative study of shoulder stabilization in 185 shoulders during a seventeen-year follow-up. J Shoulder Elbow Surg. 2011;20(7):1095-101.

56. Cho SH, Cho NS, Rhee YG. Preoperative analysis of the Hill-Sachs lesion in anterior shoulder instability: how to predict engagement of the lesion. Am J Sports Med. 2011;39(11):2389-95.

57. Ferreira Neto AA, Camanho GL, Felix AM, Benegas E, Bitar AC, Ramadan LB, Malavolta EA. Tratamento artroscópico da instabilidade 
anterior do ombro: estudo retrospectivo de 159 casos. Acta Ortop Bras. $2011 ; 19(1): 41-4$.

58. Gracitelli MEC, Helito CP, Malavolta EA, Neto AAF, Benegas E, Prada F de S, de Sousa AT, Assunção JH, Sunada EE. Results from filling "remplissage" arthroscopic technique for recurrent anterior shoulder dislocation. Rev Bras Ortop. 2015;46(6):684-90.

59. Lädermann A, Böhm E, Tay E, Scheibel M. Bone-mediated anteroinferior glenohumeral instability. Orthopade. 2018;47(2):129-138.

60. Soslowsky LJ, Flatow EL, Bigliani LU, Pawluk RJ, Ateshian GA, Mow VC. Quantitation of in situ contact areas at the glenohumeral joint: a biomechanical study. J Orthop Res. 1992;10(4):524-34.

61. Warner JJ, Bowen MK, Deng XH, Hannafin JA, Arnoczky SP, Warren RF. Articular contact patterns of the normal glenohumeral joint. $J$ Shoulder Elbow Surg. 1998;7(4):381-8.

62. Trivedi S, Pomerantz ML, Gross D, Golijanan P, Provencher MT. Shoulder Instability in the Setting of Bipolar (Glenoid and Humeral Head) Bone Loss: The Glenoid Track Concept. Clin Orthop Relat Res. 2014;472(8):2352-62.

63. Hartzler RU, Bui CNH, Jeong WK, Akeda M, Peterson A, McGarry M, Denard PJ, Burkhart SS, Lee TQ. Remplissage of an off-track hill-sachs lesion is necessary to restore biomechanical glenohumeral joint stability in a bipolar bone loss model. Arthroscopy. 2016;32(12):2466-76.

64. Schneider AK, Hoy GA, Ek ET, Rotstein AH, Tate J, Taylor DMD, Evans MC. Interobserver and intraobserver variability of glenoid track measurements. J Shoulder Elb Surg. 2017;26(4):573-9. 
65. Yamamoto N, Kawakami J, Nagamoto H, Shiota Y, Itoi E. The relationship between the glenoid track and the range of shoulder motion: A cadaver study. Orthop Traumatol Surg Res. 2017 Dec 29.

66. Ho A, Kurdziel MD, Koueiter DM, Wiater JM. Three-dimensional computed tomography measurement accuracy of varying Hill-Sachs lesion size. J Shoulder Elbow Surg. 2018;27(2):350-356.

67. Yang TC, Chen KH, Chiang ER, Chang MC, Ma HL. Using the "HillSachs interval to glenoid track width ratio" for prediction of recurrent instability after arthroscopic Bankart repair. Orthop Traumatol Surg Res. 2018 Apr 11.

68. Metzger PD, Barlow B, Leonardelli D, Peace W, Solomon DJ, Provencher MT. Clinical application of the "glenoid track" concept for defining humeral head engagement in anterior shoulder instability: a preliminary report. Orthop J Sports Med. 2013 Jul 15;1(2):2325967113496213.

69. Shaha JS, Cook JB, Rowles DJ, Bottoni CR, Shaha SH, Tokish JM. Clinical validation of the glenoid track concept in anterior glenohumeral instability. J Bone Joint Surg Am. 2016;98(22):1918-23.

70. Plath JE, Henderson DJH, Coquay J, Dück K, Haeni D, Lafosse L. Does the arthroscopic Latarjet procedure effectively correct "off-track" hillsachs lesions? Am J Sports Med. 2018;46(1):72-78.

71. Yamamoto N, Itoi E. Osseous defects seen in patients with anterior shoulder instability. Clin Orthop Surg. 2015;7(4):425-9.

72. Zienkiewicz $\mathrm{O}$. The finite element method in structural and continuum mechanics. New Jersey: Prentice-Hall; 1967. 
73. Huiskes R, Chao EY. A survey of finite element analysis in orthopedic biomechanics: the first decade. J Biomech. 1983;16(6):385-409.

74. Huiskes R. Failed innovation in total hip replacement. Diagnosis and proposals for a cure. Acta Orthop Scand. 1993;64(6):699-716.

75. Prendergast PJ. Finite element models in tissue mechanics and orthopaedic implant design. Clin Biomech (Bristol, Avon). 1997;12(6):343-366.

76. Fernandez JW, Pandy MG. Integrating modelling and experiments to assess dynamic musculoskeletal function in humans. Exp Physiol. 2006;91(2):371-82

77. Saha S, Roychowdhury A. Application of the finite element method in orthopedic implant design. J Long Term Eff Med Implants. 2009;19(1):5582.

78. Veeger DH. "What if": the use of biomechanical models for understanding and treating upper extremity musculoskeletal disorders. Man Ther. 2011;16(1):48-50.

79. Taylor M, Prendergast PJ. Four decades of finite element analysis of orthopaedic devices: where are we now and what are the opportunities? J Biomech. 2015;48(5):767-78.

80. Hinckel BB, Demange MK, Gobbi RG, Pécora JR, Camanho GL. The effect of mechanical varus on anterior cruciate ligament and lateral collateral ligament stress: finite element analyses. Orthopedics. 2016;39(4):e729-36. 
81. Engin AE, Peindl RD. On the biomechanics of human shoulder complex-I. Kinematics for determination of the shoulder complex sinus. $J$ Biomech. 1987;20(2):103-17.

82. Peindl RD, Engin AE. On the biomechanics of human shoulder complex-II. Passive resistive properties beyond the shoulder complex sinus. $J$ Biomech. 1987;20(2):119-34.

83. van der Helm FC. A finite element musculoskeletal model of the shoulder mechanism. J Biomech. 1994;27(5):551-69.

84. van der Helm FC, Veeger HE. Quasi-static analysis of muscle forces in the shoulder mechanism during wheelchair propulsion. $J$ Biomech. 1996;29(1):39-52.

85. Högfors C, Karlsson D, Peterson B. Structure and internal consistency of a shoulder model. J Biomech. 1995;28(7):767-77.

86. Garner BA, Pandy MG. Musculoskeletal model of the upper limb based on the visible human male dataset. Comput Methods Biomech Biomed Engin. 2001;4(2):93-126.

87. Holzbaur KRS, Murray WM, Delp SL. A model of the upper extremity for simulating musculoskeletal surgery and analyzing neuromuscular control. Ann Biomed Eng. 2005;33(6):829-40.

88. Charlton IW, Johnson GR. A model for the prediction of the forces at the glenohumeral joint. Proc Inst Mech Eng H. 2006;220(8):801-12.

89. Dickerson CR, Chaffin DB, Hughes RE. A mathematical musculoskeletal shoulder model for proactive ergonomic analysis. Comput Methods Biomech Biomed Engin. 2007;10(6):389-400. 
90. Favre P, Senteler M, Hipp J, Scherrer S, Gerber C, Snedeker JG. An integrated model of active glenohumeral stability. $J$ Biomech. 2012;45(13):2248-55.

91. Prinold JA, Masjedi M, Johnson GR, Bull AM. Musculoskeletal shoulder models: A technical review and proposals for research foci. Proc Inst Mech Eng H. 2013;227(10):1041-57.

92. Chadwick EK, Blana D, Kirsch RF, van den Bogert AJ. Real-time simulation of three-dimensional shoulder girdle and arm dynamics. IEEE Trans Biomed Eng. 2014;61(7):1947-56.

93. Friedman $\mathrm{RJ}$, Laberge $\mathrm{M}$, Dooley $\mathrm{RL}$, O'Hara $\mathrm{AL}$. Finite element modeling of the glenoid component: Effect of design parameters on stress distribution. J Shoulder Elbow Surg. 1992;1(5):261-70.

94. Lacroix D, Murphy LA, Prendergast PJ. Three-dimensional finite element analysis of glenoid replacement prostheses: a comparison of keeled and pegged anchorage systems. J Biomech Eng. 2000;122(4):430-6.

95. Büchler P, Ramaniraka NA, Rakotomanana LR, lannotti JP, Farron A. A finite element model of the shoulder: application to the comparison of normal and osteoarthritic joints. Clin Biomech (Bristol, Avon). 2002;17(910):630-9.

96. Sibella F, Galli M, Crivellini M. A new biomechanical model and experimental protocol for upper limbs movement analysis: Validation procedure using a mechanical model of the shoulder girdle and upper extremity; 2002.

97. Yeh ML, Lintner D, Luo Z-P. Stress distribution in the superior labrum during throwing motion. Am J Sports Med. 2005;33(3):395-401. 
98. Debski RE, Weiss JA, Newman WJ, Moore SM, McMahon PJ. Stress and strain in the anterior band of the inferior glenohumeral ligament during a simulated clinical examination. J Shoulder Elbow Surg. 2005;14(1 Suppl S):24S-31S.

99. Terrier A, Büchler P, Farron A. Influence of glenohumeral conformity on glenoid stresses after total shoulder arthroplasty. J Shoulder Elbow Surg. 2006;15(4):515-20.

100. Adams CR, Baldwin MA, Laz PJ, Rullkoetter PJ, Langenderfer JE. Effects of rotator cuff tears on muscle moment arms: A computational study. J Biomech. 2007;40(15):3373-80.

101. Terrier A, Reist A, Vogel A, Farron A. Effect of supraspinatus deficiency on humerus translation and glenohumeral contact force during abduction. Clin Biomech (Bristol, Avon). 2007;22(6):645-51.

102. Gatti CJ, Maratt JD, Palmer ML, Hughes RE, Carpenter JE. Development and validation of a finite element model of the superior glenoid labrum. Ann Biomed Eng. 2010;38(12):3766-76.

103. Moore SM, Ellis B, Weiss JA, McMahon PJ, Debski RE. The glenohumeral capsule should be evaluated as a sheet of fibrous tissue: a validated finite element model. Ann Biomed Eng. 2010;38(1):66-76.

104. Drury NJ, Ellis BJ, Weiss JA, McMahon PJ, Debski RE. Finding consistent strain distributions in the glenohumeral capsule between two subjects: Implications for development of physical examinations. $J$ Biomech. 2011;44(4):607-13. 
105. Inoue A, Chosa E, Goto K, Tajima N. Nonlinear stress analysis of the supraspinatus tendon using three-dimensional finite element analysis. Knee Surg Sports Traumatol Arthrosc. 2013;21(5):1151-7.

106. Walia P, Miniaci A, Jones MH, Fening SD. Influence of combined hillsachs and bony bankart defects on range of motion in anterior instability of the shoulder in a finite element model. Arthroscopy. 2015;31(11):211927.

107. Zheng M, Zou Z, Bartolo PJDS, Peach C, Ren L. Finite element models of the human shoulder complex: a review of their clinical implications and modelling techniques. Int J Numer Method Biomed Eng. 2017;33(2).

108. IBGE - Instituto Brasileiro de Geografia e Estatística. Dados amostrais e estimativas populacionais das medianas de altura e peso, por situação do domicílio e sexo, segundo a idade e os grupos de idade Brasil período 2008-2009 [Internet]. Disponível em: http://www.ibge.gov.br/home/estatistica/populacao/condicaodevida/pof/2 008_2009_encaa/defaulttabzip_brasil.shtm

109. Van der Helm FCT, Veeger HEJ, Pronk GM, Van der Woude LHV, Rozendal RH. Geometry parameters for musculoskeletal modelling of the shoulder system. J Biomech. 1992;25(2):129-44.

110. Meskers CG, van der Helm FC, Rozendaal LA, Rozing PM. In vivo estimation of the glenohumeral joint rotation center from scapular bony landmarks by linear regression. J Biomech. 1998;31(1):93-6.

111. Soslowsky LJ, Flatow EL, Bigliani LU, Mow VC. Articular geometry of the glenohumeral joint. Clin Orthop Relat Res. 1992;(285):181-90. 
112. Zumstein V, Kraljević M, Hoechel S, Conzen A, Nowakowski AM, MüllerGerbl M. The glenohumeral joint - a mismatching system? A morphological analysis of the cartilaginous and osseous curvature of the humeral head and the glenoid cavity. J Orthop Surg Res. 2014;9:34.

113. Zumstein V, Kraljević $M$, Conzen A, Hoechel $S$, Müller-Gerbl $M$. Thickness distribution of the glenohumeral joint cartilage: a quantitative study using computed tomography. Surg Radiol Anat. 2014;36(4):327-31.

114. lannotti JP, Gabriel JP, Schneck SL, Evans BG, Misra S. The normal glenohumeral relationships. An anatomical study of one hundred and forty shoulders. J Bone Joint Surg Am. 1992;74(4):491-500.

115. Ikemoto RY, Checchia SL, Fujiki EN, Murachovsk J, Nascimento LGP. Análise das mensurações da cavidade. Rev Bras Ortop. 2005;(11):66371.

116. Benvenuti JF. Modelisation tridimensionnelle $d u$ genou humain. Lausanne: Swiss Federal Institute of Technology; 1998.

117. Kempson GE. Mechanical properties of articular cartilage. J Physiol. 1972 May;223(1):23P.

118. Poppen NK, Walker PS. Forces at the glenohumeral joint in abduction. Clin Orthop Relat Res. 1978;(135):165-70.

119. Terrier A, Vogel A, Capezzali M, Farron A. An algorithm to allow humerus translation in the indeterminate problem of shoulder abduction. Med Eng Phys. 2008;30(6):710-6.

120. Veeger HEJ, van der Helm FCT. Shoulder function: the perfect compromise between mobility and stability. $J$ Biomech. 2007;40(10):2119-29. 
121. Engelhardt C, Malfroy Camine V, Ingram D, Müllhaupt $P$, Farron $A$, Pioletti D, Terrier A. Comparison of an EMG-based and a stress-based method to predict shoulder muscle forces. Comput Methods Biomech Biomed Engin. 2015;18(12):1272-9.

122. Yamamoto A, Massimini DF. Glenohumeral contact pressure with simulated anterior labral and osseous defects in cadaveric shoulders before and after soft tissue repair. Am J Sports Med. 2014;42(8):194754.

123. Massimini DF, Warner JJP, Li G. Glenohumeral joint cartilage contact in the healthy adult during scapular plane elevation depression with external humeral rotation. J Biomech. 2014;47(12):3100-6.

124. Sarshari E, Farron A, Terrier A, Pioletti D, Mullhaupt P. A simulation framework for humeral head translations. Med Eng Phys. 2017;49:140147.

125. Sahara W, Sugamoto K, Murai M. The three-dimensional motions of glenohumeral joint under semi-loaded condition during arm abduction using vertically open MRI. Clin Biomech (Bristol, Avon). 2007;22(3):30412.

126. Peltz CD, Baumer TG, Mende V, Ramo N, Mehran N, Moutzouros V, et al. Effect of arthroscopic stabilization on in vivo glenohumeral joint motion and clinical outcomes in patients with anterior instability. Am J Sports Med. 2015;43(11):2800-8.

127. Conzen A, Eckstein F. Quantitative determination of articular pressure in the human shoulder joint. J Shoulder Elb Surg. 2000;9(3):196-204. 
128. Yanagawa T, Goodwin CJ, Shelburne KB, Giphart JE, Torry MR, Pandy MG. Contributions of the individual muscles of the shoulder to glenohumeral joint stability during abduction. $J$ Biomech Eng. 2008;130(2):021024.

129. Bey MJ, Kline SK, Zauel R, Lock TR, Kolowich PA. Measuring dynamic in-vivo glenohumeral joint kinematics: technique and preliminary results. J Biomech. 2008;41(3):711-4.

130. DePalma AF, Cooke AJ, Prabhakar M. The role of the subscapularis in recurrent anterior dislocations of the shoulder. Clin Orthop Relat Res. 1967;54:35-49.

131. Symeonides PP. The significance of the subscapularis muscle in the pathogenesis of recurrent anterior dislocation of the shoulder. $J$ Bone Joint Surg Br. 1972;54(3):476-83.

132. Turkel SJ, Panio MW, Marshall JL, Girgis FG. Stabilizing mechanisms preventing anterior dislocation of the glenohumeral joint. $J$ Bone Joint Surg Am. 1981;63(8):1208-17.

133. Kronberg M, Broström LA, Németh G. Differences in shoulder muscle activity between patients with generalized joint laxity and normal controls. Clin Orthop Relat Res. 1991;(269):181-92.

134. Bechtol CO. Biomechanics of the shoulder. Clin Orthop Relat Res. 1980;(146):37-41.

135. Thompson WO, Debski RE, Boardman ND, Taskiran E, Warner JJP, Fu FH, Woo SL. A Biomechanical Analysis of Rotator Cuff Deficiency in a Cadaveric Model. Am J Sports Med. 1996;24(3):286-92. 
136. Masjedi M, Johnson GR. Glenohumeral contact forces in reversed anatomy shoulder replacement. J Biomech. 2010;43(13):2493-500.

137. Griffith JF, Antonio GE, Yung PSH, Wong EMC, Yu AB, Ahuja AT, Chan KM. Prevalence, pattern, and spectrum of glenoid bone loss in anterior shoulder dislocation: CT analysis of 218 patients. AJR Am J Roentgenol. 2008;190(5):1247-54.

138. Rowe CR, Zarins B, Ciullo J V. Recurrent anterior dislocation of the shoulder after surgical repair. Apparent causes of failure and treatment. $J$ Bone Joint Surg Am. 1984;66(2):159-68.

139. Sisto DJ. Revision of failed arthroscopic Bankart repairs. Am J Sports Med. 2007;35(4):537-41.

140. Schmid SL, Farshad M, Catanzaro S, Gerber C. The Latarjet procedure for the treatment of recurrence of anterior instability of the shoulder after operative repair: A retrospective case series of forty-nine consecutive patients. J Bone Joint Surg Am. 2012;94(11):e75.

141. Bushnell BD, Creighton RA, Herring MM. Bony instability of the shoulder. Arthroscopy. 2008;24(9):1061-73.

142. Motzkin NE, Itoi E, Morrey BF, An KN. Contribution of capsuloligamentous structures to passive static inferior glenohumeral stability. Clin Biomech (Bristol, Avon). 1998;13(1):54-61.

143. Favre P. A model to study active shoulder motion and stability [thesis]. Zurich: ETH Zurich; 2011.

144. DeFrances CJ, Cullen K A, Kozak LJ. National Hospital Discharge Survey: 2005 annual summary with detailed diagnosis and procedure data. Vital Health Stat 13. 2007;(165):1-209. 
145. Magermans DJ, Chadwick EKJ, Veeger HEJ, Rozing PM, van der Helm FCT. Effectiveness of tendon transfers for massive rotator cuff tears: a simulation study. Clin Biomech (Bristol, Avon). 2004;19(2):116-22.

146. Kwon YW, Powell K A, Yum JK, Brems JJ, lannotti JP. Use of threedimensional computed tomography for the analysis of the glenoid anatomy. J Shoulder Elbow Surg. 2005;14(1):85-90.

147. Ringelberg JA. EMG and force production of some human shoulder muscles during isometric abduction. J Biomech. 1985;18(12):939-47.

148. Cereatti A, Camomilla V, Cappozzo A. Estimation of the centre of rotation: A methodological contribution. J Biomech. 2004;37(3):413-6.

149. Halvorsen K, Lesser M, Lundberg A. A new method for testing the axis of rotation and the center of rotation. J Biomech. 1999;32(11):1221-7.

150. Stokdijk M, Nagels J, Rozing PM. The glenohumeral joint rotation center in vivo. J Biomech. 2000;33(12):1629-36.

151. Veeger HE. The position of the rotation center of the glenohumeral joint. J Biomech. 2000;33(12):1711-5.

152. Wu G, Van Der Helm FCT, Veeger HEJ, Makhsous M, Van Roy P, Anglin C, et al. ISB recommendation on definitions of joint coordinate systems of various joints for the reporting of human joint motion - Part II: Shoulder, elbow, wrist and hand. J Biomech. 2005;38(5):981-92.

153. Gupta S, van der Helm FCT, Sterk JC, van Keulen F, Kaptein BL. Development and experimental validation of a three-dimensional finite element model of the human scapula. Proc Inst Mech Eng $H$. 2004;218(2):127-42. 
154. Happee R. Goal-directed arm movements. II: A kinematic model and its relation to EMG records. J Electromyogr Kinesiol. 1993;3(1):13-23.

155. Werner CML, Favre $\mathrm{P}$, Gerber $\mathrm{C}$. The role of the subscapularis in preventing anterior glenohumeral subluxation in the abducted, externally rotated position of the arm. Clin Biomech (Bristol, Avon). 2007;22(5):495501.

156. D’Angelo D. Luxação recidivante anterior do ombro: tratamento cirúrgico [tese de livre docência]. Rio de Janeiro: Faculdade de Medicina da Universidade, Universidade Federal do Rio de Janeiro; 1970.

157. Ferreira Neto AA, Camanho GL, Felix AM, Benegas E, Bitar AC, Ramadan LB, Malavolta EA. Tratamento da luxação anterior recidivante do ombro pela técnica de Bristow Latarjet. Acta Ortop Bras. 2011;19(1):41-4.

158. Burns DM, Chahal J, Shahrokhi S, Henry P, Wasserstein D, Whyne C, Theodoropoulos J, Ogilvie-Harris D, Dwyer T. Diagnosis of engaging bipolar bone defects in the shoulder using 2-dimensional computed tomography: a cadaveric study. Am J Sports Med. 2016;44(11):2771-7. 


\section{$9 \quad$ ANEXOS}

ANEXO A - Aprovação pela Comissão de Ética para Análise de Projetos de Pesquisa do Hospital das Clínicas da Faculdade de Medicina da Universidade de São Paulo

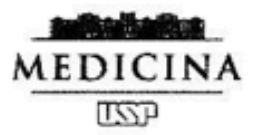

Memo/CC-OOT/38/2016

lim. Sr

Prof. Giberto Luis Camanho

Orientador

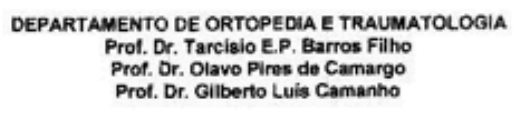

Prot. Or. Olavo Piros de Camargo

Prot. Dr. Gilberto Luis Camanho

São Paulo, 04 de março de 2016

Ref: Protocolo de Pesquisa $N^{\circ}$ IOT 1182 "Análise da trilha da glenóide na instabilidade gleno-umeral: avaliaçāo por modelo de elementos finitos".

Pesquisador Executante: Dr. José Otávio Reggi Pécora

Grau da Pesquisa: Doutorado

A Comissâo Clentífica do Departamento de Ortopedia e Traumatologia da Faculdade de Medicina da Universidade de Sâo Pauio analisou aprovou em 04/03/2016, o protocolo de pesquisa acima mencionado.

Atenciosamente,

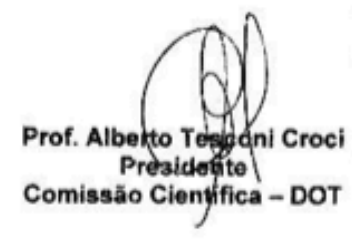

Comissâo Cientifica do Departamento de Ortopedia e Traumatologia da FMUSP

$1^{\circ}$ andar - Hall - Tel. (11) 2661-6942 - e-mail: com cientrica.iot@hc. $m$ usp.br 
ANEXO B - Apreciação geral da proposta pela comissão científica IOT-HCFMUSP

\section{DEPARTAMENTO DE ORTOPEDIA E TRAUMATOLOGIA \\ Faculdade de Medicina da Universidade de São Paulo \\ COMISSÃO CIENTÍFICA}

\section{IDENTIFICAÇĀO $\quad$ Protocolo IOT $n^{\circ} 1182$}

Pesquisador Responsável: Prof. Gilberto Luis Camanho

Pesquisador Executante: Dr. José Otávio Reggi Pécora

Título: Análise da trilha da glenóide na instabilidade gleno-umeral: avaliaç̃o por modelo de elementos finitos.

Grau de Pesquisa: Doutorado

\section{APRECIAÇÃO GERAL DA PROPOSTA}

\section{Parecer}

Projeto interessante e bem estruturado.

Proposta de utilizar um voluntário normal e criar modelo para se ter um padrão de normalidade da "trilha da glenóide"

Bem justificado e referenciado.

TCLE expōe bem os riscos da realização dos exames.

Observação sobre o título: $\mathrm{A}$ análise da trilha da glenóide é na articulação gleno umeral e nāo na instabilidade gleno umeral.( o modelo é num ombro normal) Favor alterar o título.

Aprovado com alteração do título.

\section{Relator \\ Comissão Científica \\ 07/03/2016}


ANEXO C - Termo de consentimento livre e esclarecido

\author{
HOSPITAL DAS CLINICAS DA FACULDADE DE MEDICINA DA \\ UNIVERSIDADE DE SÃO PAULO-HCFMUSP \\ TERMO DE CONSENTIMENTO LIVRE E ESCLARECIDO
}

\title{
DADOS SOBRE A PESQUISA
}

1. TítULO dO PROTOCOLO DE PESQUISA: Análise da trilha da glendide na instablidade gleno-umeral: avaliaçăo através de elementos finitos.

2. PESQUISADOR : José Otávio Reggi Pécora

CARGOVFUNÇĀO: médico pós-graduando INSCRIÇĀO CONSELHO REGIONAL No 124972

UNIDADE DO HCFMUSP: DOT - HCFMUSP

\section{AVALIAÇĀO DO RISCO DA PESQUISA: RISCO MINIMOX RISCO MEDIO a RISCO BAIXO D RISCO MAIOR}

\section{DURAÇĀO DA PESQUISA : 2 anOs}

Essas informaçōes estîo sendo fornecidas para sua participaçẫo voluntária neste estudo, que visa o desenvolvimento de um modelo tridimensional do ombro através do método de elementos finitos. Para a construçâo do modelo será necossário colhermos dados de ressonância magnébica e tomografia computadorizada de um voluntário escolhido par suas características antropométricas ideais a sem histárico de lesīes no ombro.

A ressonância magnética é um exame de imagem que utiliza campos magnéticos. Neste exame, você deverá ficar deitado, com o brạ̧o em posiçâa previamente estabelecida, enquanto os dados são colhidos. Algumas pessoas podem sentir um desconforto ao ficar dentro do aparelho, chamado claustrofobia (medo de lugares apertados). Pessoas que tenham marca-passo, ou materiais metálicos no corpo (oomo stents, clps metálicos, agulhas ou parafusos) não serão escolhidas para 
realizar o exame por conta de riscos. Caso você tenha algum destes materiais informe ao pesquisador. Para a realzzaçấo exame será administrado contraste iodado. Este contraste será introduzido através de agulha, dentro de seu ombro. Agumas pessoas possuem reap̧ōes alérgicas ao contraste de iodo, o que pode levar a irritaçōes, dores articulares e depressão respiratb́ria. Caso você jấ tenha tido reação prévia a contraste ou tenha casos na familia, informe ao pesquisador.

A tomografia computadorizada é um exame que ufliza radiaçâa ionizante para obtençẩo de suas imagens. E o mesmo tipo de radiaçẩo da radiografia (raio X), mas com uma intensidade maior. A exposição excessiva à radiação ionizante pode levar a distúrbios celulares como processos tumorais ou transtornos de função de órgâos como as gônadas e a tireoide. Ném disso, algumas pessoas podem sentir um desconforto ao ficar dentro do aparelho, chamado claustrofobia (medo de lugares apertados).

Nỉo hả beneficio direto para o participante, porém, indiretamente, distúrbios podem ser identficados pelos exames de imagem, e assim tratados precocemente.

Em qualquer etapa do estudo, você terá acesso aos profissionais respansáveis pela pesquisa para esclarecimento de eventuais dúvidas. O principal investigador ó o Dr. José Otśvio Reggi Pécora, que pode ser encontrado no enderę̧o Rua Ovídio Pires de Campos, 333 - $3^{\circ}$ Andar - Telefone(s) 2661-2486. Se você tiver alguma consideração ou dúvida sobre a ética da pesquisa, entre em contato com o Comitê de Etica em Pesquisa (CEP) - Rua Ovidio Pires de Campos, 225 - $5^{\circ}$ andar - tel: 26616442 ramais 16, 17, 18. ou (11) 2661.7585; c-mail cappesq.adm Bho.fm.usp.br.

E garantida a liberdade da rabirada de consentimento a qualquer mamento a deixar de participar do estudo, sem qualquer prejuizo à continuidade de seu tratamento na Instituiģăo;

As informaçôes obtidas serão analisadas diretamente pelos envolvidos no trabalho, não sendo divulgado a sua identificação. Você tem direito de ser mantido atualizado sobre os resultados parciais das pesquisas e de resultados que sejam do conhecimento dos pesquisadores. Não há despesses pesesais para o participante em qualquer fase do estudo, incluindo exames e consultas. Também não há compensação financeira relacionada à sua participação. Se existir qualquer despesa adicional, ela será absorvida pelo orçamento da pesquisa. Em caso de dano pessoal, diretamente causado pelos procedimentos ou tratamentos propostos neste estudo (nexo causal comprovado), o participante tem direito a tratamento médico na Instituição, bem oomo às indenizạ̧̄es legalmente estabelecidas. 
Os pesquisadores se comprometem ainda a utilizar os dados e o material coletado somente para esta pesquisa.

Acredito ter sido suficientemente informado a respeito das informaçōes que li ou que foram lidas para mim, descrevendo o estudo: "Análise da trilha da glenbide na instabilidade gleno-umeral: avalaçẫo atrovés de elementos finiłos".

Eu discuti com o Dr. José Otávio Reggi Pécora sobre a minha decisão em participar nesse estudo. Ficaram claros para mim quais sẩo os propósitos do estudo, os procedimentos a serem realizados, seus desconfortos e riscos, as garantias de confidencialidade e de esclarocimentos permanentes. Ficou claro também que minha participação é isenta de despesas e que tenho garantia do acesso a tratamento hospitalar quando necessário. Concordo voluntariamente em participar deste estudo e poderei retirar o meu consentimento a qualquer momento, antes ou durante o mesmo, sem penalidades ou prejulzo ou perda de qualquer beneficio que eu possa ter adquirido, ou no meu atendimento neste Serviço.

Assinatura do pacienteirepresentante legal

Data

Assinatura do responsável pelo estudo

Data / / 
DADOS DE IDENTIFICAÇĀO DO PARTICIPANTE DA PESQUISA OU RESPONSAVEL LEGAL

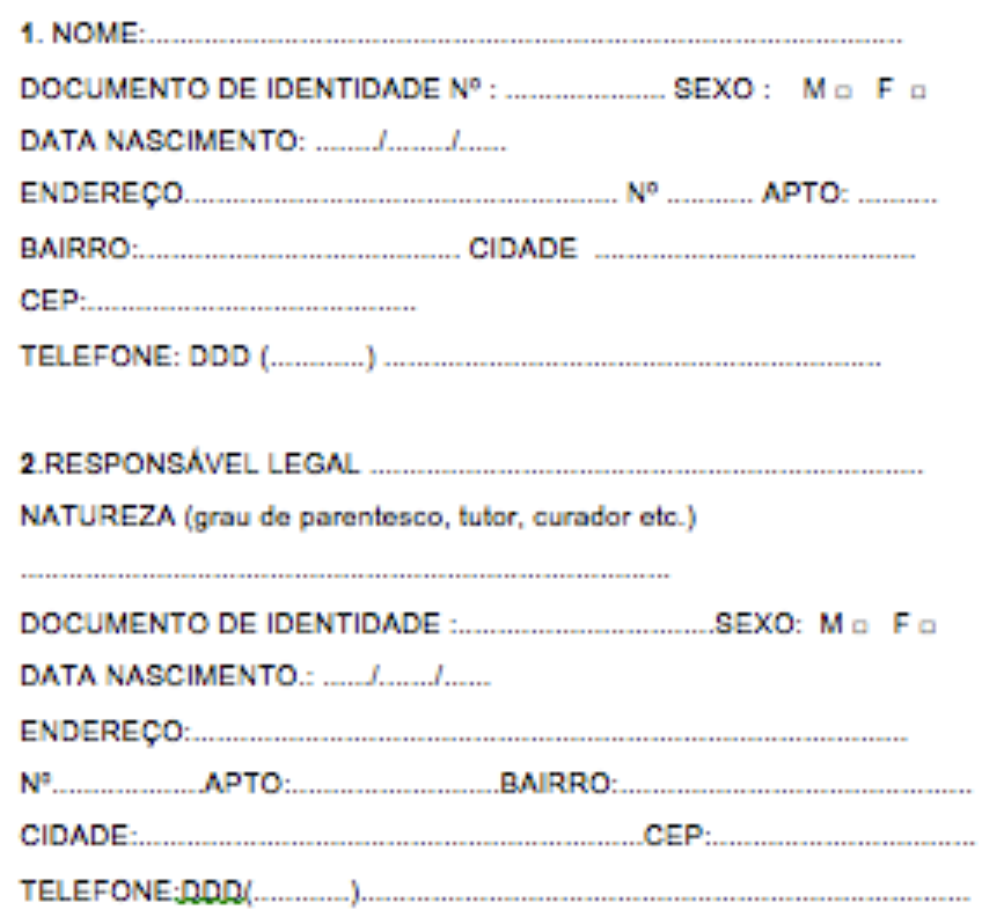


ANEXO D - Aprovação da FAPESP

\section{DFAPESP}

Fundação de Amparo à Pesquisa do Estado de São Paulo

\begin{tabular}{l|l}
\hline \multicolumn{1}{|c}{ Histórico de Aceitação de Termos } \\
\hline $\begin{array}{l}\text { Processo } \\
\begin{array}{l}\text { Linha de } \\
\text { Fomento }\end{array}\end{array}$ & $\begin{array}{l}\text { Programas Regulares / Auxílios a Pesquisa / Projeto de Pesquisa / Projeto de Pesquisa } \\
\text { - Regular - Fluxo Contínuo }\end{array}$ \\
\hline Situação & Em Execução \\
\hline Vigência & $01 / 02 / 2017$ a 31/01/2019 \\
\hline Beneficiário & Gilberto Luís Camanho 9 \\
\hline Responsável & Gilberto Luís Camanho \\
\hline $\begin{array}{l}\text { Vínculo } \\
\text { Institucional do } \\
\text { Processo }\end{array}$ & Faculdade de Medicina/FM/USP \\
\hline
\end{tabular}

\begin{tabular}{|l|l|l|l|l|l|l|l|}
\hline $\begin{array}{c}\text { Resposta } \\
\text { do } \\
\text { Aceite }\end{array}$ & Justificativa & $\begin{array}{c}\text { Data do } \\
\text { Aceite }\end{array}$ & $\begin{array}{c}\text { Usuário do } \\
\text { Aceite }\end{array}$ & $\begin{array}{c}\text { Resposta } \\
\text { Aprovação }\end{array}$ & $\begin{array}{c}\text { Justificativa } \\
\text { Aprovação }\end{array}$ & $\begin{array}{c}\text { Data } \\
\text { Aprovação }\end{array}$ & $\begin{array}{c}\text { Usuário } \\
\text { Aprovação }\end{array}$ \\
\hline Sim & $17 / 01 / 2017$ & $\begin{array}{c}\text { Gilberto Luís } \\
\text { Camanho }\end{array}$ & Concordo & & $17 / 01 / 2017$ & $\begin{array}{c}\text { Gilberto Luís } \\
\text { Camanho }\end{array}$ \\
\hline & & & & & & \\
\hline & & & & & & \\
\hline
\end{tabular}

